\title{
Sediment Acoustic Index Method for Computing Continuous Suspended-Sediment Concentrations
}

Chapter 5 of

Section C, Sediment and Erosion Techniques

Book 3, Applications of Hydraulics

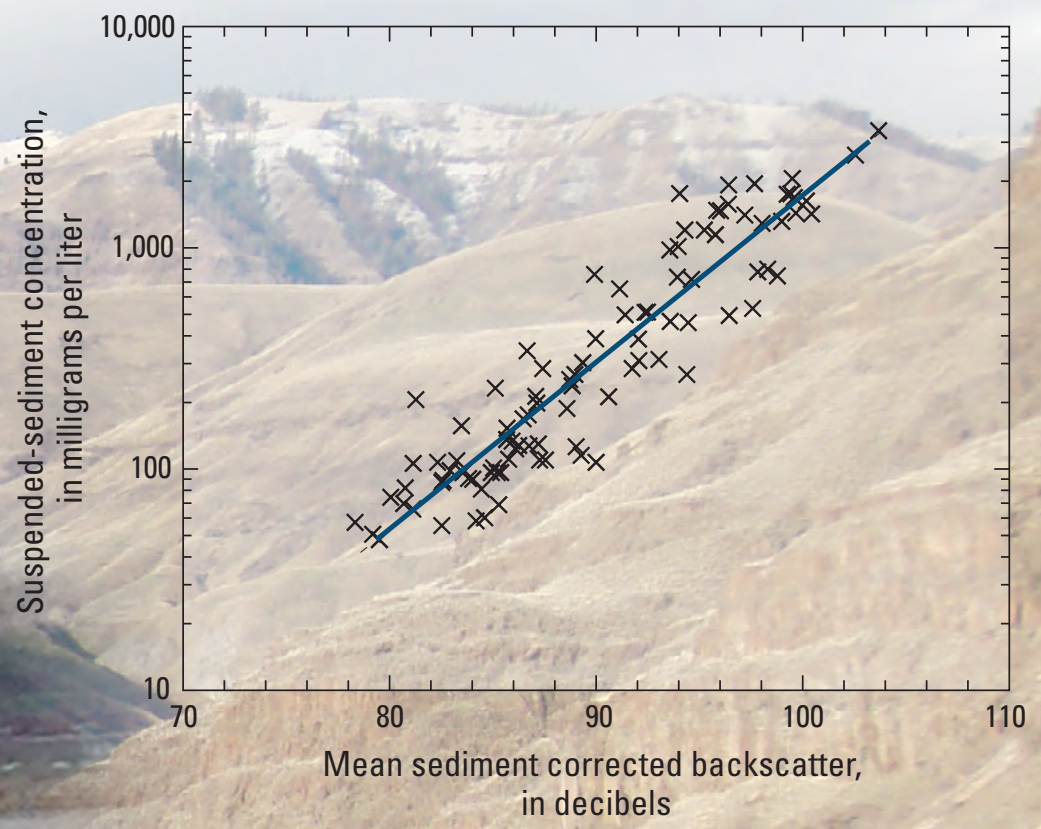

Techniques and Methods 3-C5

U.S. Department of the Interior

U.S. Geological Survey 
Background photograph: Snake River near Anatone, Washington, near U.S. Geological Survey (USGS) streamgage 13334300, taken February 20, 2014, by Molly Wood, USGS.

Boat inset, left: Photograph of USGS employee collecting a suspended-sediment sample from a boat on the Mississippi River near Vicksburg, Mississippi, taken February 25, 2014, by Mark Landers, USGS.

Instrument inset, lower right: Photograph of a 1.5- $\mathrm{MHz}$ acoustic Doppler velocity meter installed at West Fork Double Bayou at Eagle Ferry Road near Anahuac, Texas, near USGS streamgage 08042558, taken April 17, 2012, by Mike Lee, USGS.

Plot, upper right: Sediment acoustic surrogate rating between mean sediment-corrected backscatter and suspended-sediment concentration data collected at the Spoon River at Seville, Illinois, USGS 05570000. 


\section{Sediment Acoustic Index Method for Computing Continuous Suspended- Sediment Concentrations}

By Mark N. Landers, Timothy D. Straub, Molly S. Wood, and Marian M. Domanski

Chapter 5 of

Section C, Sediment and Erosion Techniques

Book 3, Applications of Hydraulics

Techniques and Methods 3-C5 


\title{
U.S. Department of the Interior SALLY JEWELL, Secretary
}

\section{U.S. Geological Survey Suzette M. Kimball, Director}

\author{
U.S. Geological Survey, Reston, Virginia: 2016
}

For more information on the USGS - the Federal source for science about the Earth, its natural and living resources, natural hazards, and the environment-visit http://www.usgs.gov or call 1-888-ASK-USGS.

For an overview of USGS information products, including maps, imagery, and publications, visit http://store.usgs.gov.

Any use of trade, firm, or product names is for descriptive purposes only and does not imply endorsement by the U.S. Government.

Although this information product, for the most part, is in the public domain, it also may contain copyrighted materials as noted in the text. Permission to reproduce copyrighted items must be secured from the copyright owner.

Suggested citation:

Landers, M.N., Straub, T.D., Wood, M.S., and Domanski, M.M., 2016, Sediment acoustic index method for computing continuous suspended-sediment concentrations: U.S. Geological Survey Techniques and Methods, book 3, chap. C5, 63 p., http://dx.doi.org/10.3133/tm3C5.

ISSN 2328-7047 (print)

ISSN 2328-7055 (online)

ISBN 978-1-4113-4061-9 


\section{Contents}

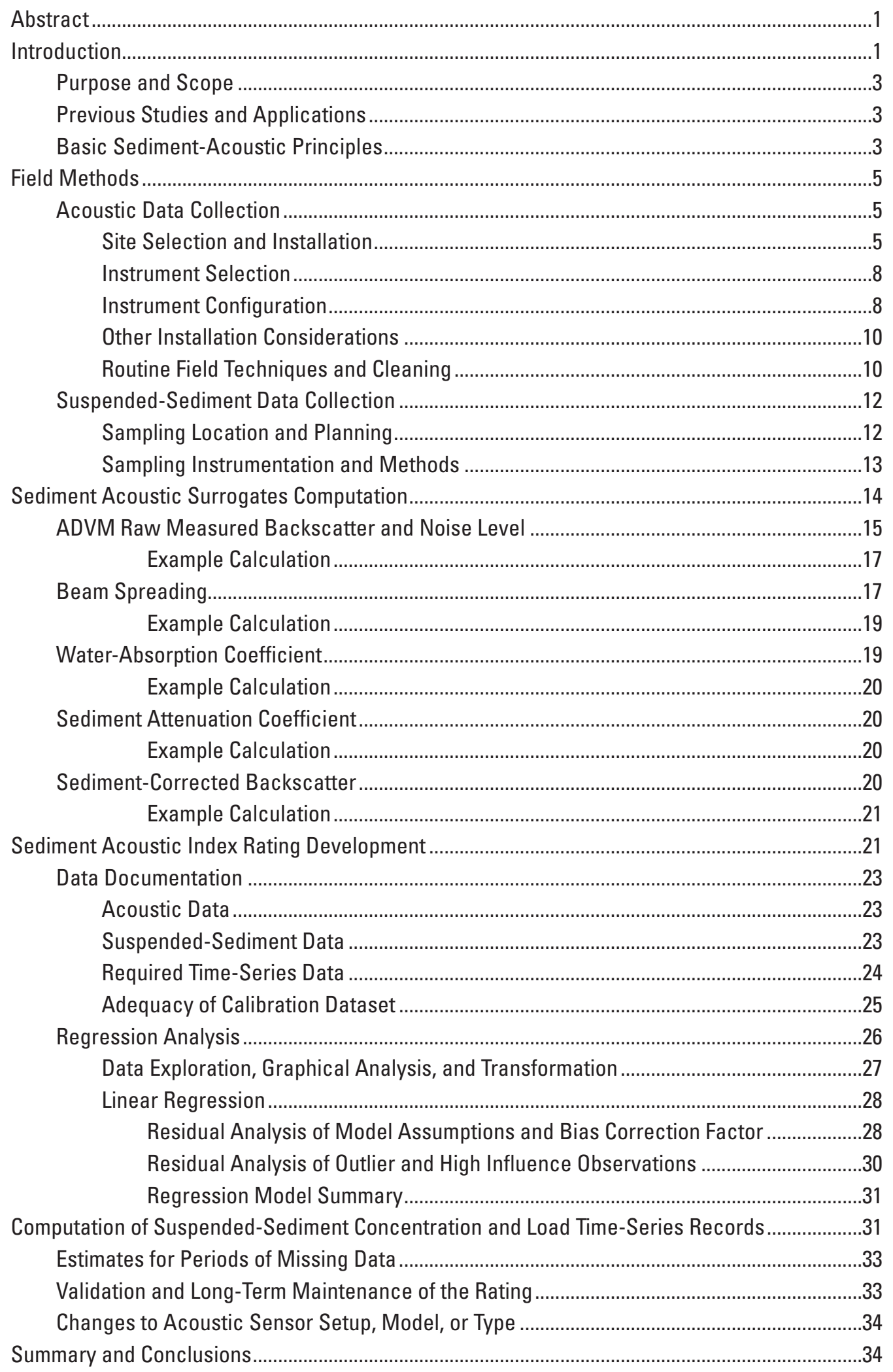




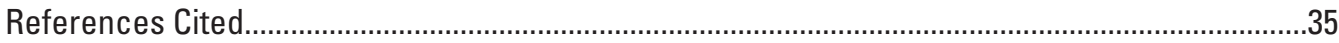

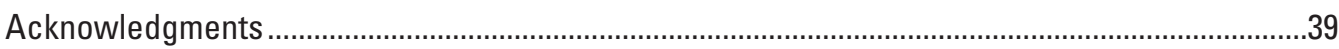

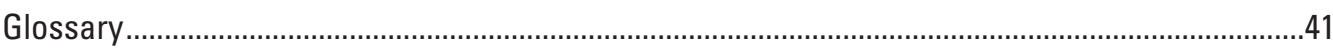

Appendix 1. Example Station Analysis Format for Sediment Acoustic Index Rating....................42

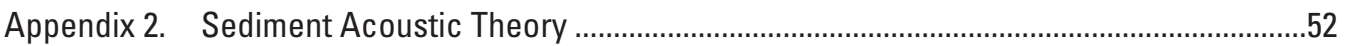

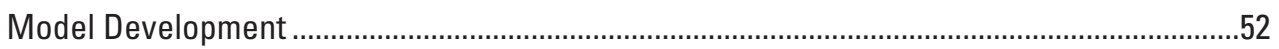

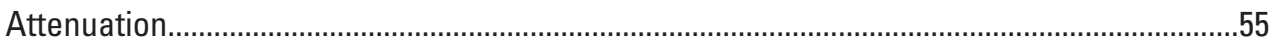

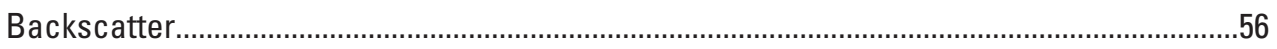

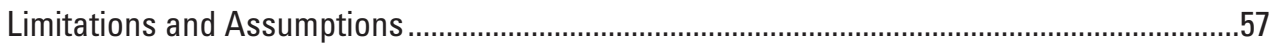

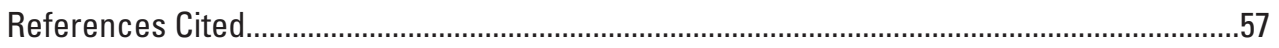

Appendix 3. Sensitivity of Suspended-Sediment Concentration Computed from a

Sediment Acoustic Index Rating to Changes in Acoustic Attenuation................................60

\section{Figures}

1. Graphs showing streamflow and suspended-sediment concentrations from samples and estimated using the sediment acoustic index method during a storm event on Kickapoo Creek near Bloomington, Illinois..........................................................

2. Diagram showing acoustic backscatter from suspended particles................................4

3. Concept of multicell, two-horizontal beam acoustic Doppler velocity meter, and an example of a sediment acoustic index gage ..................................................................

4. Graphs showing velocity, acoustic backscatter, and estimated suspended-sediment concentration data collected using an acoustic Doppler current profiler

5. Example evaluation of the suitability of a sediment acoustic site using an aerial photograph.

6. Graph showing suspended-sediment concentrations in four discrete sample sets collected in the Clearwater River at Spalding, Idaho (USGS 13342500), at the approximate depth of deployed acoustic Doppler velocity meters, to evaluate horizontal stratification of sediment across the stream channel...

7. Diagram showing generalized measurement volumes for a side-looker acoustic Doppler velocity meter.

8. Graph showing time series of signal-to-noise ratio readings and photographs before and after cleaning in 2012 for a 1.5 megahertz acoustic Doppler velocity meter installed at West Fork Double Bayou at Eagle Ferry Road near

Anahuac, Texas

9. Photograph showing example of channel depth- and width-integrated physical sampling, which provides the only direct measure of representative suspended-sediment concentration in a stream

10. Graph showing example of multicell measured backscatter and computed acoustic parameters for the Spoon River at Seville, Illinois (USGS 05570000) on April 18, 2013, at 15:00 Central Standard Time. 
11. Graph showing example of effects of ice on records of backscatter noise, amplitude, and signal-to-noise ratio for a 0.5 megahertz system on the Hudson

River below Poughkeepsie, New York . .16

12. Graphs showing comparison of measured, water-corrected, and sediment-corrected backscatter profiles along the acoustic axis of the beam for full range of cells and range of cells within the range of the minimum water-corrected backscatter

13. Graphic showing spherical spreading of acoustic energy in water

14. Graph showing transmission loss due to beam spreading and range normalized by the critical near-field range, with and without the near-field correction for the 1.5 megahertz transducer specified in table 3 .

15. Graphs showing measured and computed acoustic parameters matched with four suspended-sediment concentration sample values at the Spoon River at Seville, Illinois (USGS 05570000)

16. Graphs showing model-calibration samples plotted on flow-duration curves for daily data from water year 2003-2013 for suspended-sediment concentration and for streamflow for the Spoon River at Seville, Illinois (USGS 05570000)

\section{Appendix Figures}

1-1. Graph showing evaluation of the relation between suspended-sediment concentration from equal-width-interval cross-section samples and from single-station depth-integrated samples using 54 concurrent samples

1-2. Graphs showing suspended-sediment concentration measurements plotted on duration curves for daily computed daily SSC, streamflow, and sediment-corrected backscatter

1-3. Plots of $\log 10 \mathrm{SSC}$ and explanatory variables and residual diagnostic plots

1-4. Graph showing predicted and observed suspended-sediment concentration

1-5. Graph showing an example of predicted time series from concurrent acoustic Doppler velocity meter and suspended-sediment sample observations for February 7 through May 17, 2013

1-6. Graphs showing an example of an evaluated regression model where residuals were not homoscedastic

2-1. Graph showing coefficients of acoustic attenuation due to suspended sediment and particle size, for 3.0- megahertz (MHz) frequency at concentration of 1,000 parts per million from hybrid Urick-Shen-Hay equation

3-1. Graph showing sensitivity of suspended-sediment concentration to changes in acoustic attenuation for values of sediment-corrected backscatter.. 


\section{Tables}

1. Typical maximum ranges and blanking distances (along beam path) for acoustic Doppler velocity meters..

2. Acoustic and environmental parameter values used in examples calculation from measured backscatter to water-corrected backscatter to sediment-corrected backscatter.

3. Example near-field range for specified frequencies and effective transducer areas

4. Variation in water absorption for temperatures ranging from 0 to 35 degrees Celsius in freshwater at 0.5-, 1.5-, and 3.0-megahertz frequencies, using equation 8

5. The National Water Information Summary parameter code, description, and units for discrete suspended-sediment data and metadata

6. The National Water Information Summary parameter code, name, description, and unit for measured and computed continuous time-series data used in sediment acoustic index ratings .....

7. Checklist for sediment acoustic index rating development and time-series prediction

8. Conversion factors for the computation of load. .33

\section{Appendix Table}

3-1. Sensitivity of suspended-sediment concentration to changes in acoustic attenuation for values of sediment-corrected backscatter 


\section{Conversion Factors}

U.S. customary units to International System of Units

\begin{tabular}{lcc}
\hline \multicolumn{1}{c}{ Multiply } & By & To obtain \\
\hline foot $(\mathrm{ft})$ & Length & meter $(\mathrm{m})$ \\
\hline & 0.3048 & \\
\hline cubic foot $\left(\mathrm{ft}^{3}\right)$ & Volume & cubic meter $\left(\mathrm{m}^{3}\right)$ \\
\hline & 0.02832 & \\
\hline cubic foot per second $\left(\mathrm{ft}^{3} / \mathrm{s}\right)$ & Flow rate & cubic meter per second $\left(\mathrm{m}^{3} / \mathrm{s}\right)$ \\
\hline & 0.02832 & metric ton, megagram $(\mathrm{Mg})$ \\
\hline ton, short $(2,000 \mathrm{lb})$ & Mass & \\
\hline pound per square foot $\left(\mathrm{lb} / \mathrm{ft}^{2}\right)$ & 0.9072 & kilopascal $(\mathrm{kPa})$ \\
\hline pound per cubic foot $\left(\mathrm{lb} / \mathrm{ft}^{3}\right)$ & Pressure & \\
\hline
\end{tabular}

Temperature in degrees Fahrenheit $\left({ }^{\circ} \mathrm{F}\right)$ may be converted to degrees Celsius $\left({ }^{\circ} \mathrm{C}\right)$ as follows:

$$
{ }^{\circ} \mathrm{C}=\left({ }^{\circ} \mathrm{F}-32\right) / 1.8
$$

Specific conductance is given in microsiemens per centimeter at 25 degrees Celsius $(\mu \mathrm{S} / \mathrm{cm}$ at $\left.25^{\circ} \mathrm{C}\right)$.

International System of Units to U.S. customary units

\begin{tabular}{lcc}
\hline \multicolumn{1}{c}{ Multiply } & By & To obtain \\
\hline meter $(\mathrm{m})$ & Length & foot $(\mathrm{ft})$ \\
\hline & 3.281 & \\
\hline cubic meter $\left(\mathrm{m}^{3}\right)$ & Volume & cubic foot $\left(\mathrm{ft}^{3}\right)$ \\
\hline & 35.31 & \\
\hline cubic meter per second $(\mathrm{m} 3 / \mathrm{s})$ & Flow rate & cubic foot per second $\left(\mathrm{ft}^{3} / \mathrm{s}\right)$ \\
\hline & 35.31 & ton, short $(2,000 \mathrm{lb})$ \\
\hline metric ton, megagram $(\mathrm{Mg})$ & Mass & \\
\hline kilopascal $(\mathrm{kPa})$ & 1.102 & pound per square foot $\left(\mathrm{lb} / \mathrm{ft}^{2}\right)$ \\
\hline & Pressure & \\
\hline gram per cubic centimeter $\left(\mathrm{g} / \mathrm{cm}^{3}\right)$ & 20.88 & pound per cubic foot $\left(\mathrm{lb} / \mathrm{ft}^{3}\right)$ \\
\hline
\end{tabular}

Temperature in degrees Celsius $\left({ }^{\circ} \mathrm{C}\right)$ may be converted to degrees Fahrenheit $\left({ }^{\circ} \mathrm{F}\right)$ as follows:

$$
{ }^{\circ} \mathrm{F}=\left(1.8 x^{\circ} \mathrm{C}\right)+32
$$

Specific conductance is given in microsiemens per centimeter at 25 degrees Celsius $(\mu \mathrm{S} / \mathrm{cm}$ at $\left.25^{\circ} \mathrm{C}\right)$. 



\title{
Sediment Acoustic Index Method for Computing Continuous Suspended-Sediment Concentrations
}

\author{
By Mark N. Landers, Timothy D. Straub, Molly S. Wood, and Marian M. Domanski
}

\section{Abstract}

Suspended-sediment characteristics can be computed using acoustic indices derived from acoustic Doppler velocity meter (ADVM) backscatter data. The sediment acoustic index method applied in these types of studies can be used to more accurately and cost-effectively provide time-series estimates of suspended-sediment concentration and load, which is essential for informed solutions to many sedimentrelated environmental, engineering, and agricultural concerns. Advantages of this approach over other sediment surrogate methods include: (1) better representation of cross-sectional conditions from large measurement volumes, compared to other surrogate instruments that measure data at a single point; (2) high temporal resolution of collected data; (3) data integrity when biofouling is present; and (4) less rating curve hysteresis compared to streamflow as a surrogate. An additional advantage of this technique is the potential expansion of monitoring suspended-sediment concentrations at sites with existing ADVMs used in streamflow velocity monitoring. This report provides much-needed standard techniques for sediment acoustic index methods to help ensure accurate and comparable documented results.

A sediment acoustic index gage is used to collect continuous acoustic backscatter data, using an ADVM deployed in a fixed location, which are related to results from discrete suspended-sediment samples. The raw ADVM backscatter data are adjusted for variables affecting backscatter other than the sediment concentration to compute the sediment-corrected backscatter $(S C B)$ and sediment attenuation coefficient $(S A C)$. The sediment acoustic index rating (rating) is then developed by relating the sediment characteristics from the periodic samples to the $S C B$ and (or) $S A C$ and other explanatory variables in a site-specific, instrument-specific, simple or multiple linear regression model. The rating is reviewed and checked to ensure the technique has been applied appropriately. This review includes an assessment of the theoretical soundness, the adequacy of the model calibration dataset, and the quality of the regression model and regression diagnostics. The rating can then be applied to the acoustic surrogates and other explanatory variables to obtain continuous records of computed suspended-sediment concentration. The estimates of suspended-sediment concentration can then be paired with streamflow data, if available, to compute continuous records of suspended-sediment load.

Once developed, sediment acoustic index ratings must be validated with additional suspended-sediment samples, beyond the period of record used in the rating development, to verify that the regression model continues to adequately represent sediment conditions within the stream. Changes in ADVM configuration or installation, or replacement with another ADVM, may require development of a new rating. The best practices described in this report can be used to develop continuous estimates of suspended-sediment concentration and load using sediment acoustic surrogates to enable more informed and accurate responses to diverse sedimentation issues.

\section{Introduction}

The five most common causes of stream impairment (pathogens, nutrients, metals other than mercury, organic enrichment/oxygen depletion, and sediment, as of 2014) in the U.S. Environmental Protection Agency's (EPA's) 303(d) list are associated with and commonly transported by sediment; together they account for more than half of all stream impairments. Alone, sediment is the fifth most common cause of impairment; it accounts for 6,463 impaired stream segments or 8.6 percent of all impairments (U.S. Environmental Protection Agency, 2014). Success in managing and solving these and other sedimentation problems requires more complete (spatially and temporally) and accurate fluvial sediment data and understanding.

Despite its increasing relevance, fluvial sediment is monitored primarily by collecting discrete samples without the substantial information benefit of continuous monitoring using surrogates. Physical samples obtained using standard methods represent the sediment concentration for a particular river location and time. Sediment concentrations can vary, however, by orders of magnitude with changing river conditions and seasons; this variation is not typically characterized by physical samples alone because of long gaps between discrete samples. On the other hand, continuous estimates of sediment concentration can be obtained by developing relations between discrete samples and continuously measured surrogate data. 
Continuously measured streamflow has traditionally been used to estimate suspended-sediment concentration (SSC); however, streamflow often does not adequately represent changes in SSC because concentrations may vary for the same streamflows, exhibiting hysteresis over the rising and falling limb of the streamflow hydrograph during a storm event or multiple storm events (fig. 1; Landers and Sturm, 2013).

Surrogates from optical or acoustic instruments are much less affected by hysteresis compared to streamflow and are increasingly used to provide continuous fluvial SSC that can be used to monitor and understand many sediment-related phenomena (Gray and Gartner, 2009; Rasmussen and others, 2009). If acoustic suspended-sediment measurements are

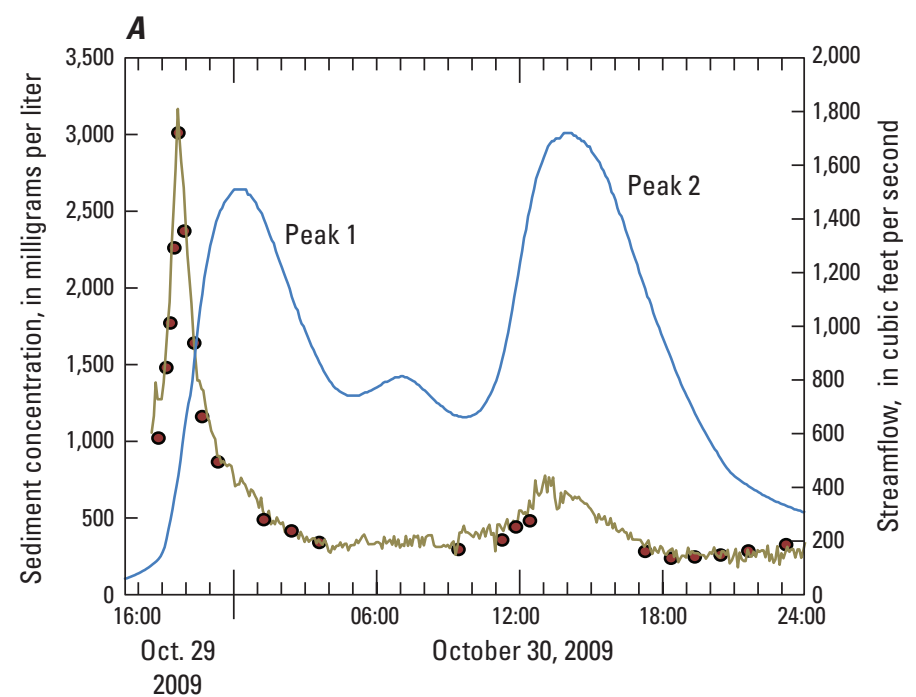

EXPLANATION

- Sediment concentration estimated using sediment acoustic index method
- Streamflow - Sample

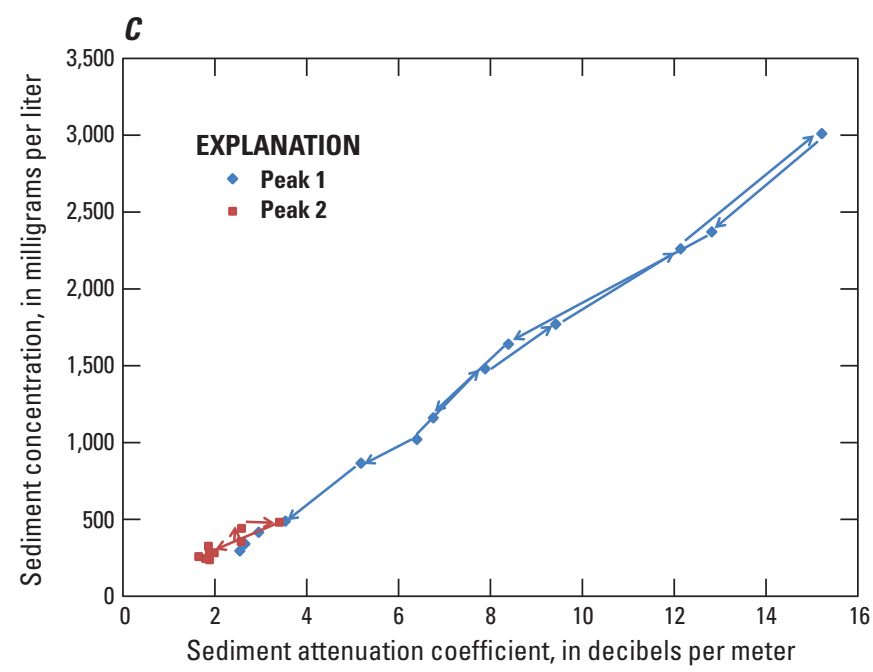

made properly using multiple frequencies, then hysteresis effects can be further minimized (Topping and others, 2015). Additionally, use of sediment acoustic surrogates can reduce long-term monitoring costs (Wood, 2014).

Methods and applications are rapidly advancing to estimate sediment characteristics in aquatic systems using acoustic surrogates of backscatter (the acoustic energy scattered by sediment back toward the signal source) and attenuation (the attenuation by sediment of acoustic energy along the beam path). Sediment acoustic surrogates are being used to estimate SSC, and for multi-frequency acoustics, sediment size (Moore and others, 2013; Topping and others, 2015). Sediment acoustic surrogates offer substantial advantages over other
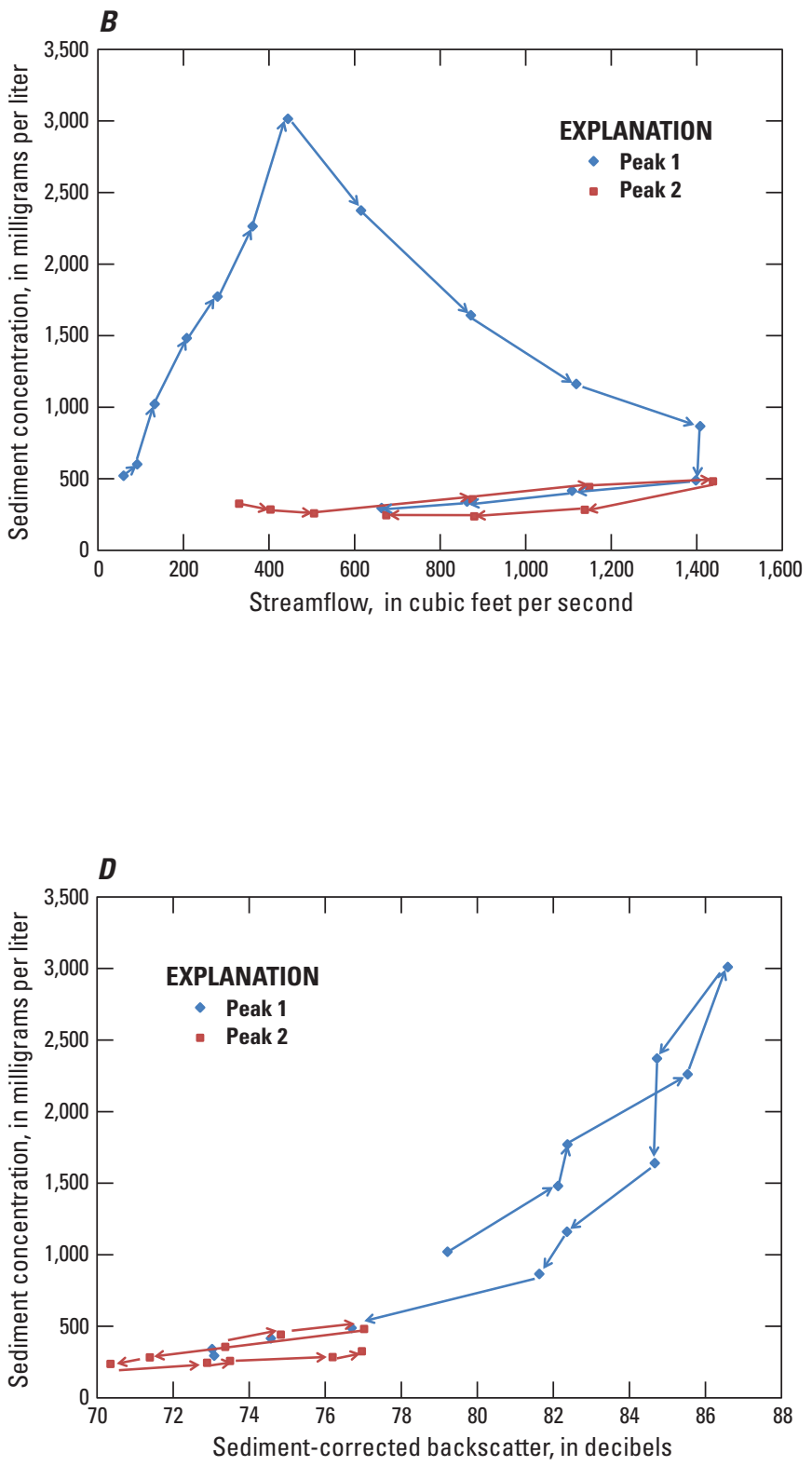

Figure 1. A, Streamflow and suspended-sediment concentrations (SSC) from samples and estimated using the sediment acoustic index method during a storm event on Kickapoo Creek near Bloomington, Illinois (USGS 05579630). B, Relation and hysteresis between streamflow and SSC samples. $C$ and $D$, Relation between sediment acoustic parameters and SSC samples. 
monitoring methods, including greater accuracy and information content due to high temporal resolution compared to samples alone, measurement of a larger, and thus, more representative sampling volume than other surrogate metrics, and the increasing availability of environmentally robust instruments, along with the benefit of simultaneous production of measured water-velocity data (Wood, 2014). Sediment acoustic index methods also can leverage the widespread use of acoustic Doppler velocity meters (ADVMs), which are commonly used for streamflow monitoring but also record acoustic backscatter data that can be related to sediment concentration.

The opportunity to obtain continuous suspended-sediment data is being pursued by many scientists within and outside of the U.S. Geological Survey (USGS), following general principles that are well founded in theory and described in the literature (Topping and others, 2006; Landers, 2012; Wood and Teasdale, 2013; Gray and Landers, 2014; Topping and others, 2015; Wood and others, 2015). Standard protocols, however, are lacking, and best methods require detailed data computations that have not consistently been described and used (Landers and others, 2012). The USGS formed the Sediment Acoustic Leadership Team (SALT) in 2013 to advance research and practice in sediment acoustic science and to identify best practices. The best practices described in this report reflect the collaborative efforts of the SALT and many scientists who developed and tested these methods. These techniques and methods can be used to develop reliable, continuous estimates of suspended-sediment concentration and load using acoustic surrogates to enable more informed and accurate responses to diverse sedimentation questions.

\section{Purpose and Scope}

The purpose of this techniques and methods report is to provide standardized protocols and best practices for calculating sediment acoustic surrogates using ADVMs to develop sediment acoustic index ratings. The calibrated acoustic surrogates and index ratings can then be used to compute continuous SSC and, together with discharge, to compute sediment load. This report outlines field methods, sediment acoustic surrogate computations, sediment acoustic index ratings, and computation of suspended-sediment time-series records. The methods will help enable more accurate, consistent, and widespread continuous monitoring of suspended sediment using sediment acoustic index methods. While the sediment acoustic index principles have general application, the scope of the methods described in this report is specific to sediment acoustic index gages using in-situ, fixed-mounted, horizontally profiling, continuously recording ADVMs (similar to indexvelocity streamgages described in Levesque and Oberg, 2012), and not for discrete acoustic measurements (as for acoustic instruments deployed from a moving boat). The methods described in this report require only a single frequency ADVM to obtain computed SSC. The methods require site-specific and instrument-specific calibration and verification with physical samples resulting in a site-specific sediment acoustic index rating. The methods have been tested and proven in a range of coastal and fluvial environments but entail specific assumptions and limitations that require site-specific evaluation.

\section{Previous Studies and Applications}

Characterization of suspended sediment using acoustic backscatter in water has been described and developed for several decades (Urick, 1948, 1975, 1983; Flammer, 1962; Hay, 1983; Sheng and Hay, 1988; Flagg and Smith, 1989; Thorne and others, 1991; Hay and Sheng, 1992; Thevenot and Kraus, 1993; Lynch and others, 1994; Thorne and Hardcastle, 1997; Holdaway and others, 1999; Gartner, 2004; Topping and others, 2006; Wall and others, 2006; Gray and Gartner, 2009; Simmons and others, 2010; Guerrero and others, 2011; Thorne and others, 2011; Landers, 2012; Wood and Teasdale, 2013; Clark and others, 2013; Gray and Landers, 2014; Medalie and others, 2014; Topping and others, 2015; Wood and others, 2015). A review of the theory and its development is provided in appendix 2 of this report. Many hydrologists and hydrographers are comparing acoustic surrogates with sediment data; in part, because of the widespread use of acoustic velocity meters and the initial ease (despite the incomplete methods) of comparing unadjusted acoustic backscatter with sampled sediment concentration. From 2002 to 2013, concurrent sediment samples and continuous acoustic backscatter data have been collected by the USGS at over 70 sites in 20 states. Some of the earliest USGS research at sediment acoustic sites was done by Wall and others (2006), Topping and others (2006), Wright and others (2010), Landers (2012), and Wood and Teasdale (2013). Topping and others (2015) describe methods to obtain sediment-size and sediment-concentration data using multiple frequencies of ADVMs. This report is based on the general methods and results of previous work.

\section{Basic Sediment-Acoustic Principles}

Acoustic waves passing through a water-sediment mixture will scatter and attenuate as a function of fluid, sediment, and acoustic instrument characteristics. Acoustic backscatter and attenuation relate functionally to the characteristics of the sediment mixture (concentration, size, shape, and density) within an insonified volume after adjusting for the influence of fluid and instrument characteristics. Because acoustic backscatter is typically measured and recorded by ADVMs as a quality-assurance parameter for velocity measurement, backscatter data must be adjusted when used as a sediment surrogate for several factors to isolate the attenuation and backscatter characteristics of sediment.

Acoustic methods for measuring velocity are briefly described below to provide a background of how ADVMs collect and process data; the methods for calculating sediment acoustic surrogates to correlate with SSC are outlined in the Sediment Acoustic Surrogates Computation section. 
A fixed array of two to four acoustic transducers measures axial velocities along their emission axes to obtain a two- or three-dimensional stream velocity. An acoustic transducer is a (typically piezoelectric) device that converts voltage into a sound-wave producing pulse, and vice versa. The transducer emits the acoustic pulse and then, after an interval just long enough to stop "ringing," it receives the returned echoes

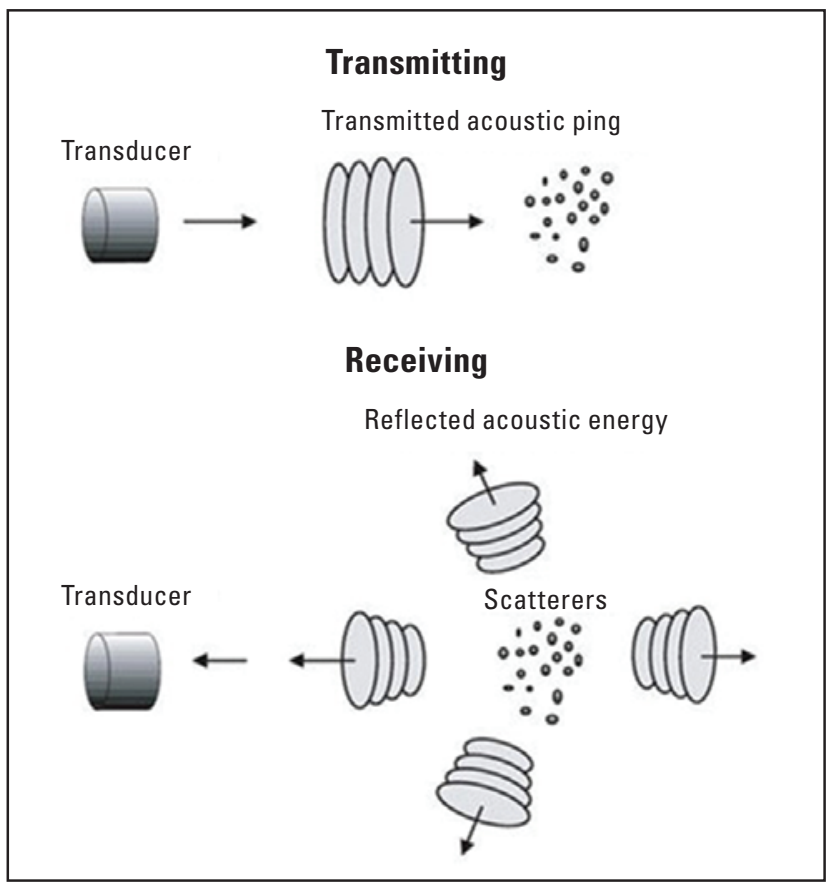

Figure 2. Acoustic backscatter from suspended particles (Simpson, 2001). of the pulse that have been scattered and reflected back from particles suspended in the acoustic path as illustrated in figure 2. If the suspended backscattering particles have a nonzero velocity along the axis of the acoustic beam, then there will be a Doppler shift in the frequency of the returned signal. Assuming the suspended particles are moving at the same velocity as the water, the axial water velocity can then be computed from the change in frequency phase of the backscatter as:

$$
u=\frac{c f_{D}}{2 f_{0}},
$$

where

$$
\begin{array}{cl}
u & \text { is the axial water velocity, } \\
c & \text { is the speed of sound in water, } \\
f_{0} & \text { is the system (emitted) frequency, and } \\
f_{D} & \text { is the Doppler-shifted frequency measured at } \\
\text { the transducer. }
\end{array}
$$

ADVMs measure temperature continuously and store a userspecified salinity to compute $c$ for each measurement. The returned sound wave is measured, digitized, and sliced by time interval into ranges or cells to produce a velocity profile along the insonified volume (fig. 3). The strength of the returned pulse echoes (herein referred to as backscatter) also is recorded. Backscatter should theoretically increase when more particles are present in the water.

Velocity measurement requires the magnitude of the measured backscatter to be greater than that of ambient acoustic noise from the environment and instrument. The maximum range of an ADVM, if it does not intersect a physical boundary, such as the water surface or channel bed, is dependent on the ambient acoustic noise and the signal attenuation, which is a function of instrument, water, and sediment characteristics.

Figure 3. Concept of multicell (indicated by nontransparent circles in the beam path), two-horizontal beam acoustic Doppler velocity meter, and an example of a sediment acoustic index gage.

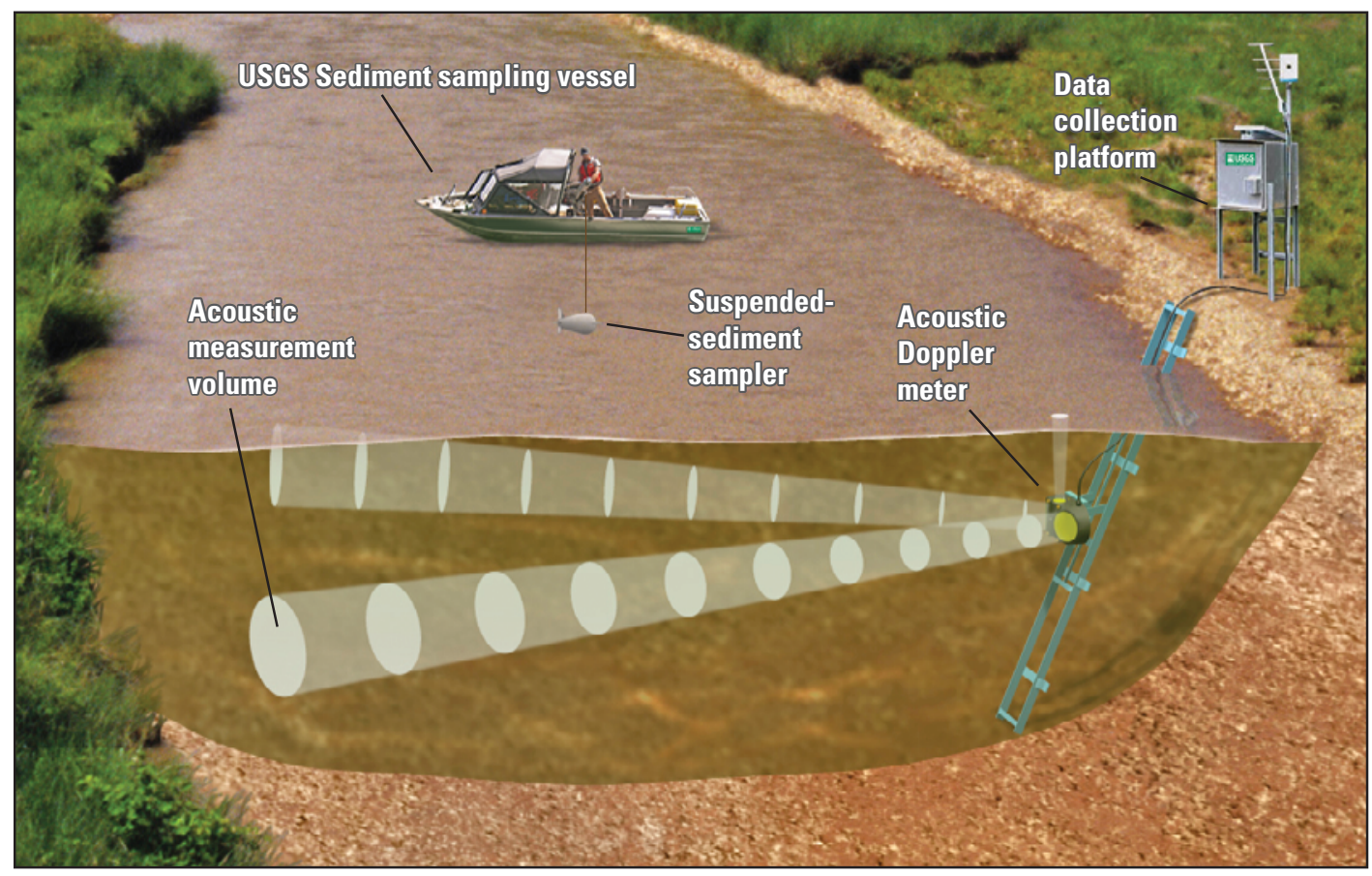




\section{Field Methods}

Field methods for establishing and operating a sediment acoustic index site include both acoustic and SSC data collection. Comprehensive key guidance and USGS protocols for both acoustic index velocity and SSC data collection have been addressed in other USGS reports but are referenced and summarized in this report. Knowledge and understanding of index-velocity methods, particularly as provided in the Computing Discharge Using the Index Velocity Method section (USGS Techniques and Methods 3-A23, Levesque and Oberg, 2012) and sediment sampling techniques as described in Field Methods for Measurement of Fluvial Sediment (USGS Techniques of Water-Resource Investigation 3-C2, Edwards and Glysson, 1999), and associated experience and training in those methods, are required for successful operation of a sediment acoustic index site.

\section{Acoustic Data Collection}

Use of acoustic surrogate data to estimate SSC is based on the following assumptions:

- The average SSC in the acoustic measurement volume is directly proportional to the cross-section average $\mathrm{SSC}$ for all conditions.

- Sediment-concentration and grain-size characteristics within the acoustic measurement volume are homogeneous or have only variations that offset and do not affect the average value.

- Sediment-concentration and grain-size characteristics are constant for the duration of a discrete acoustic measurement (within the ADVM's timeaveraging period).

- Any variation in sediment grain-size distribution is either insignificant or is systematic with SSC and can be quantified in the regression-slope coefficients of the acoustic surrogates and (or) other included explanatory variables.

Deviations from these assumptions can produce increased prediction error and (or) bias, and may make the method non-usable. Designing gages that meet these assumptions is reflected in guidance for selection, installation, and configuration of the ADVM, and evaluation of these assumptions is part of the rating development and evaluation process. These assumptions are more easily met in rivers dominated by finesize sediments (silt and clay sizes smaller than 62.5 microns) that tend to be well mixed compared to those dominated by sand-sized sediments; however, the sediment acoustic index methods often work well in both, with a well-designed installation and configuration.

\section{Site Selection and Installation}

Proper site reconnaissance is critical for successful implementation of sediment acoustic sites. Many of the siteselection criteria described for index-velocity streamgages in Levesque and Oberg (2012) are applicable to selection of sediment acoustic sites. Examples, tips, and forms for use in site reconnaissance and selection, instrument installation, and configuration are available at the USGS Hydroacoustics Web site for Index Velocity at http://hydroacoustics.usgs.gov/indexvelocity/index.shtml. Ideal sediment acoustic index sites have the following properties of which the first three need to be evaluated with measurements and sampling:

1. Sediment properties in the ADVM measurement volume should index (correlate well with) cross-section sediment properties over the range of flow conditions.

2. Sediment concentrations and grain-size properties within the acoustic measurement volume should be homogeneous or have variations that offset and do not affect the average for a given measurement.

3. Changes in the cross-section distribution of flow and sediment characteristics should be systematic, such that they can be represented in the rating curve, and gradual, such that they are measured at the time step of the ADVM measurement interval.

4. The sediment sampling location should be reasonably close to the ADVM, but not so close that the sampler obstructs one or both acoustic beams during sample collection.

5. The ADVM installation should be accessible for servicing and cleaning throughout the expected range of flows.

6. The ADVM installation should have reasonable protection from debris.

7. Sites should have adequate depth at low flow for continuous measurement of backscatter without interference from beams striking the water surface, streambed, or other boundaries or obstructions.

8. The river reach is relatively straight for the greater of about 300 feet (ft) or 5 to 10 channel widths upstream and downstream from the gage site.

9. The degree of sediment mixing downstream of tributary inflows or flow-control structures needs to be verified. Sites should be installed at least 5 to 10 channel widths downstream from tributaries or structures, but further distances may be required. 
Tools to evaluate suitability of sites include cross-channel measurements of velocity and backscatter made with an acoustic Doppler current profiler (ADCP; fig. $4 A-B$ ), aerial photos (historic and current; fig. 5), digital orthophotos, point-sediment and turbidity samples over the cross section to evaluate horizontal (fig. 6) and vertical sediment mixing, temperature and salinity profiles to evaluate water-density changes, and temporary installation of an ADVM. A software
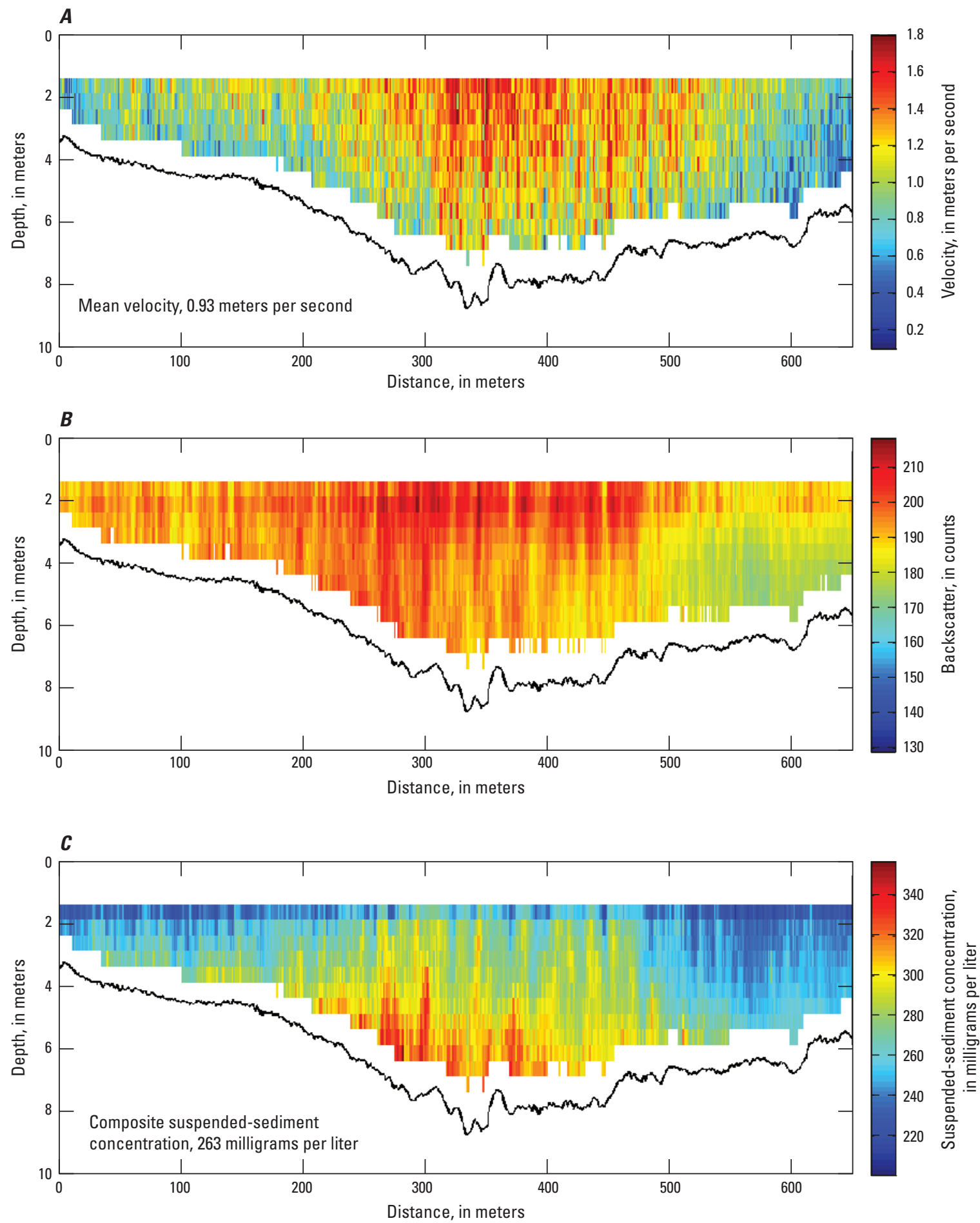

Figure 4. $A$, Velocity, $B$, acoustic backscatter, and $C$, estimated suspended-sediment concentration (SSC) data collected using an acoustic Doppler current profiler (ADCP). The zone of highest velocities ( $A$, depicted by red cells) does not directly align with the zone of highest backscatter and sediment ( $B$ and $C$ also depicted by red cells). The backscatter values in $B$ need to be adjusted using a calibration dataset of concurrent ADCP and physical SSC point samples. 
tool has been developed to assist in using backscatter data obtained from mobile ADCP measurements to evaluate spatial variability of SSC (fig. 4C) (Boldt, 2015). The tool utilizes concurrent sampling of SSC to obtain calibrated SSC estimates at each acoustic bin, or it is used in an uncalibrated mode to evaluate spatial variability of adjusted backscatter over a range of conditions. Additionally, local agencies and residents often can provide qualitative information on historical sediment and flow patterns.

Sediment acoustic index sites may be operated in a variety of conditions to meet diverse objectives, including the monitoring of ephemeral streams, through episodic events, such as high or low flows, or through various seasons of the year. During periods when ice is present, ADVMs can be removed in order to avoid instrument damage. The methods described in this report may be used to obtain discontinuous records at such sites; however, it is assumed that the method will be applied to produce continuous sediment records. Sites should have adequate depth at low flow for continuous measurement of backscatter without interference from beams striking the water surface, streambed, or other boundaries or obstructions. The evaluation of beam interference using methods in Levesque and Oberg (2012) is an essential step in selecting and positioning an ADVM.

The sediment acoustic index method involves building a rating between the acoustic surrogates measured in the insonified volume and the concurrent average sediment concentration in the cross section obtained by cross-section sampling. The most stable relations between acoustic readings in the ADVM's measurement volume and the overall sediment concentration and grain size in the channel typically occur when the ADVM's measurement volume captures a zone of average to above-average sediment concentration relative to the overall sediment concentration and grain size. As a result, the sediment concentration and grain-size distribution within the ADVM's measurement volume should change proportionally with the overall sediment concentration and grain-size distribution in the channel. The large ADVM measurement volume is an advantage of acoustic surrogates over other in-situ surrogates; however, the ADVM beams do not have to

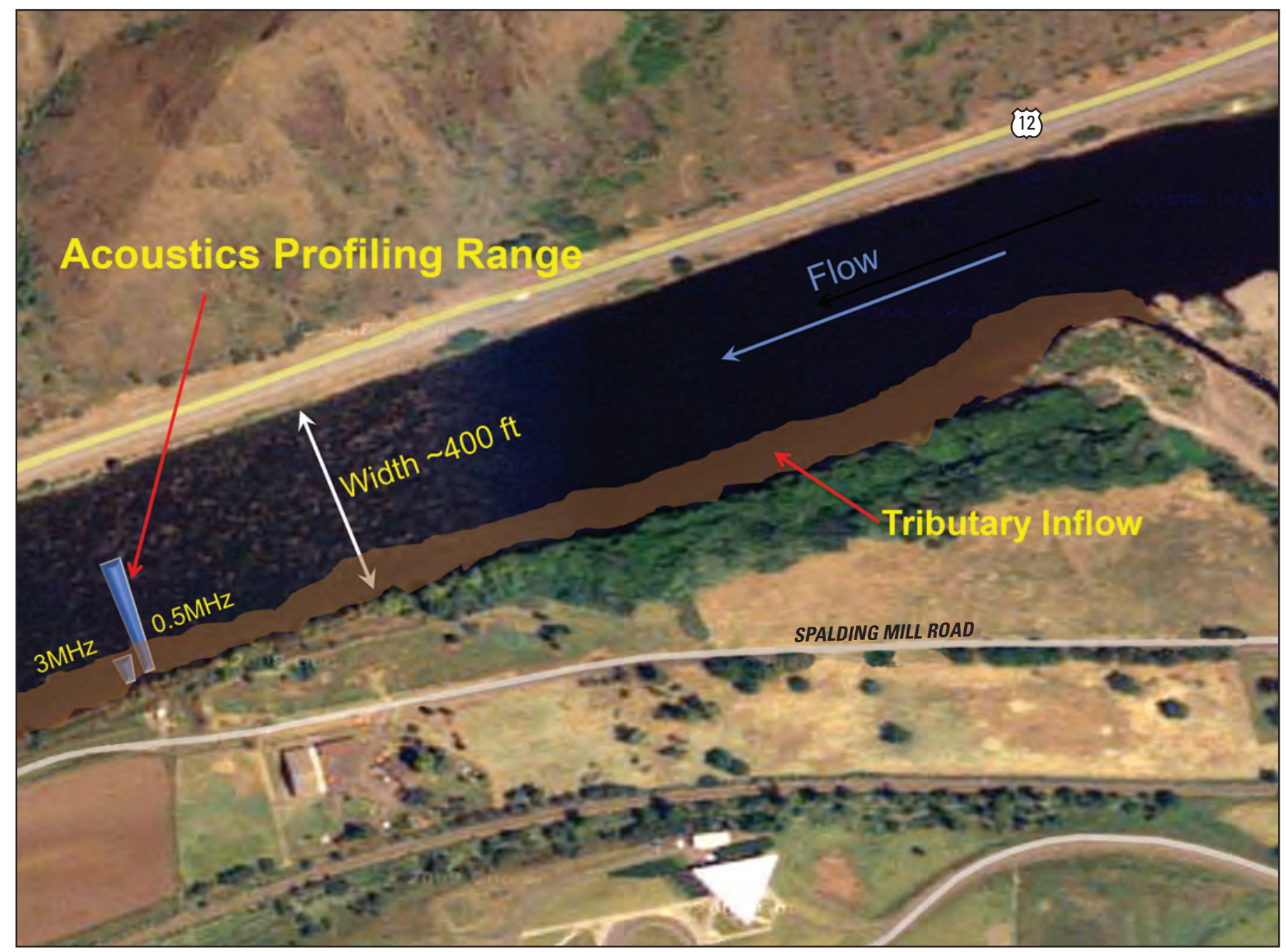

Figure 5. Example evaluation of the suitability of a sediment acoustic site using an aerial photograph. 


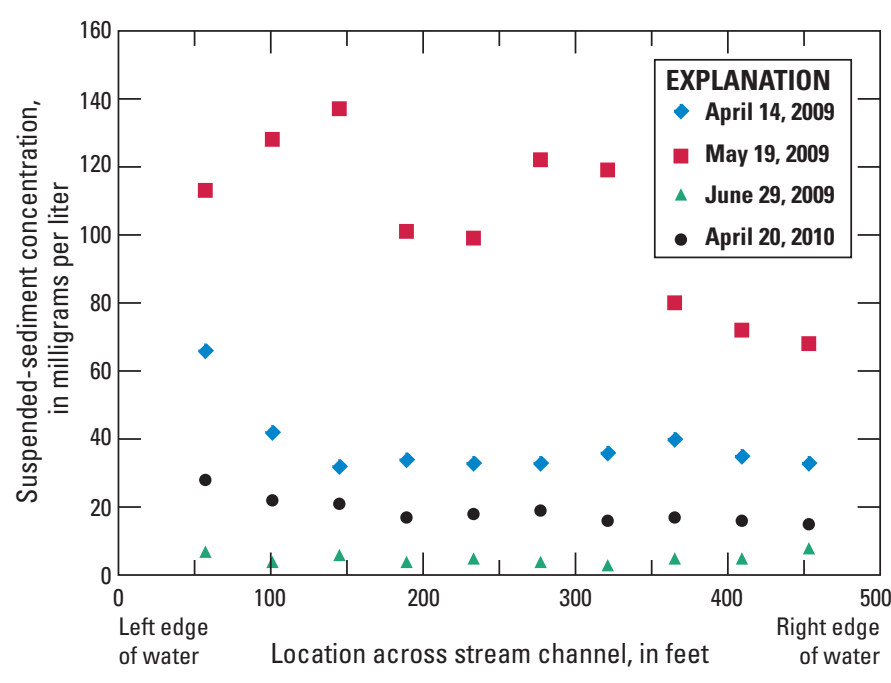

Figure 6. Suspended-sediment concentrations in four discrete sample sets collected in the Clearwater River at Spalding, Idaho (USGS 13342500), at the approximate depth of deployed acoustic Doppler velocity meters (ADVM), to evaluate horizontal stratification of sediment across the stream channel. Highest concentrations are generally observed near the left bank. Whether or not the horizontal stratification is systematic should be considered when installing and configuring an ADVM. These data should be considered in the context of overall streamflow and water depth to provide context of the range of conditions at this site.

extend across any minimum portion of the channel, so long as concentration and grain size in the measurement volume changes proportionally with the overall average concentration and grain size in the cross section.

Site conditions that may hamper or prevent a successful sediment acoustic index rating include major flow disturbances (as from bridge piers or hydraulic structures) near the acoustic measurement volume and poorly mixed tributary inflows. The effects of tributary inflow mixing and hydraulic structures typically vary with flow conditions and must be evaluated accordingly.

\section{Instrument Selection}

Sediment acoustic surrogates are highly dependent on transmitted frequency. Typical frequencies of commercially available ADVMs used in rivers range from 0.3 to $3.0 \mathrm{MHz}$ (megahertz, where $1 \mathrm{Hertz}(\mathrm{Hz})$ is one cycle per second). For index-velocity streamgages, low frequencies often are used on large rivers to increase the range, and higher frequencies are used on smaller rivers to increase the resolution (by measuring smaller, individual acoustic cells) and to reduce the unsampled zone near the ADVM (blanking distance). For sediment acoustic index gages, these factors are equally important, but an additional factor is the response of the ADVM frequency to specific sediment sizes.
Both backscatter and attenuation vary with ADVM frequency and sediment characteristics following theoretical relations. Acoustic attenuation increases exponentially with frequency, increases linearly with sediment concentration, and has a complex, multimodal relation with particle-size distribution. For higher frequency ADVMs, at high suspendedsediment concentrations, the attenuation may cause the signal to rapidly decrease below the noise level, limiting the useful range of the acoustic device. Acoustic backscatter increases with sediment size and has a complex relation with acoustic frequency (Topping and others, 2015). Typical maximum ranges and blanking distances reported by manufacturer specifications are provided in table 1; but the actual maximum range is affected by sediment particle-size characteristics and may be shorter for very high or low concentration conditions.

Current (2015) knowledge indicates that good sediment acoustic index ratings depend on the appropriate selection of instrumentation that considers frequency, multicell profiling characteristics, and internal components. Good sediment acoustic index ratings can be developed using frequencies in the $0.5-\mathrm{MHz}$ to $3-\mathrm{MHz}$ range for most conditions of sediment concentration and grain size, assuming an appropriate location in the cross section can be measured with these frequencies. In recent studies employing this range of frequencies, sediment acoustic index ratings have been used for minimum concentrations from 3 to 8 milligrams per liter $(\mathrm{mg} / \mathrm{L})$, and for maximum concentrations of about 30,000 mg/L (Landers, 2012; Medalie and others, 2014; Moore and others, 2013; Topping and others, 2015; Wood and Teasdale, 2013).

Instrument selection also must consider the number of cells that can be measured because the measurement of acoustic attenuation is based on backscatter from multiple cells. Most currently available (2015) ADVMs measure at least 10 cells, and some measure over 100 . Testing in various conditions has shown that testing 10 cells is adequate to measure the acoustic attenuation for the acoustic index method (Landers, 2012; Wood and Teasdale, 2013); however, 10 or more cells may improve measurements of acoustic attenuation. Instrument-based limitations to this method include the range, resolution, and accuracy of the analog-to-digital processing of the ADVM's backscatter measurements. At the writing of this report (2015), most major ADVM manufacturers do not design their instruments for high-resolution backscatter measurement (beyond what is needed for velocity quality assurance), though this would be a highly desirable feature for improvement of sediment acoustic index methods. Metadata regarding ADVM instrument characteristics and configuration are essential in documentation of sediment acoustic computations and must be reported as described in appendix 1 .

\section{Instrument Configuration}

A hydrographer should evaluate and optimize the ADVM configuration during the initial planning and deployment of a sediment acoustic index gage because changes in system configuration, such as the cell size, generally cause a change in 
the sediment acoustic index rating (fig. 7). The acoustic measurement volume, averaging period, and measurement interval criteria - outlined in USGS Techniques and Methods, book 3, chapter A23 (Levesque and Oberg, 2012) — for index-velocity streamgages also should be applicable to sediment acoustic index gages in most cases, as long as the basic assumptions stated previously under the Acoustic Data Collection section are met. The acoustic measurement volume (range, cell selection, and size) should be configured to avoid interference from boundaries such as the water surface or streambed, and from obstructions such as rocks, debris, and bridge piers. Absent any boundaries or obstructions, the extent of the measurement volume should be limited to ensure that backscatter is at least 10 to 20 counts above the instrument's noise level over a range of sediment conditions. If the stream site transports silt and clay concentrations above several thousand milligrams per liter, then cells should be smaller and closer to the instrument, particularly for higher frequency ADVMs. Additional guidance and examples are provided in Levesque and Oberg (2012).

Configuration of averaging period and measurement interval depends on the rate of change and on turbulent fluctuations in SSC at a site. The averaging period should be longer than a few times the turbulent SSC fluctuations driven by eddy currents. A 2-minute averaging period is adequate for this purpose on most streams; however, longer periods may be more representative for deep, low velocity streams. The averaging period must be shorter than or equal to the measurement interval. The measurement interval should be short enough to capture the peak and temporal trends of the SSC. Typical measurement intervals are 1 to 15 minutes. If the ADVM is connected to a data collection platform (DCP) using Serial

Table 1. Typical maximum ranges and blanking distances (along beam path) for acoustic Doppler velocity meters.

[MHz, megahertz; m, meter]

\begin{tabular}{lcccccccc}
\hline \multicolumn{1}{c}{ Frequency (MHz) } & $\mathbf{0 . 3}$ & $\mathbf{0 . 5}$ & $\mathbf{0 . 6}$ & $\mathbf{1 . 0}$ & $\mathbf{1 . 2}$ & $\mathbf{1 . 5}$ & $\mathbf{2 . 0}$ & $\mathbf{3 . 0}$ \\
\hline Maximum range $(\mathrm{m})$ & 300 & 120 & 90 & 25 & 25 & 20 & 10 & 5 \\
Blanking distance $(\mathrm{m})$ & 1.0 & 1.5 & 0.5 & 0.3 & 0.2 & 0.2 & 0.1 & 0.1 \\
\hline
\end{tabular}

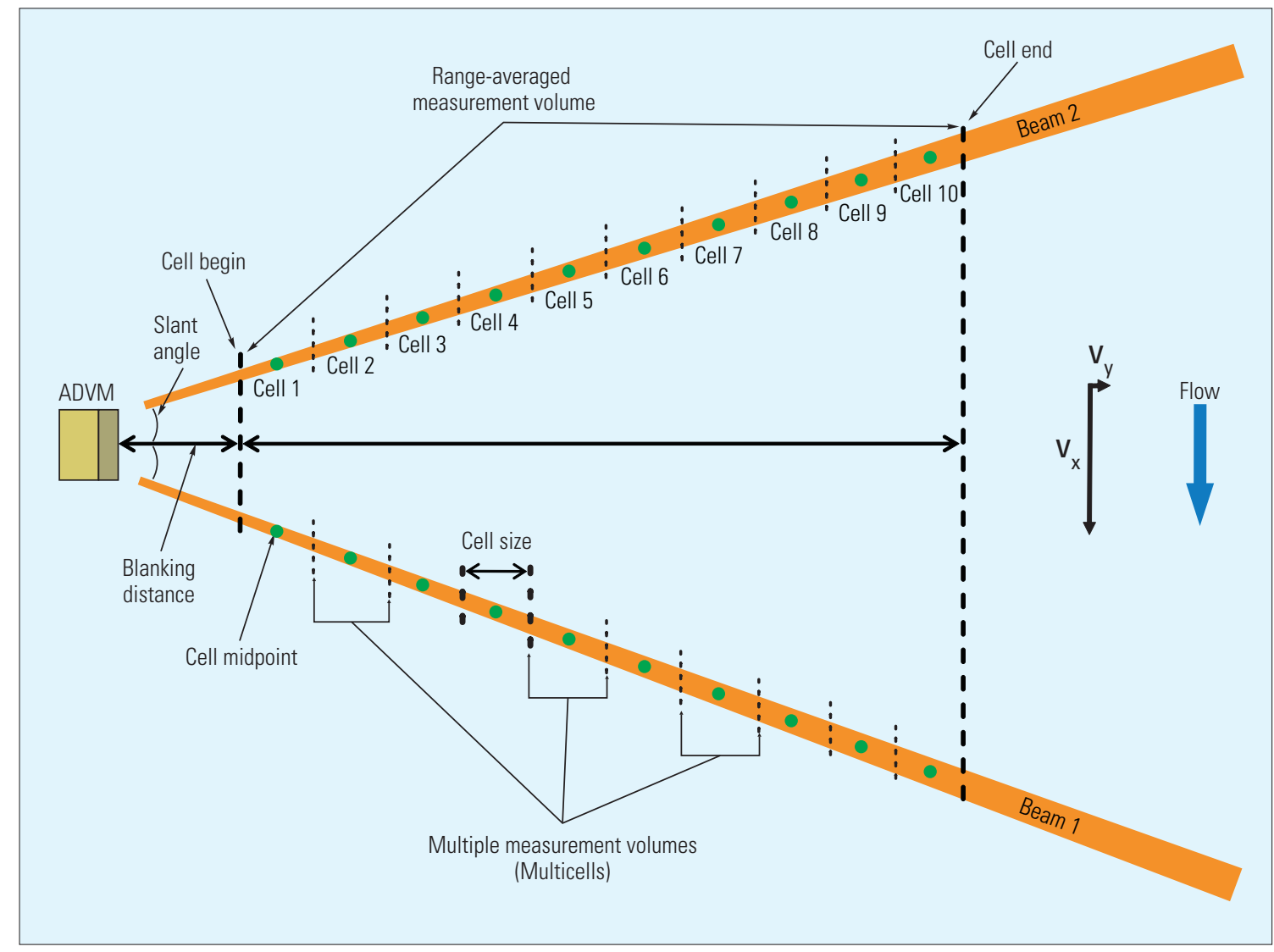

Figure 7. Generalized measurement volumes for a side-looker acoustic Doppler velocity meter (modified from Levesque and Oberg, 2012). 
Data Interface (SDI-12) communication protocol, the averaging period should be at least 1 minute less than the measurement interval to allow a buffer for data transfer before the start of the next measurement.

Activating and configuring multicell capability in ADVMs is required to interpret and measure the sediment acoustic attenuation coefficient (rate of decline in the backscatter signal with distance from the ADVM), the sedimentcorrected backscatter, and ultimately, to develop sediment acoustic index ratings. Evaluation of the optimal number and size of acoustic cells to measure acoustic attenuation may be an iterative process during initial instrument configuration. The instrument should ideally be configured to measure backscatter in 10 or more equal-sized cells to optimize resolution and the measurement of the sediment attenuation coefficient. It is important to evaluate the backscatter at high and low concentrations to ensure that the signal is higher than the noise level, particularly for the cells farthest from the ADVM. The evaluation of cell size and sediment attenuation coefficient is facilitated by the Surrogate Analysis and Index Developer (SAID) software program (Domanski and others, 2015; http:// water.usgs.gov/osw/SALT/). Cell size also affects the acoustic backscatter amplitude, because larger cell sizes contain more sediment (scattering surface area) for a given concentration. Cell sizes must be equal as is required for most ADVMs.

The blanking distance should be configured to be greater than or equal to the near-field range and to possibly locate the measurement volume in a more representative portion of the stream cross section. The near-field range can be computed as described in the Beam Spreading section of this report. In some applications, it is necessary to measure backscatter for SSC from within the near field, in which case the near-field correction must be applied.

Some ADVMs may allow only a limited number of cells (three for some instruments) to be transmitted via SDI-12 data protocols, and this may limit the number of cells that can be transmitted for real-time evaluation and reporting of SSC. If a user desires real-time SSC and can transmit data from only a limited number of cells, then sediment acoustic index models should simultaneously be developed (1) using all cells and (2) using the limited number of cells that could be transmitted. The model using selected transmitted cells can be used in realtime applications if it is representative of the variations in SSC and results in a reliable, predictive model.

Most instruments can store all measured cells internally and can transmit all cells using alternate data-transmission protocols, such as RS-232. Users can obtain information on configuring ADVMs for RS-232 communications from the USGS Hydroacoustics Community forum (http://hydroacoustics.usgs.gov/list_info.shtml). Most commercially available ADVMs have internal recorders that can be activated to store all measured data. The data files stored on the internal recorder contain valuable information for quality assurance that cannot be transferred to a DCP and can serve as a backup to the data stored on the DCP. As a result, ADVM internal recorders (if available) must be activated and periodically downloaded according to guidance in Levesque and Oberg (2012).

\section{Other Installation Considerations}

The ADVM should ideally be integrated with a secured gage house and data collection platform to allow cable protection, storage and transmission of data, and connection to a power source. Most ADVMs require a direct current (DC) power supply that can be provided through batteries recharged with solar panels or through alternating current (AC) converters. Typically at a site with AC power, the charging output is about 13.4 volts $(\mathrm{V})$ with some fluctuations, and at a site with solar-panel power, the output averages about $11.8 \mathrm{~V}$ with potential diurnal fluctuations. Fluctuating transmit power should not affect the way the instrument interprets the Doppler shift, and hence, the velocity of the backscattering particles; but these power fluctuations cause differences in acoustic signal amplitude, which will affect backscatter and computed SSC data. Voltage regulators should be used for sites with either AC or DC (solar) power supplies, but are most critical for sites with DC power due to the typical diurnal power fluctuations. The regulator should be installed between the power source and the ADVM.

The ADVM should be mounted to allow access during all flows for cleaning and servicing. It is essential that the mount allow for the ADVM to be redeployed to the same location after servicing or cleaning, otherwise the location of the insonified measurement volume will change and the acoustic index-sediment rating may change. ADVMs should not be moved unless the data are so poor at a site that they cannot be used for suspended-sediment estimates. Stop bars and locking mechanisms are useful for ensuring that the ADVM is returned to the exact same position and that the mounting configuration is repeatable and secure against vandalism. Levesque and Oberg (2012) and the USGS Hydroacoustics Web site (http:// hydroacoustics.usgs.gov/indexvelocity/index.shtml) provide examples of ADVM mounts that meet these specifications.

\section{Routine Field Techniques and Cleaning}

Routine field techniques and cleaning practices presented in Levesque and Oberg (2012) should be followed. Biofouling (such as growth of algae) on the ADVM transducers degrades (to a substantially greater degree) the detection and measurement of backscatter more than it does the measurement of velocity. For this reason, added effort and use of antifouling techniques should be used as outlined in Levesque and Oberg (2012). Beam amplitude checks should be collected and recorded during every site visit to verify ADVM performance and to illuminate the effects of any interference or fouling on the transducers. If biofouling is observed, the ADVM should be cleaned, and another beam amplitude check should be collected and recorded to document that biofouling was 
removed. Figure 8 illustrates the effects of ADVM biofouling from barnacles on the measured backscatter signal-to-noise ratio $\left(\mathrm{MB}_{\mathrm{SNR}}\right)$, a backscatter metric that is discussed later in this report. In this case, the biofouling from barnacle growth caused an apparent "shift" of about 7 decibels (dB) in the $\mathrm{MB}_{\mathrm{SNR}}$, which would substantially affect the estimated SSC. If biofouling has affected the acoustic record, as in this example, it may or may not be possible to estimate the affected SNR with a time-prorated shift. If a shift is applied, it must be fully documented when processing the sediment acoustic record in the station analysis.
Temperature measured by the ADVM is used to interpret the acoustic signal according to the expected speed of sound and is used in the computation of acoustic surrogates that are used in the sediment acoustic index rating. For these reasons, it is important to verify that the ADVM's temperature sensor is functioning properly. The ADVM's temperature sensor must be checked with an independent reference temperature sensor during each site visit, according to guidelines in Levesque and Oberg (2012). The temperature difference between the two readings should be consistently less than $2^{\circ} \mathrm{C}$; otherwise, the ADVM may need to be replaced or repaired (U.S. Geological Survey, 2010).
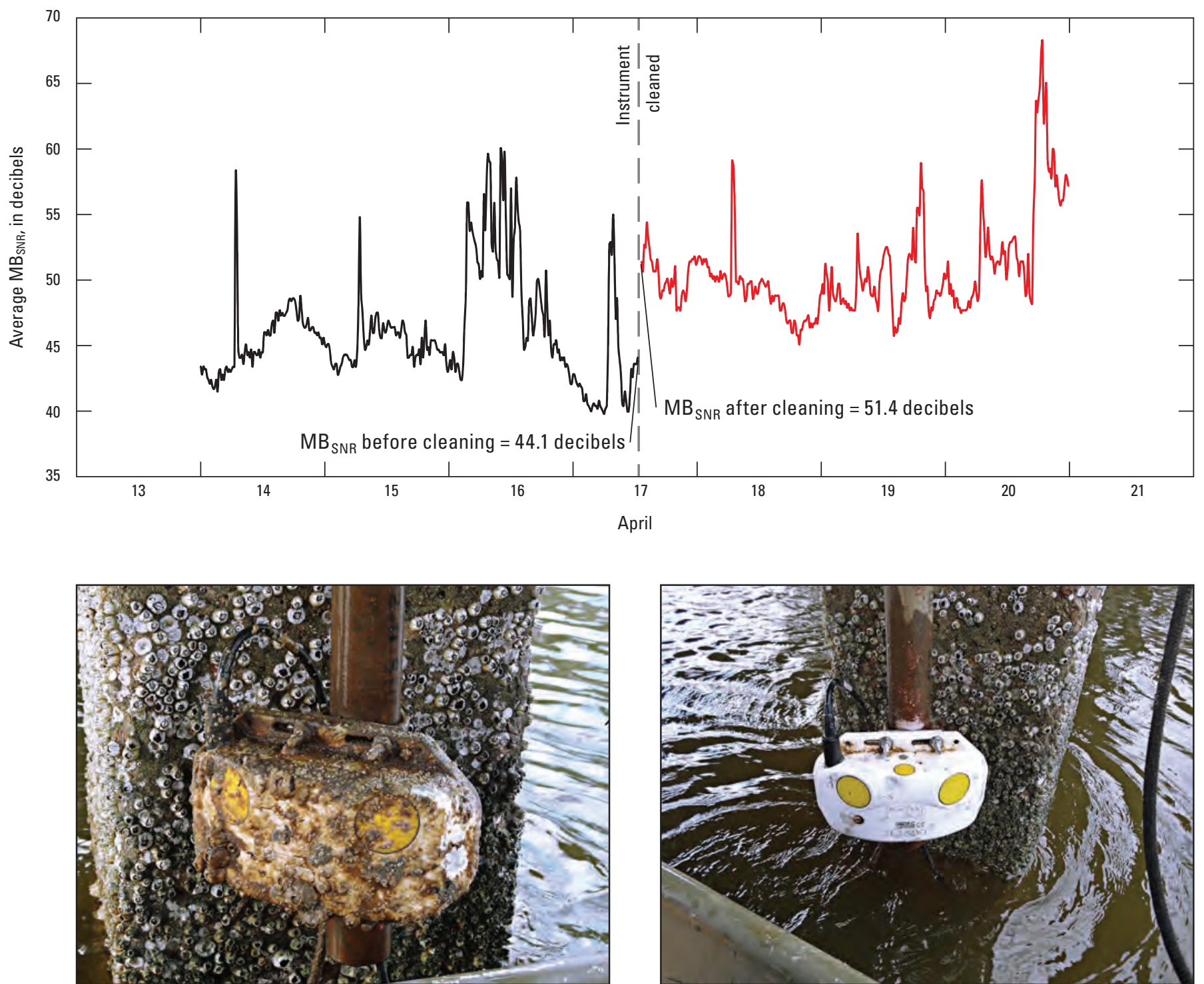

Figure 8. Time series of signal-to-noise ratio $\left(\mathrm{MB}_{\mathrm{SNR}}\right)$ readings and photographs before and after cleaning in 2012 for a 1.5 megahertz acoustic Doppler velocity meter installed at West Fork Double Bayou at Eagle Ferry Road near Anahuac, Texas (USGS 08042558; photographs by Mike Lee, USGS). 


\section{Suspended-Sediment Data Collection}

Collection and analyses of channel depth- and widthintegrated physical samples (fig. 9) provide the only direct measure of SSC in a stream. Thus, sampling over the range of sediment and acoustic conditions for a site is essential to the successful development of a sediment acoustic index rating. A representative sample has sediment concentration and size distribution equal to (within measurement and analytical uncertainty) the actual average concentration and size distribution over the stream cross section at the time of sample collection. The ADVM location and configuration must be constant for all concurrent SSC samples to be used in the sediment acoustic index rating.

Collection of accurate, representative samples requires that trained personnel use correct instruments and methods over a range of hydrologic and sediment conditions. Suspended-sediment concentration data used for developing sediment acoustic index ratings should be collected following the guidance in "Field Methods for Measurement of Fluvial Sediment" (USGS Techniques of Water-Resources Investigations Report, book 3, chapter C2; Edwards and Glysson, 1999). Knowledge of the principles and methods in Edwards and Glysson (1999) as applied to site-specific conditions is considered a prerequisite to obtaining the SSC data for these sediment acoustic index methods and is only summarized herein. Additional key references include the following: discussion of samplers and their operation in Davis (2005) and Topping and others (2011), and in the Federal Interagency Sedimentation Project Web pages (water.usgs.gov/fisp), and in a video introduction to sampling in Nolan and others (2005), and in the USGS National Field Manual for the Collection of Water-Quality Data (Techniques of Water-Resources Investigations Report 9-A4, 2006).

\section{Sampling Location and Planning}

The site-selection criteria described under Acoustic Data Collection apply, in general, to physical SSC sampling locations. Samples must be collected over the range of observed flow which, for high flows, often requires sampling from bridges, boats, or cableways. The locations of the SSC sampling section and the ADVM measurement section need to be close enough to ensure there are no significant differences in the sediment concentration, particle size, and transport. There should be no opportunity for sediment deposition, erosion, or additional sediment contributions from tributaries between the two locations. Hydraulic structures could introduce errors in this regard; for example, if the ADVM and SSC sampling sections are separated by a scour-producing flow dike or bridge pier, sediment could be disproportionately introduced into the channel. A secondary purpose of sampling is to characterize

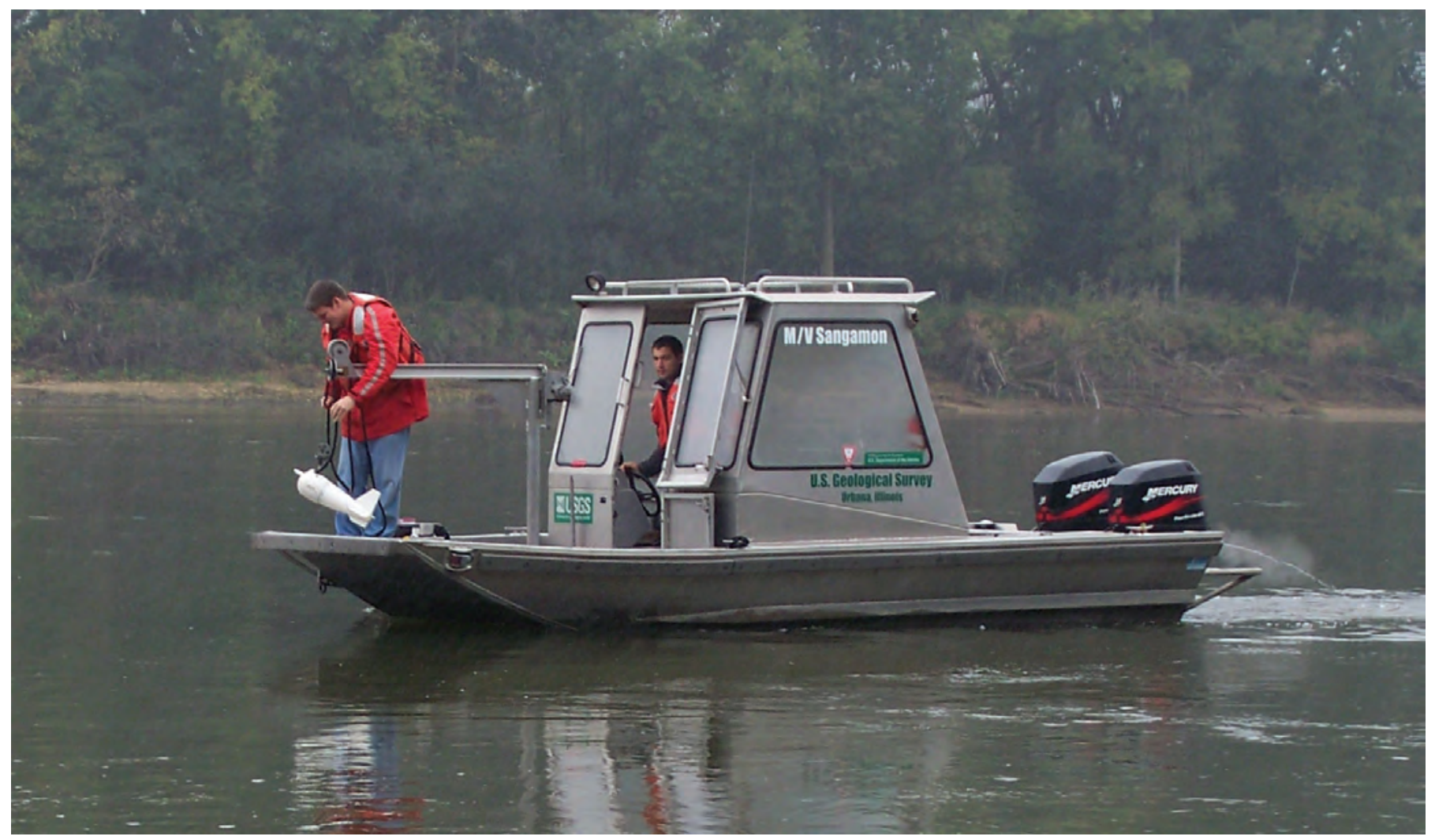

Figure 9. Example of channel depth- and width-integrated physical sampling, which provides the only direct measure of representative suspended-sediment concentration in a stream. 
spatial variability in SSC and particle size in the cross section and within the ADVM insonified measurement volume. Samples also may be needed to establish the relation between representative cross-section concentrations and those from a fixed-point pumping sampler. Sampling for these purposes, especially during the reconnaissance phase of the study, may require additional planning if the regular SSC sampling section is not close to the ADVM measurement section.

A detailed sampling plan, particularly for high flows, is needed to cover safety, access, manpower, sampler and deployment equipment requirements, sample labeling and handling, and other factors. That plan should comply with relevant policies and previously referenced key guidance. The sampling plan should be designed to collect a good model calibration dataset for the sediment acoustic index rating. Samples should reasonably represent the range of flow and sediment conditions observed in the time series for the site, with particular focus on medium- and high-flow conditions. The optimal sampling plan is likely to include a combination of scheduled periodic plus event-based samples (Horowitz and others, 2014).

\section{Sampling Instrumentation and Methods}

The general methods for collecting representative depthand width-integrated SSC samples are covered in the referenced key guidance. Representative samples require isokinetic samplers and cannot be obtained using grab- or fixed-point pumping samples. Sampler selection requires consideration of the maximum depth and velocity conditions that may need to be sampled and whether or not the sample will be analyzed for trace-metal water-quality constituents. Davis (2005) contains sampler selection guidance based on these and other criteria. Depth-integrating samplers are most commonly used; however, a point-integrating sampler may also be used, particularly during reconnaissance to characterize the vertical variation in SSC.

Depth-integrated samples should be collected using the equal discharge interval (EDI) or equal width interval (EWI) method described in Edwards and Glysson (1999). The EDI method involves collecting depth-integrated samples at five to nine cross-section stations defined at the centroids of equaldischarge increments. The EDI vertical transit rate of the sampler can vary between sampling stations and between sampler descent and ascent. This method requires some knowledge of the streamflow distribution at the section for the measurement conditions to determine the centroid sampling stations. Samples from each station are analyzed separately and averaged to obtain a mean discharge-weighted concentration. The EWI method does not require a knowledge of flow distribution, but requires samples at 10 to 20 cross-section stationsmore than for the EDI method. The EWI method requires a uniform transit rate for all samples, and this sample rate must be determined for the deepest, fastest section prior to obtaining the cross-section sample. EWI samples can be composited for a single sample analysis or EWI samples from each station can be analyzed separately to evaluate variation in SSC and the sample-volume-weighted composite concentration can then be computed. The maximum vertical transit rate for EDI or EWI methods is 0.4 times the ambient stream velocity in the vertical. Each sample should be visually inspected as it is removed from the sampler, for potential overfilling of the sample bottle and any unusual concentrations (such as from digging the bottom), in which cases the sample must be re-collected.

Recommended practices for both EDI and EWI methods include the collection of two samples (a sample and replicate) at each sample station. This is important for quality assurance (as it may identify a nonrepresentative sample due to sampler operation or handling problems) and to quantify temporal variability. Sample bottles must be labeled according to USGS practices, and use of electronic field forms is recommended to facilitate sample handling and laboratory logistics. Stream temperature also should be recorded at the time of the measurement as this can affect sediment entrainment and transport.

Fixed-point pumping samplers can be useful for estimating average cross-section SSC, if the SSC at the fixed-point pumping sampler intake varies proportionally with the average cross-section SSC. If a fixed-point pumping sampler is being used, then concurrent cross-section samples must be collected to determine the relation of the fixed-point sample concentration to the cross-section SSC (sometimes called a "box coefficient"). The fixed-point intake location should be carefully evaluated using similar criteria and tools as discussed in the Site Selection and Installation section. The fixed-point sampler box coefficient must be established with concurrent sampling and verified periodically (typically two to six times per year, including during high-flow conditions). Fixed-point pumping samples may be composited over stormflow hydrographs or may be collected and analyzed for discrete-flow or time intervals. Fixed-point samples (adjusted by box coefficients) can be used in the sediment acoustic index rating development if they are proven to be representative of the concurrent cross-section concentration.

The sediment acoustic index method assumes that sediment concentration does not vary significantly or varies systematically within the ADVM insonified measurement volume. Periodic point samples along the ADVM insonified beam path would help confirm that this condition is met. It may be valuable but it is not required to establish a quantitative relation by concurrent sampling in the cross section and ADVM insonified measurement sections. It is not required to do so because this relation will be quantitatively included in the sediment acoustic index rating coefficients.

The laboratory analysis required to develop the sediment acoustic index rating is the SSC of the composite cross-section sample. Each sample should be analyzed (at a minimum) for SSC and for the percent of the sample sediment that is finer than 62.5 microns (the percent fines or silt-sand split). The concentration of the sand portion and of the fines portion of the SSC are needed because typically the acoustic surrogate of sediment-corrected backscatter is more responsive to sand-sized particles while the sediment attenuation 
coefficient is more responsive to fine-sized materials. These relative responses can be evaluated using the percent fines data. Accurate acoustic calibrations when sand comprises a substantial fraction of the suspended sediment can require the suspended-sand median-grain size to ensure suspended-sand grain-size distribution is constant enough to allow use of a single frequency (Topping and others, 2015).

The results of one or more full particle-size distribution (PSD) analyses of sampled suspended sediment can be useful in evaluating the effect of sediment size on backscatter and attenuation for the site. Analysis of organic matter through a loss-on-ignition test also can be useful to explain outliers or seasonal trends when evaluating sediment acoustic index ratings. Particulate organic matter in the water column can scatter and reflect the acoustic pulse from the ADVM and can contribute to the ADVM's backscatter reading. However, some organic matter may be burned off during sample analysis and not fully reported in the SSC result. Changing amounts of particulate organic matter over seasons or flow conditions can result in errors or variability in the sediment acoustic index rating (Voichick and Topping, 2014).

\section{Sediment Acoustic Surrogates Computation}

This section describes analytical methods to adjust raw measured acoustic backscatter data for several factors to compute two sediment acoustic surrogates. These surrogates are then used to develop the sediment acoustic index rating from the calibration dataset, and the rating is used to compute continuous SSC time series from the in-situ ADVM measurements. Evaluation and computation of the acoustic surrogates is facilitated by the SAID program (Domanski and others, 2015), as discussed later in the report.

The two primary acoustic surrogates of SSC that are used as explanatory variables to compute SSC time-series data are the sediment-corrected backscatter $(S C B$, in $\mathrm{dB})$ and the sediment attenuation coefficient $\left(S A C\right.$, also referred to as $\alpha_{s}$, in $\mathrm{dB} / \mathrm{m})$. Starting with a simplified form of the sonar equation (Urick, 1983), which is fully developed in appendix 2, the general equation to compute $S C B$ is given below and the method of calculating $\alpha_{s}$ is discussed in the Sediment Attenuation Coefficient section.

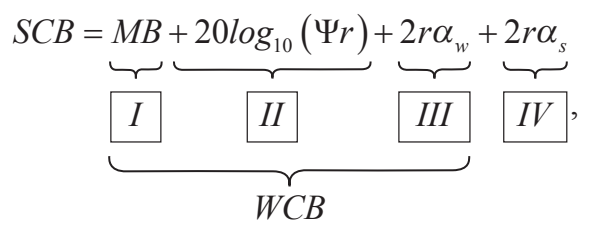

where

$$
\begin{gathered}
I \quad \text { is the ADVM Raw Measured Backscatter, } \\
\text { is the correction for Beam Spreading (as } \\
\text { typically expressed), } \\
\text { iII the correction for Water Absorption } \\
\text { (acoustic absorption due to water } \\
\text { properties), and } \\
\text { iV the correction for Sediment Attenuation } \\
\text { (acoustic absorption due to sediment } \\
\text { properties). }
\end{gathered}
$$

Each variable in the equation is briefly defined below and in more detail in the following sections:

- $S C B$ is the sediment-corrected backscatter (dB), which is that portion of the $M B$ after correcting for transmission losses. The $S C B$ is driven by sediment properties for a given acoustic signal.

- $M B$ is the raw backscatter (in $\mathrm{dB}$ ) measured by the ADVM (also referred to as the volume reverberation level MB).

- $W C B$ is the water-corrected backscatter $(\mathrm{dB})$, which is the measured backscatter adjusted for the physical acoustic signal beam spreading and acoustic absorption due to water properties, and which can be determined directly from measured properties.

- $\Psi$ is the near field correction coefficient applicable if data are retained from the near field zone.

- $r$ is the range or distance from the transducer along the acoustic axis of the beam [in meters (m)].

- $\alpha_{w}$ is the water-absorption coefficient (in $\mathrm{dB} / \mathrm{m}$ ), which is controlled primarily by water temperature in rivers for a given acoustic frequency.

- $\alpha_{s}$ is the sediment attenuation coefficient, also referred to as $S A C(\mathrm{~dB} / \mathrm{m})$, which is controlled by sediment properties for a given acoustic frequency.

- The coefficient of 2 is used to account for the travel of the signal to and from the target sediment (two way).

In equation 2, items $I I, I I I$, and $I V$ are sometimes combined and denoted as 2TL, where TL stands for transmission loss. Measurements of the acoustic return signal can be digitally sliced into specific range-gated "cells" to provide data on velocity and acoustic metrics at integral points along the acoustic axis of the beam. These data offer an effective means to directly measure the sediment acoustic attenuation at a high temporal resolution, as was recognized by Topping and others (2006). The $M B, W C B$, and $S C B$ along the acoustic beam are illustrated in figure 10 for a single time-step measurement. 
The $S C B$ is computed using equation 2 for each time step. Items $I I$ and $I I I$ in equation 2 are functions of the fixed instrument configuration and the measured water temperature. Items $I$ and $I V$ in equation 2 are obtained from the measured acoustic backscatter and attenuation. All four items are described in more detail in the following sections, where also the multicell measured backscatter and computed acoustic parameters shown in figure 10 and table 2 will be used as example calculations from $M B$ to $W C B$ to $S C B$.

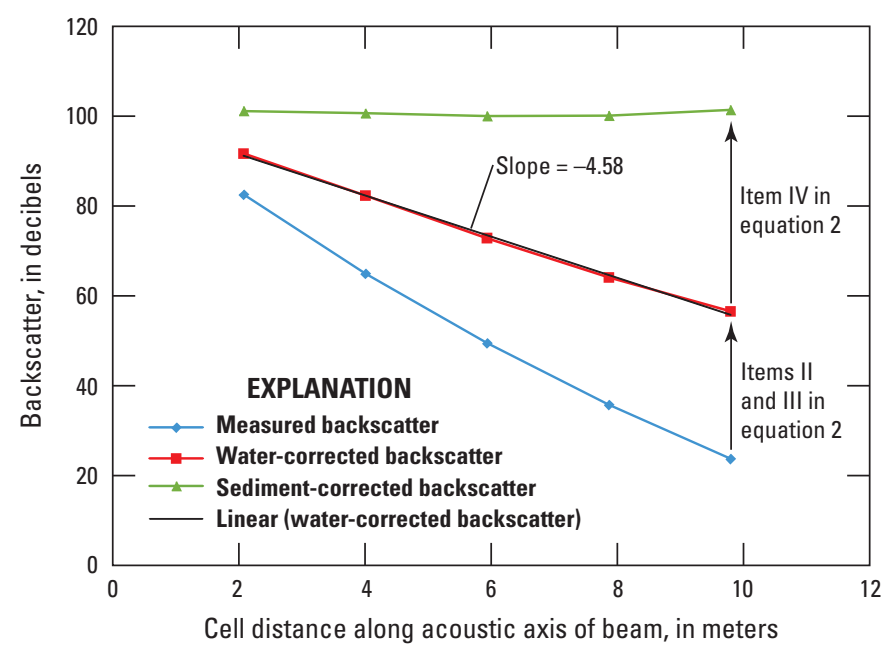

Figure 10. Example of multicell measured backscatter and computed acoustic parameters for the Spoon River at Seville, Illinois (USGS 05570000) on April 18, 2013, at 15:00 Central Standard Time.

\section{ADVM Raw Measured Backscatter and Noise Level}

The raw amplitude of acoustic backscatter is measured and recorded by the ADVM. This reading is sometimes abbreviated as Amp or RSSI (received signal strength indicator) in counts, depending on the manufacturer of the instrument. For purposes of this report, Amp will be used to denote raw amplitude of acoustic backscatter. The instrument-specific accuracy and precision of the Amp measurement is a primary instrumentation factor controlling the overall accuracy and precision of the sediment acoustic index method. The Amp (in counts) of the acoustic backscatter can be converted to measured backscatter [in decibels $(\mathrm{dB})$ ] by the following equation

$$
M B=K \times A m p,
$$

where

$$
K \quad \text { is the instrument echo intensity scale factor }
$$$$
\text { (in } \mathrm{dB} / \text { count). }
$$

The echo intensity value ensures that the measured and computed expressions in equation 2 have consistent units of $\mathrm{dB} ; K$ should be obtained for each instrument from the manufacturer. Some manufacturers measure and provide transducer-specific (beam-specific) $K$ values for each instrument (recorded with instrument serial number) while others provide a constant $K$ as for a particular model ADVM (typically given in the instrument manual). The values for $K$ generally range from 0.35 to 0.55 (Deines, 1999). The precise instrument-specific $K$ factor has little effect on the accuracy of the sediment acoustic index rating; however, it can affect rating coefficients. This is one reason that sediment acoustic index ratings can be instrument specific.

The instrument noise level $(N L)$, sometimes referred to as the RSSI reference level or detection threshold, is used to quality assure the $M B$ data and to compute $M B$ in terms of signal-to-noise ratio $\left(M B_{S N R}\right) \cdot M B_{S N R}$ for some commonly used ADVMs is defined as

$$
M B_{S N R}=K \times(A m p-N L) .
$$

The $N L$ is affected by instrument-generated electronic noise (thermal noise) and environmental noise (such as cavitation or ice flow) in the measured frequency range. In the sediment acoustic index method, $M B$ typically is used; however, $M B_{S N R}$ has been used successfully in place of $M B$ (Landers, 2012; Wood and Teasdale, 2013). Instrument-recorded $N L$, however, may include extraneous information resulting in erroneous $M B_{S N R}$ computations and inverse relations between $M B_{S N R}$ and SSC as described in Wood and Teasdale (2013). Measurement error or bias in acoustic surrogates can result where $N L$ is significant and ignored or incorrectly accounted for, as in the example of noise due to ice conditions as shown in figure 11. Best practices require review of the raw $M B, N L$, and (or) $M B_{S N R}$ time-series data to determine if environmental or anthropogenic noise is affecting the acoustic data.

Accurate measurements of velocity, $S C B$, and $S A C$ require $M B$ amplitude above the $\mathrm{K} \times N L$ level. The $M B$ for cells farthest away from the ADVM may asymptotically approach $\mathrm{K} \times N L$ and could drop below $\mathrm{K} \times N L$ levels during high-sediment concentrations because of increased $S A C$ and resultant transmission losses, or during low sediment concentrations because of insufficient particles for acoustic scattering. In these cases, the cells with $M B$ or $M B_{S N R}$ values approaching or below the noise level are not used in the computation of $S A C$ and $S C B$. This scenario is illustrated in figure 12 where the $M B$ reaches the $\mathrm{K} \times N L$ level near the sixth cell so that beyond this location the $M B$ data are not meaningful. Using $M B$ data below the noise level results in erroneous $W C B$ and $S C B$ values that increase with range as seen in figure 12 (cells beyond the "Cells used" line shown in fig. 12A).

If the $W C B$ increases with range from the ADVM, then it is reasonable to assume the $M B$ is affected by the noise level. 


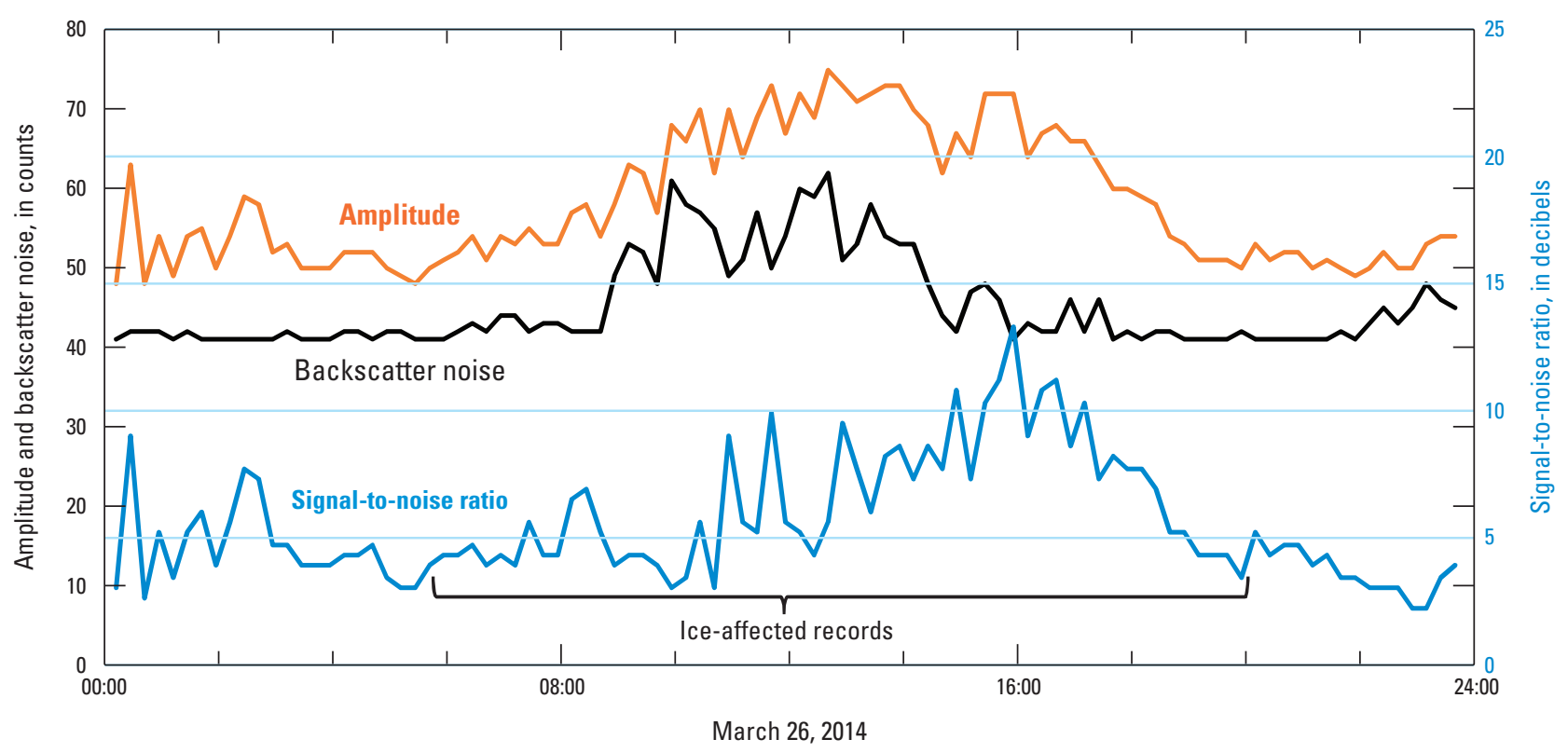

Figure 11. Example of effects of ice on records of backscatter noise, amplitude, and signal-to-noise ratio for a 0.5 megahertz system on the Hudson River below Poughkeepsie, New York.

This is an undesirable condition because it requires truncating the acoustic measurement volume and may cause changes in the relation to the cross section, and if this condition occurs the data should receive detailed review. If the $W C B$ increases with range, then cells that include and are beyond the cell with the minimum $W C B$ should not be included in the calculation of $S C B$ nor $S A C$ (fig. 12), unless the cell with the minimum $W C B$ is the last or first cell in the index measurement volume. If the cell with the minimum $W C B$ is the last cell, the value is retained and all cells are used to calculate the sedimentcorrected backscatter and attenuation coefficient. If the cell with the minimum $W C B$ is the first or second cell, then all other cells are not considered, the $W C B$ value in the first cell is used as the $S C B$ value for the observation, and no attenuation coefficient should be calculated. For the data shown in figures 10 and 12 , the $M B$ was affected by the noise level and the last five of the original 10 cells were removed.

Figure 12. Comparison of measured, water-corrected, and sediment-corrected backscatter profiles along the acoustic axis of the beam for $A$, full range of cells and $B$, range of cells within the range of the minimum water-corrected backscatter.
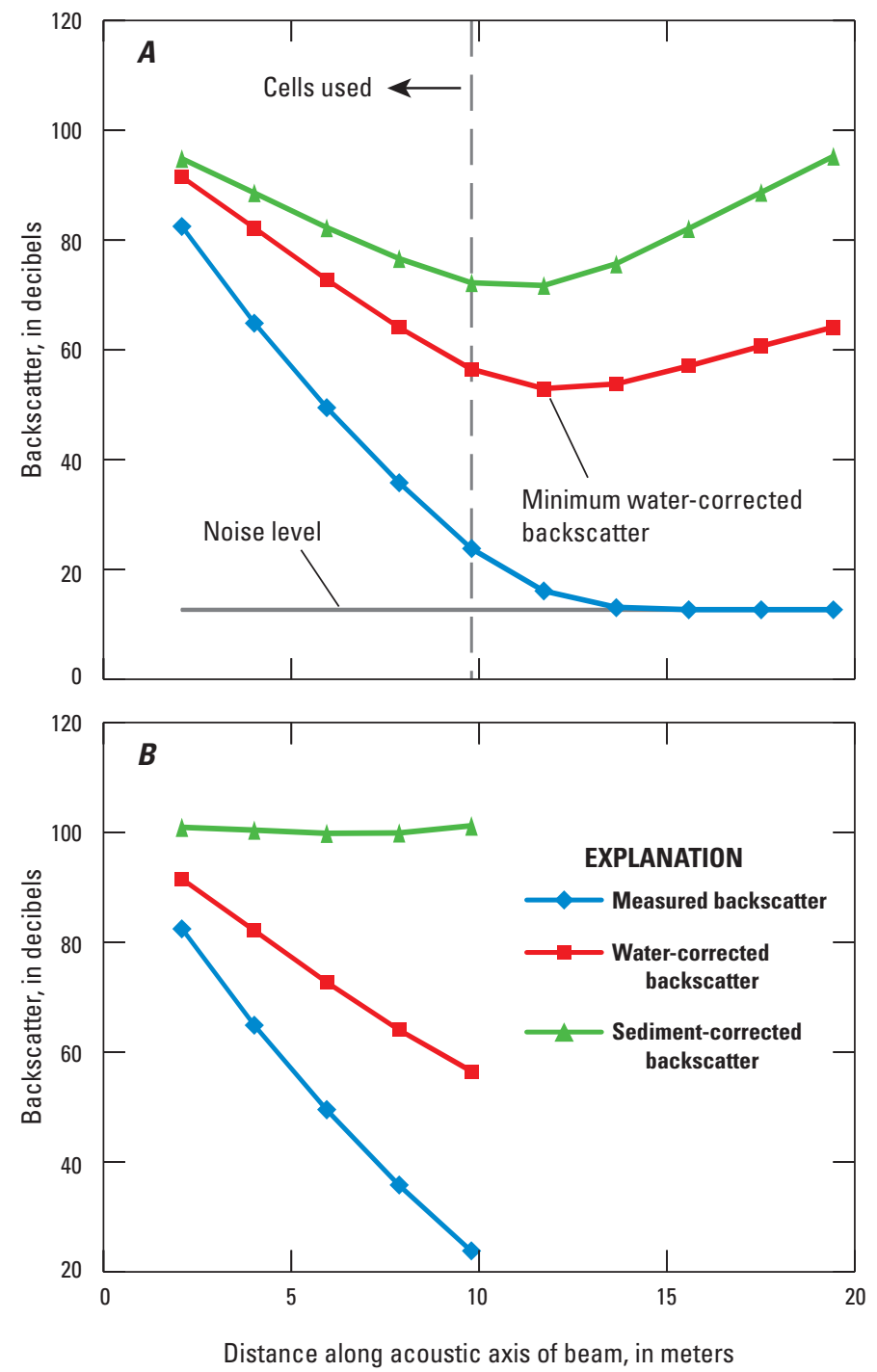


\section{Example Calculation}

The example data from the Spoon River at Seville, Illinois (USGS streamgage 05570000) on April 18, 2013, at 15:00 Central Standard Time (CST) during a flood event is shown in figure 10 and table 2 . This example calculation is shown only for cells 1 through 5 of the full acoustic profile, both for simplicity and because backscatter data in cells 6 through 10 were below the noise-level criteria, as discussed. An EWI SSC sample was taken at 14:53 CST and the mass concentration was $1,850 \mathrm{mg} / \mathrm{L}$. The ADVM multicell readings shown are from a $1.5-\mathrm{MHz}$ Sontek Argonaut SL. The raw amplitude of acoustic backscatter was multiplied by an echointensity scale factor $(\mathrm{K})$ of 0.43 (standard echo-intensity scale factor for SonTek Argonaut ADVMs) to obtain the measured backscatter MB. Substituting the values into equation 3a for cell 5 gives:

$$
M B_{\text {cell } 5}=0.43 \frac{d B}{\text { count }} \times 55 \text { counts }=23.65 \mathrm{~dB} .
$$

The instrument was set to a blanking distance of 1.00 meter (m) and the cell size is $1.75 \mathrm{~m}$. As discussed previously, the blanking distance and the cell size are measured perpendicular to the instrument; however, the acoustic parameters are measured to the center location of each cell along the acoustic axis of the beam. In this case, the beam angle relative to the axis of the instrument perpendicular to flow (called the slant angle) is 25 degrees ( 0.4363 radian), so for cell 5 , the midpoint along the acoustic axis of the beam can be calculated as

$$
r_{\text {cell } 5}=\frac{1 \mathrm{~m}+4(1.75 \mathrm{~m})+(1.75 \mathrm{~m}) / 2}{\cos (0.4363)}=9.792 \mathrm{~m} .
$$

These calculations are repeated for each cell and the values are used in the Beam Spreading and (or) Sediment-Corrected Backscatter Example Computation section.

\section{Beam Spreading}

Beam spreading is simply the physical spreading of the acoustic wave pressure as it radiates outward from the transducer. In an ideal, unbounded medium, acoustic pressure is equally spread over the surface area of a sphere at any range $(r)$ from the point source, outside of the near-field range (fig. 13). The surface area of the sphere increases with the square of the range from the point source, and the oneway spherical spreading in decibels is $10 \log \left(r^{2}\right)$ or $20 \log (r)$. The actual two-way spherical spreading would be double this quantity; however, that doubling is offset by a further correction for the increasing volume of the measurement cell with increasing $r$ as described for the full sonar equation in appendix 2.

Beam spreading in the near-field range from the transducer is highly nonspherical and irregular. The parameter $\Psi$ in equation 2 is used to estimate the effects of nonspherical energy spreading in the near field and varies with the ratio of $r / r_{n}$. The parameter $\Psi$ is not as physically based or reliable as the other components of equation 2. To avoid this source of uncertainty, the blanking distance for the ADVM should be greater than or equal to the $r_{n}$ computed conservatively, using the cold season water temperature. The division between the near and far fields occurs at the critical range or distance (known as the Rayleigh distance), $r_{n}$, which is defined by $A / \lambda$, where $A$ is the "effective" transducer area $\left(\mathrm{m}^{2}\right)$, and $\lambda$ is the

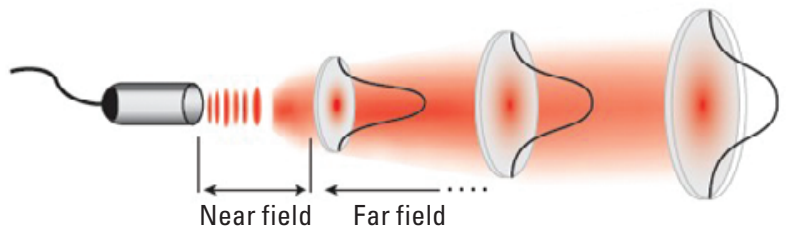

Figure 13. Spherical spreading of acoustic energy in water.

Table 2. Acoustic and environmental parameter values used in examples calculation from measured backscatter $(M B)$ to watercorrected backscatter $(W C B)$ to sediment-corrected backscatter $(S C B)$, as also shown in figure 10.

\begin{tabular}{|c|c|c|c|c|c|}
\hline Intensity scale factor $(K)$, in $\mathrm{dB} /$ count & 0.43 & & & & \\
\hline Effective transducer area $(A)$, in $\mathrm{m}^{2}$ & 0.000707 & & & & \\
\hline Water temperature $(T)$, in degrees Celsius & 11.45 & & & & \\
\hline Frequency of $\mathrm{ADVM}(f)$, in $\mathrm{kHz}$ & 1,500 & & & & \\
\hline Cell number & 1 & 2 & 3 & 4 & 5 \\
\hline Cell distance along acoustic axis of beam $(r)$, in meters & 2.069 & 4.000 & 5.931 & 7.862 & 9.792 \\
\hline Measured backscatter $(M B)$, in $\mathrm{dB}$ & 82.56 & 64.93 & 49.45 & 35.69 & 23.65 \\
\hline Water-corrected backscatter $(W C B)$, in $\mathrm{dB}$ & 91.63 & 82.30 & 72.81 & 64.07 & 56.51 \\
\hline Sediment-corrected backscatter $(S C B)$, in $\mathrm{dB}$ & 101.11 & 100.62 & 99.98 & 100.09 & 101.35 \\
\hline
\end{tabular}

[dB, decibel; $\mathrm{m}^{2}$, square meter; KHz, kilohertz] 
wavelength of the acoustic signal (m). Note that the effective transducer diameter is not the same as the physical diameter that is measured on the instrument. The effective transducer diameter needs to be obtained from the manufacturer of the instrument. The wavelength is equal to the speed of sound in water in meters per second $(\mathrm{m} / \mathrm{s})$ divided by the acoustic frequency in hertz $(\mathrm{Hz})$. The speed of sound is a function of temperature (primarily), salinity, and depth. In rivers with salinity less than 5 parts per thousand and depth less than $100 \mathrm{~m}$, these factors affect the speed of sound by less than 0.5 percent; however, equations are available in the literature if these conditions are significant. The speed of sound in water can be calculated for water temperatures ranging from 0 to $95^{\circ} \mathrm{C}$, using equation 4 from Marczak (1997).

$$
\begin{aligned}
\mathrm{c}=1.402385 & \times 10^{3}+5.038813 T \\
& -5.799136 \times 10^{-2} T^{2} \\
& +3.287156 \times 10^{-4} T^{3} \\
& -1.398845 \times 10^{-6} T^{4} \\
& +2.787860 \times 10^{-9} T^{5}
\end{aligned}
$$

where

c is the speed of sound in water in $\mathrm{m} / \mathrm{s}$ and

$T$ is water temperature in Celsius.

Best practices for this method are to set the blanking distance greater than the near-field range; however, if an application requires measurement in the near field, then the correction factor $\Psi$ can be computed and used. Note that some users have found the Downing near-field factor to overcorrect, biasing the resultant $S C B$ high, and it may be preferable to use uncorrected data if one must measure in the near field.

If needed, the parameter $\Psi$ is estimated as (Downing and others, 1995):

$$
\Psi=1+\frac{1}{1.35 Z+(2.5 Z)^{3.2}},
$$

where $Z=r / r_{n}$. The term in equation 2 to quantify transmission loss (to and from the transducer) due to spherical spreading in the near and far field is:

$$
20 \log _{10}(\Psi r)
$$

If $r>r_{n}$, then $\Psi=1.0$. The variation of transmission loss with $r / r_{n}$ is illustrated in figure 14. Example values of $r_{n}$ and of $\Psi$ for a cell centered at $1 / 2 r_{n}$ are shown in table 3 ; however, these values are for illustration only, as the actual effective transducer diameter (area) for a given instrument must be obtained from the manufacturer.

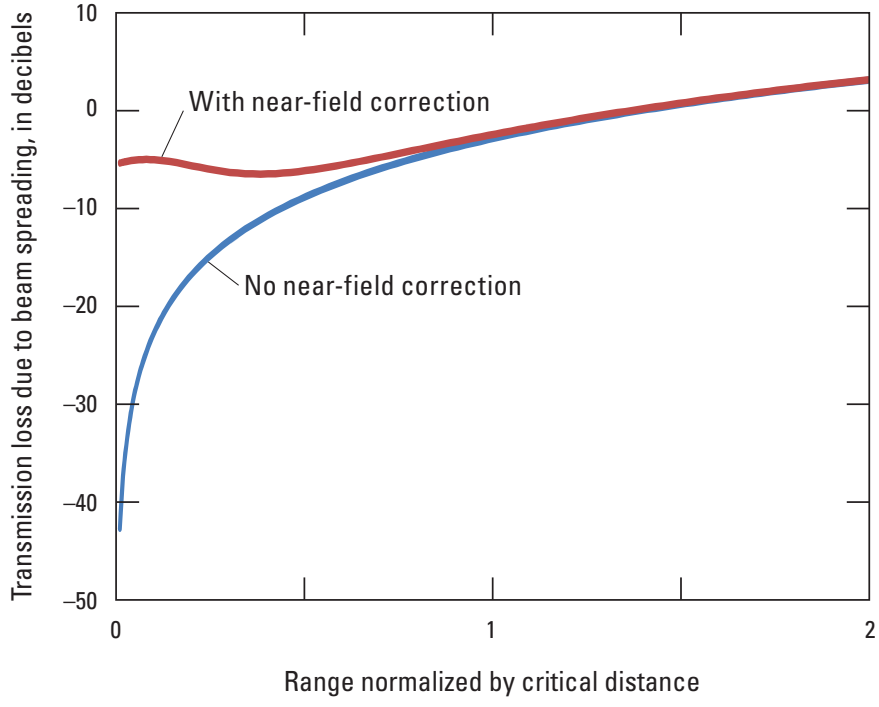

Figure 14. Transmission loss due to beam spreading and range normalized by the critical near-field range $\left(r / r_{n}\right)$, with and without the near-field correction for the 1.5 megahertz transducer specified in table 3.

Table 3. Example near-field range for specified frequencies and effective transducer areas (effective transducer diameters must be obtained from manufacturer).

[Assuming water temperature $=20^{\circ} \mathrm{Celsius}$, which makes the speed of sound 1,482 meters/second; $f$, frequency of ADVM; A, "effective" transducer area; $\lambda$, the wavelength of the acoustic signal; $r_{n}$, near-field critical range; $r$, distance from the transducer along the acoustic axis of the beam; $\mathrm{m}$, meter; $\mathrm{mm}$, millimeter; "E" signifies scientific numerical notation]

\begin{tabular}{ccccc}
\hline $\boldsymbol{f}(\mathbf{M H z})$ & $\mathbf{A}\left(\mathbf{m}^{2}\right)$ & $\lambda(\mathbf{m m})$ & $\boldsymbol{r}_{\boldsymbol{n}}(\mathbf{m})$ & $\Psi$ at $\mathbf{r}=1 / 2 \boldsymbol{r}_{\boldsymbol{n}}$ \\
\hline 0.5 & $6.36 \mathrm{E}-03$ & 2.964 & 2.15 & 1.37 \\
1.5 & $7.07 \mathrm{E}-04$ & 0.988 & 0.73 & 1.37 \\
3.0 & $1.77 \mathrm{E}-04$ & 0.494 & 0.36 & 1.37 \\
\hline
\end{tabular}




\section{Example Calculation-Continued}

Continuing the example from the Spoon River at Seville on April 11, 2013, as shown in table 2 for a temperature of 11.45 degrees Celsius, the speed of sound computed using equation 4 is

$$
\begin{aligned}
\mathrm{c}=1.402385 & \times 10^{3}+5.038813 \times 11.45 \\
& -5.799136 \times 10^{-2} \times 11.45^{2} \\
& +3.287156 \times 10^{-4} \times 11.45^{3} \\
& -1.398845 \times 10^{-6} \times 11.45^{4} \\
& +2.787860 \times 10^{-9} \times 11.45^{5}
\end{aligned}
$$

$$
=1,452.95 \mathrm{~m} / \mathrm{s} \text {, }
$$

then the wavelength for a $1.5 \mathrm{MHz}$ (where $1 \mathrm{~Hz}$ is one cycle per second) instrument equals

$$
\lambda=\frac{1452.95 \frac{\mathrm{m}}{\mathrm{s}}}{1500000 \mathrm{~Hz}}=0.000969 \mathrm{~m} .
$$

Then the near-field distance can be calculated as

$$
r_{n}=\frac{0.000707 \mathrm{~m}^{2}}{0.000969 \mathrm{~m}}=0.73 \mathrm{~m} .
$$

At this site, the blanking distance was set to $1.00 \mathrm{~m}$, which is greater than the near-field distance (as recommended), so the user does not need to further evaluate $\Psi$ for near-field effects. For this example, however, $\Psi$ can be computed, noting that $Z$ for cell 1 , with a midpoint distance along the acoustic axis of beam $(r=2.07 \mathrm{~m})$, equals

$$
Z=\frac{2.07 \mathrm{~m}}{0.73 \mathrm{~m}}=2.83,
$$

so the near field correction for cell 1 can then be calculated as

$$
\Psi=1+\frac{1}{1.35 \times 2.83+(2.5 \times 2.83)^{3.2}}=1.00 .
$$

Now the transmission loss (to and from the transducer) due to beam spreading at cell 5 can be quantified as

$$
20 \log _{10}(1.00 \times 9.792)=19.82 \mathrm{~dB} \text {. }
$$

This value is used in the Sediment-Corrected Backscatter Example Computation section.

\section{Water-Absorption Coefficient}

Water absorption is the attenuation of the acoustic intensity along the acoustic beam due to the properties of the water, and is accounted for using the water-absorption coefficient, $\alpha_{w}$. The full equation used to estimate the water-absorption coefficient includes salinity, acoustic frequency, temperature, and pressure and is described by Schulkin and Marsh (1962):

$$
\alpha_{w}=8.69\left(\frac{S A_{w} f_{T} f^{2}}{f_{T}^{2}+f^{2}}+\frac{B_{w} f^{2}}{f_{T}}\right)\left(1-6.54 \times 10^{-4} P\right),
$$

where

$$
\begin{aligned}
& S \quad \text { is the salinity in parts per thousand (ppt), } \\
& A_{w} \quad \text { is } 2.34 \times 10^{-6} \text {, a constant for ionic relaxation } \\
& \text { process in sea water, } \\
& f_{T} \quad 21.9 \times 10^{[6-1520 /(\mathrm{T}+273)]} \text {, the temperature- } \\
& \text { dependent relaxation frequency in } \mathrm{kHz} \text {, } \\
& T \text { is the temperature of water in degrees Celsius, } \\
& f \text { is the acoustic frequency in } \mathrm{kHz} \text {, } \\
& B_{w} \quad \text { is } 3.38 \times 10^{-6} \text {, a constant for viscosity } \\
& \text { characteristic of pure water, and } \\
& P \quad \text { is pressure in atmospheres. }
\end{aligned}
$$

The sensitivity of $\alpha_{w}$ to changes in $P$ is less than 0.3 percent at depths less than $30 \mathrm{~m}$ and is negligible for most riverine conditions. The sensitivity of $\alpha_{w}$ to $S$, for $S=0.5 \mathrm{ppt}$ (near upper limit for freshwater) is $2.6,0.3$, and 0.1 percent for 0.5 , 1.5 , and 3.0 MHz frequencies, respectively. In higher salinity conditions, the term for $S$ should be included in equation 7 , particularly for low-frequency transducers. If this method is being applied in freshwater rivers at shallow depths (less than $30 \mathrm{~m}$ ), the terms with salinity and pressure are considered negligible and equation 7 simplifies to

$$
\alpha_{w}=8.69 \frac{B_{w} f^{2}}{f_{T}} .
$$

Using equation 8 , the change in $\alpha_{w}$ is presented for temperatures ranging from 0 to 35 degrees Celsius for three frequencies in table 4 . The typical accuracy of temperature measured by ADVMs is considered adequate for determination of $\alpha_{w}$. For example, the Sontek Argonaut SL and SW instruments have a specified accuracy in temperature measurements of \pm 0.5 degree Celsius. 
Table 4. Variation in water absorption $\left(\alpha_{w}\right)$ for temperatures ranging from 0 to 35 degrees Celsius in freshwater at 0.5-, 1.5-, and 3.0-megahertz frequencies, using equation 8.

$[\mathrm{dB}$, decibel; m, meter]

\begin{tabular}{cccc}
\hline $\begin{array}{c}\text { Temperature } \\
\text { (degrees Celsius) }\end{array}$ & $\begin{array}{c}\boldsymbol{\alpha}_{\boldsymbol{w - 0 . 5}} \\
(\mathbf{d B} / \mathbf{m})\end{array}$ & $\begin{array}{c}\boldsymbol{\alpha}_{w-1.5} \\
(\mathbf{d B} / \mathbf{m})\end{array}$ & $\begin{array}{c}\boldsymbol{\alpha}_{w-3.0} \\
(\mathbf{d B} / \mathbf{m})\end{array}$ \\
\hline 0 & 0.12 & 1.12 & 4.46 \\
5 & 0.10 & 0.89 & 3.54 \\
10 & 0.08 & 0.71 & 2.84 \\
15 & 0.06 & 0.57 & 2.29 \\
20 & 0.05 & 0.46 & 1.86 \\
25 & 0.04 & 0.38 & 1.52 \\
30 & 0.03 & 0.31 & 1.25 \\
35 & 0.03 & 0.26 & 1.04 \\
\hline
\end{tabular}

\section{Example Calculation-Continued}

Continuing the example from the Spoon River at Seville on April 11, 2013, as shown in table 2. for a temperature of 11.45 degrees, the water-absorption coefficient is

$$
\alpha_{w}=8.69 \frac{3.38 \times 10^{-6} \times 1500^{2}}{21.9 \times 10^{[6-1520 /(11.45+273)]}}=0.6657 \mathrm{~dB} / \mathrm{m} .
$$

This value is used in the Sediment-Corrected Backscatter Example Computation section.

\section{Sediment Attenuation Coefficient}

The sediment attenuation coefficient, $S A C$ (also designated as $\alpha_{s}$ ), is the acoustic energy attenuation per unit distance and is a function of acoustic physics and sediment properties. Methods to determine $\alpha_{s}$ prior to Topping and others (2006; 2007) required iterative numerical estimates and (or) extensive assumptions as described in appendix 2. The collection of multicell data offers an effective means to directly measure the sediment acoustic attenuation at a high temporal resolution. Topping and others $(2006 ; 2007)$ observed that $\alpha_{s}$ can be measured from the slope of the multicell acoustic WCB-range profile, assuming a constant concentration and grain-size distribution, with range along the acoustic axis of the beam. This novel observation has removed a major uncertainty source in the calculation of $S C B$ and provides a second valuable explanatory variable that may be used in the sediment acoustic index relation.

Equation 2 can now be written as

$$
S C B=W C B+2 r \alpha_{s}
$$

Assuming the $S C B$ to be constant along the acoustic beam and taking the derivative with respect to range of this equation yields

$$
\frac{d}{d r}(S C B)=\frac{d}{d r}\left(W C B+2 r \alpha_{s}\right)=0 .
$$

Solving the above equation for $\alpha_{s}$ follows:

$$
\alpha_{s}=-\frac{1}{2} \frac{d}{d r}(W C B)
$$

Thus, we may directly measure $-2 \alpha_{s}$ from the slope of the multicell $W C B$ profile as shown in figure 10 and in the example calculation. Practically, we may obtain this slope using a simple linear regression on the multiple cells of $W C B$ and $r$ at a given time step, and then calculate $\alpha_{s}$ as simply $-1 / 2$ times the slope of the regression equation.

\section{Example Calculation-Continued}

In the example from the Spoon River at Seville on April 11, 2013 (15:00 CST), as shown in table 2, the slope of the $W C B$ versus $r$ line is -4.58 , then

$$
\alpha_{s}=-\frac{1}{2} \times-4.58 \frac{\mathrm{dB}}{\mathrm{m}}=2.29 \mathrm{~dB} / \mathrm{m} \text {. }
$$

This value is used in the sediment-corrected backscatter example computation.

\section{Sediment-Corrected Backscatter}

Using the results in the preceding sections, values can now be substituted into equation 2 (repeated below):

$$
S C B=M B+20 \log _{10}(\Psi r)+2 r \alpha_{w}+2 r \alpha_{s}
$$

For a given measured time $t$, this computation is completed for each of the $n$ cells from 1 to $n$, and the average $S C B(\overline{S C B})$ is

$$
\overline{S C B}=\frac{1}{n} \sum_{i=1}^{n} S C B_{i}
$$

This expression can be written for each time step as

$$
\overline{S C B}=\frac{1}{n}\left[\sum_{i=1}^{n} M B_{i}+20 \sum_{i=1}^{n} \log _{10}\left(\psi_{i} r_{i}\right)+2\left(\alpha_{w}+\alpha_{s}\right) \sum_{i=1}^{n} r_{i}\right] .
$$

The value of $\overline{S C B}$ is determined for each measurement in the calibration dataset to develop the sediment acoustic index rating and then is determined for each time step to compute SSC on a continuous basis using the developed rating. 


\section{Example Calculation-Continued}

Taking the values used in the examples for cell 5 for the Spoon River at Seville on April 11, 2013, at 15:00 (fig. 10 and table 2),

$$
\begin{gathered}
S C B_{\text {cell } 5}=23.65 \mathrm{~dB}+19.82 \mathrm{~dB}+2 \times 9.792 \mathrm{~m} \times 0.6657 \frac{\mathrm{dB}}{\mathrm{m}}+2 \times 9.792 \mathrm{~m} \times 2.29 \frac{\mathrm{dB}}{\mathrm{m}} \\
S C B_{\text {cell } 5}=101.35 \mathrm{~dB} .
\end{gathered}
$$

This computation is then repeated for each cell. Then using the values in table 2, the average $S C B$ for the five cells $\overline{S C B}$ for this measurement can be computed as

$$
\begin{gathered}
\overline{S C B}=(101.13 \mathrm{~dB}+100.63 \mathrm{~dB}+99.99 \mathrm{~dB}+100.10 \mathrm{~dB}+101.35 \mathrm{~dB}) / 5 \\
\overline{S C B}=100.64 \mathrm{~dB} .
\end{gathered}
$$

This analysis is performed for each time step to obtain a time series of $\overline{S C B}$ and $\alpha_{s}$ (also referred to as $S A C$ ). Computation of $\overline{S C B}$ and $S A C$ will typically be done in a spreadsheet application or a program specifically written for evaluation of acoustic surrogates and surrogate-to-SSC rating development, such as the SAID program (Domanski and others, 2015; http://water.usgs.gov/osw/SALT/).

\section{Sediment Acoustic Index Rating Development}

Quality sediment acoustic index ratings are founded on best practices in site selection and installation, instrument configuration and operation, physical SSC sampling and analyses, and concurrent collection of acoustic data over the range of observed sediment and hydrologic conditions. The calibration dataset for developing the rating is simply the concurrent measurements of $\overline{S C B}, S A C$, and physical SSC from samples. The $M B, W C B, S A C$, and $S C B$ are illustrated in figure 15 for four measured SSC values $(136 \mathrm{mg} / \mathrm{L}, 776 \mathrm{mg} / \mathrm{L}, 1,850 \mathrm{mg} / \mathrm{L}$, and 2,770 mg/L) at the Spoon River at Seville (the 1,850-mg/L data is the same as the data presented in fig. 12). The documentation for the analysis of the sediment acoustic index rating is similar to that for a USGS stage-discharge rating and should closely follow the Sediment Station Analysis format shown in appendix 1 . The adequacy of the rating model calibration dataset, selection of explanatory variables, and regression methods are discussed in this section. 

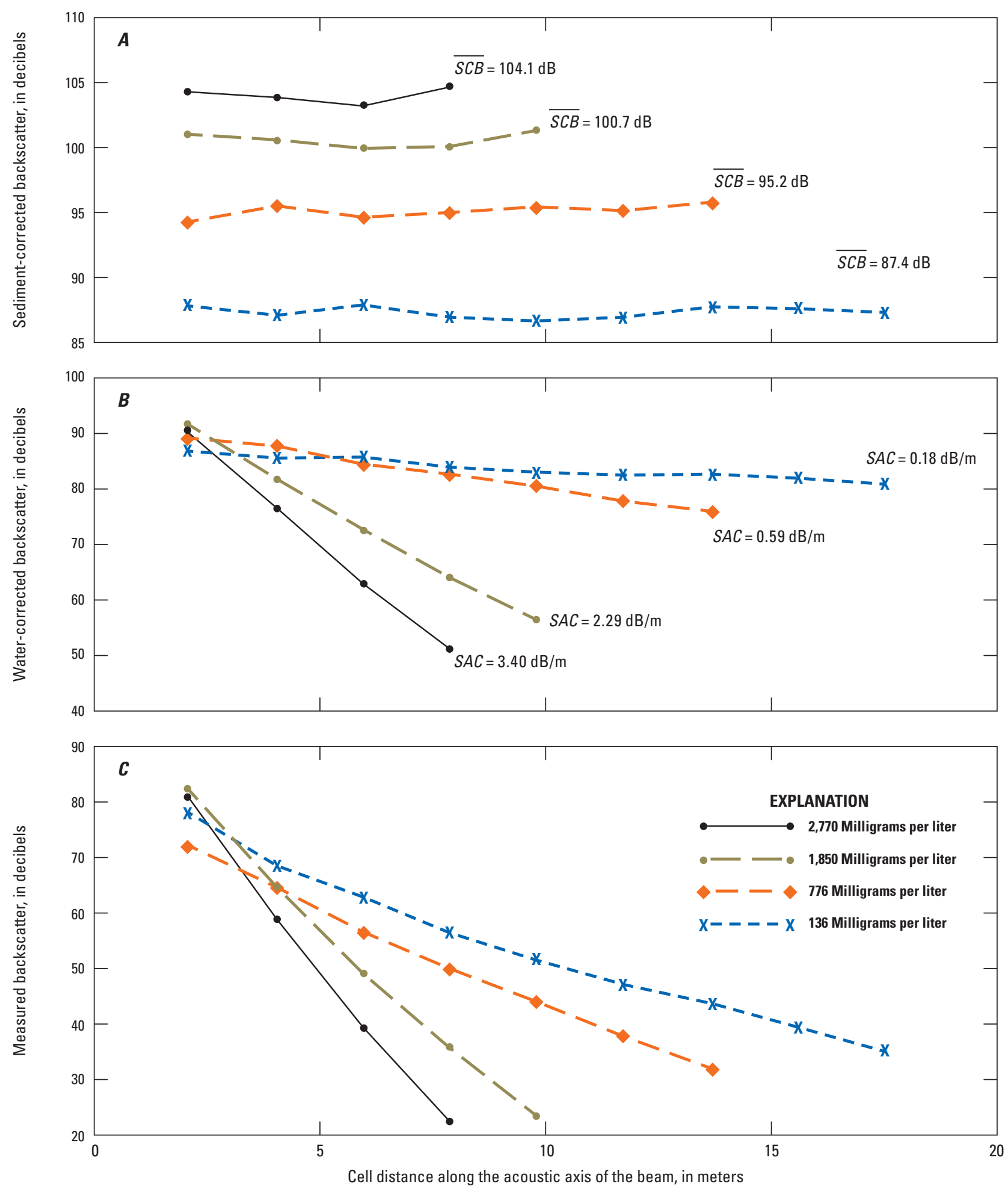

Figure 15. Measured and computed acoustic parameters matched with four suspended-sediment concentration sample values at the Spoon River at Seville, Illinois (USGS 05570000). The sample concentration date and times are as follows: the 2,770-mg/L sample was on April 18, 2013, at 8:00 CST; the 1,850-mg/L sample was on April 18, 2013, at 14:53 Central Standard Time (CST); the 776-mg/L sample was on May 5, 2013, at 12:00 CST, and the 136-mg/L sample was on April 29, 2013, at 12:45 CST [( $\overline{S C B})$, average sediment-corrected backscatter; $S A C$, sediment attenuation coefficient; $\mathrm{dB}$, decibels; $\mathrm{m}$, meter]. 


\section{Data Documentation}

Documentation of the data, metadata, and models used in the sediment acoustic index method must be complete and coherent for initial and ongoing review, approval, and use of computed SSC. Discrete, physical SSC sample analyses must be stored in the USGS National Water Information System (NWIS) database per Office of Surface Water (OSW) (http:// water.usgs.gov/admin/memo/SW/sw10.03.pdf). Computed SSC and explanatory variable(s) time-series data also should be stored in NWIS. The raw ADVM files should be stored in the station electronic data archive. The analysis and metadata should be documented in the station analysis as shown in appendix 1 .

The sediment station analysis must contain and (or) reference all of the essential data used to develop the sediment acoustic index rating, similar to a USGS streamflow discharge station analysis. The sediment station analysis should document the instrument characteristics and configuration, site metadata, calibration-verification datasets, discussion of the analysis, and statistical summary of the rating. A publicly viewable format following the template in appendix 1 is recommended. Additional documentation, such as station descriptions that are required for USGS streamgages, are detailed in Sauer (2002) and Levesque and Oberg (2012), and should be provided for sediment acoustic index sites. If a sediment acoustic index rating uses additional explanatory variables, such as turbidity, then the relevant location, instrument, and time-series data should be documented for that additional explanatory variable in the sediment station analysis.

\section{Acoustic Data}

Most of the required acoustic data and metadata are recorded in the default ADVM instrument measurement files (in binary or other formats). The following ADVM information is required to be documented in the sediment station analysis as shown in appendix 1.

\section{ADVM manufactured characteristics:}

Manufacturer make; model; frequency; serial number; effective diameter of transducer; slant beam angle; echo intensity scale factor $(K)$

\section{ADVM installed characteristics:}

Location description; water-level stage (reference to gage datum) of transducer; orientation (should be horizontally profiling and perpendicular to flow); power supply; power regulator; characteristics of the ADVM mount

\section{ADVM configuration:}

Blanking distance; number of cells; cell size; averaging period; and measurement interval
Note that the above information may also be included in the equipment description under the station description for the site; however, it should be repeated here because this information is essential to the sediment station analysis.

The files downloaded from the ADVM's internal recorder (including the time series of measured temperature, power, and raw backscatter for each cell) must be stored in the station electronic data archive. These measured time-series data include the following:

\section{Acoustic time-series data:}

Date; time; cell number; amplitude (or count); noise (if available); $M B_{S N R}$ (if available); temperature; power

In addition to these metadata and time-series data, any explanatory variables (such as $\overline{S C B}$ and (or) $S A C$ ) for the discrete measurements in the calibration and verification datasets, together with the concurrent SSC data, must be included. The $\overline{S C B}$ and (or) $S A C$ measurements should be matched to the date, time, and duration of the concurrent SSC measurements. If the SSC sample took less than 15 minutes to collect (as perhaps from a calibrated fixed-point sample), data from the ADVM's nearest 15-minute measurement interval should be used in the calibration dataset. If the sample duration is longer than 15 minutes, all measurements collected by the ADVM during sample collection should be averaged together for use in the calibration dataset. In some cases, such as highly unsteady or variable sediment transport, evaluation data may be collected by setting the ADVM averaging period and measurement interval to 1 minute, as is done for index-velocity streamgages during discharge measurements and discussed in Levesque and Oberg (2012). The SAID program (Domanski and others, 2015) performs the matching of SSC with acoustic parameters based on a user-specified time window.

\section{Suspended-Sediment Data}

Mandatory storage of discrete SSC data and selected metadata in NWIS and use of SedLOGIN software to assist in data entry comply with OSW Technical Memorandum 2010.03. The date and time of the SSC sample are essential, as they will be used to match the SSC with concurrent acoustic data from the ADVM. When the laboratory analysis is complete, the metadata and analytical results should be stored in NWIS using the appropriate parameter codes listed in table 5. The minimum data requirements to be recorded for discrete measurements are the SSC and codes for sampling method and sampler type. In addition to the NWIS data storage, the SSC calibration dataset should be recorded in the sediment station analysis. 
Table 5. The National Water Information Summary parameter code, description, and units for discrete suspended-sediment data and metadata.

[mg/L, milligram per liter; \%, percent; PSD, particle size distribution; ${ }^{\circ} \mathrm{C}$, degrees Celsius; $\mathrm{ft}$, foot]

\begin{tabular}{clc}
\hline Parameter code & \multicolumn{1}{c}{ Parameter description } & Unit \\
\hline \multicolumn{1}{c}{ Sample analytical results } \\
\hline 80154 & Suspended-sediment concentration & $\mathrm{mg} / \mathrm{L}$ \\
70331 & Sample mass finer than 0.0625 millimeter, sieve diameter & $\%$ \\
Various & PSD as sample finer than range of particle sizes & $\%$ \\
\hline & & Sample metadata \\
\hline 82398 & Sampling method code & Code \\
00010 & Sampler type code & Code \\
00009 & Sample vertical location in cross section, from left bank (if recorded) & ${ }^{\circ} \mathrm{C}$ \\
00063 & Number of sampling points (verticals) in composite (if recorded) & $\mathrm{ft}$ \\
\hline
\end{tabular}

\section{Required Time-Series Data}

The raw acoustic time-series data can be stored in the NWIS database but must be stored with the station electronic data archive. All time-series data used as explanatory variables for the rating should be stored in NWIS, including computed acoustic surrogates $(\overline{S C B}$ and $S A C)$, as well as streamflow. It is important that the appropriate parameter and method codes be used for storing and retrieving data in NWIS, as designated in table 6. In some cases, the units or details should be specified by the user in the data descriptor attribute (DD) for the parameter. For example, the acoustic backscatter signal strength would be stored in parameter code 99968 , and metadata for this parameter would be stored (constant value) in the $\mathrm{DD}$, including: instrument frequency, units, instrument measure (such as Amps or RSSI); units of measurement (counts or $\mathrm{dB}$ ); and designation as for beam number, beam average, or cell number.

Additional time-series data from the ADVM that must be stored are water temperature measured by the ADVM thermistor and the ADVM's "cell end." Water temperature is required for the computations described in this report. The ADVM's cell end is further described in Levesque and Oberg (2012). Cell end is not directly used in calculating sediment acoustic surrogates, but it is useful in tracking possible problems (such as an obstruction in the ADVM's measurement volume or insufficient scattering material in the water to reflect the sound wave above the noise level) or changes to the instrument configuration. Cell end can be stored as one of two parameter codes, depending on the units (table 6).

The SSC computed from the sediment acoustic index rating should be stored in NWIS using parameter code 99409. The suspended-sediment load (SSL) (in tons/day) can be computed by multiplying the SSC $(\mathrm{mg} / \mathrm{L})$ by the streamflow (in $\mathrm{ft}^{3} / \mathrm{s}$ ) by a conversion factor of 0.0027 and storing the SSL using parameter code 80297 (table 6). Time-series estimates of upper and lower prediction limits also should be stored and reported in NWIS because these time-series data are computed from a regression model. Prediction limits at the 90th or 95th percentile may be used. Display of these data (in real time or historical) should include these prediction interval data.

Continuous streamflow data are important for sediment acoustic index gages for at least three reasons: (1) streamflow data can be examined to determine if there are adequate sample points over the range of observed stream conditions; (2) streamflow also is a possible explanatory variable in the acoustic index rating development; and (3) streamflow data are needed to compute SSL. Streamflow data collection and storage should be performed in accordance with Mueller and others (2013), Rantz and others (1982), and Turnipseed and Sauer (2010). 
Table 6. The National Water Information Summary parameter code, name, description, and unit for measured (M) and computed (C) continuous time-series data used in sediment acoustic index ratings.

$\left[{ }^{\circ} \mathrm{C}\right.$, degrees Celsius; $\mathrm{DD}$, data descriptor; $\mathrm{ft}$, foot; $\mathrm{m}$, meter; $\mathrm{dB}$, decibel; $\mathrm{mg} / \mathrm{L}$, milligram per liter; $\mathrm{SSC}$, suspended-sediment concentration]

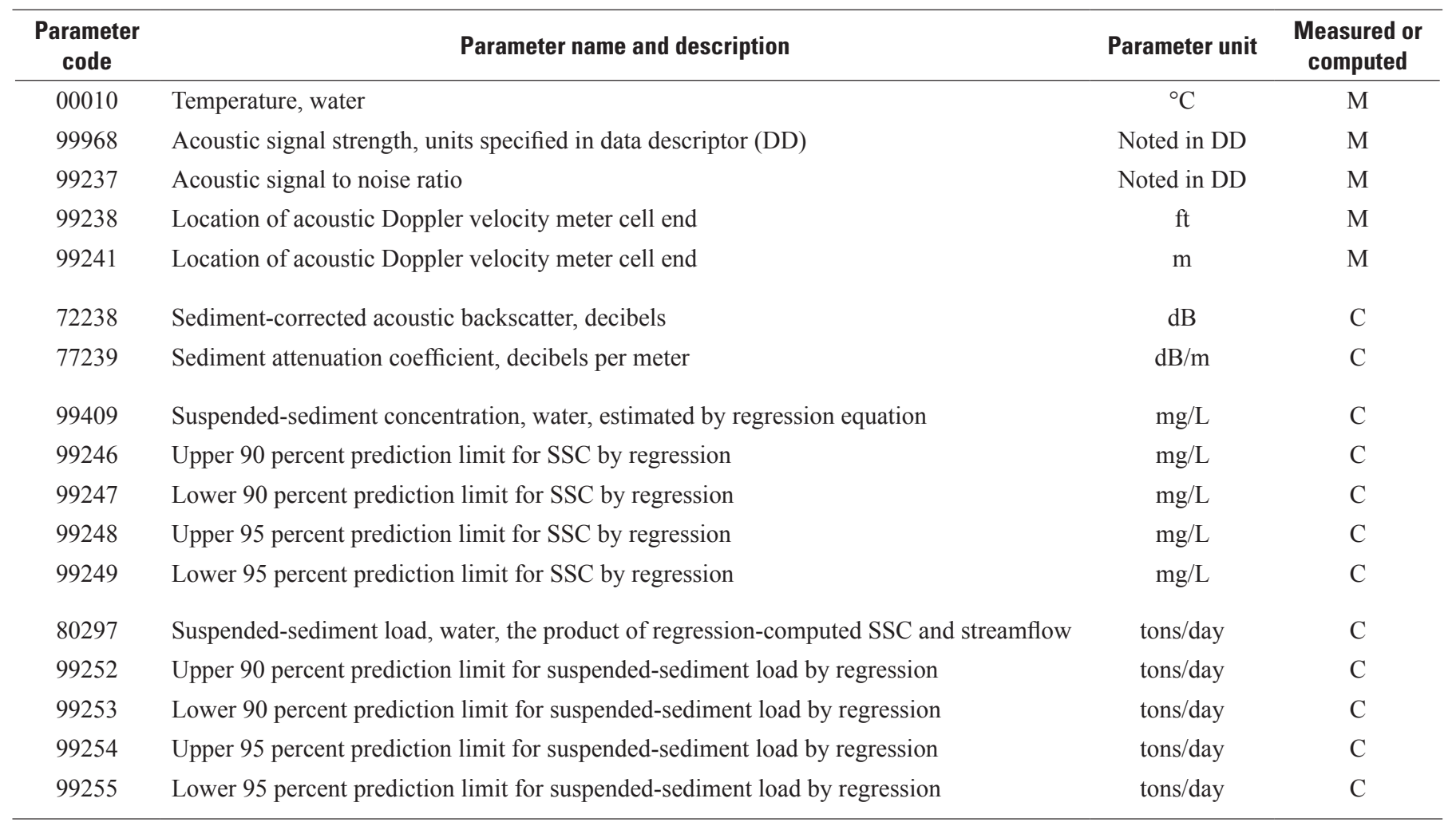

\section{Adequacy of Calibration Dataset}

The calibration dataset consists of the sampled SSC and concurrently measured explanatory variables used to develop the sediment acoustic index rating. The adequacy of the calibration dataset depends primarily on how well it represents the range of hydrologic and sedimentologic conditions that the rating uses to estimate SSC. The dataset also should represent different seasons that may affect the sediment acoustic index rating, and calibration-verification measurements are needed to evaluate potential long-term trends or event-based changes. These factors, more than the count of measurements, determine calibration dataset adequacy. Samples made during medium- and high-streamflow conditions are usually more important than those made during low-flow conditions, particularly if the results will be used to compute SSL. Sampling at high SSC conditions is also important because these extreme high (as well as the extreme low SSC) values will have the greatest effect on the slope of the rating. A good sampling plan will typically include scheduled periodic sampling as well as event-based sampling.

The number of measurements in the calibration dataset must be sufficient to provide robust regression model coefficients and statistics. More measurements are needed for sites that have larger variability around the sediment acoustic index rating curve, as reflected in the model statistics. An adequate dataset could take 2-3 years to develop using monthly samples (Rasmussen and others, 2009), or could be developed much more quickly using intensive calendar-based plus eventbased sampling (Horowitz and others, 2014). Ideally, the rating calibration dataset envelopes the entire range of observed flow and sediment conditions for the period of continuous SSC time-series computation, so that there is no need to extrapolate the rating.

The adequacy of the calibration dataset should be evaluated by comparing the range of observed with the range of sampled SSC and streamflow. This comparison should at least be done in simple table form as shown in the sediment station analysis (app. 1). Flow-duration curves also provide a valuable tool to evaluate the distribution of sampled SSC over the range of sediment and discharge conditions for the site, as shown in figure 16. These curves also can be used to indicate where additional samples are needed. Methods for constructing flow-duration curves are described in Rasmussen and others (2009). The adequacy of the number of samples in the calibration dataset should be evaluated using graphical and statistical analysis of the variance of the data around the rating curve. Once developed, the rating must be validated with data from additional seasons and years. 

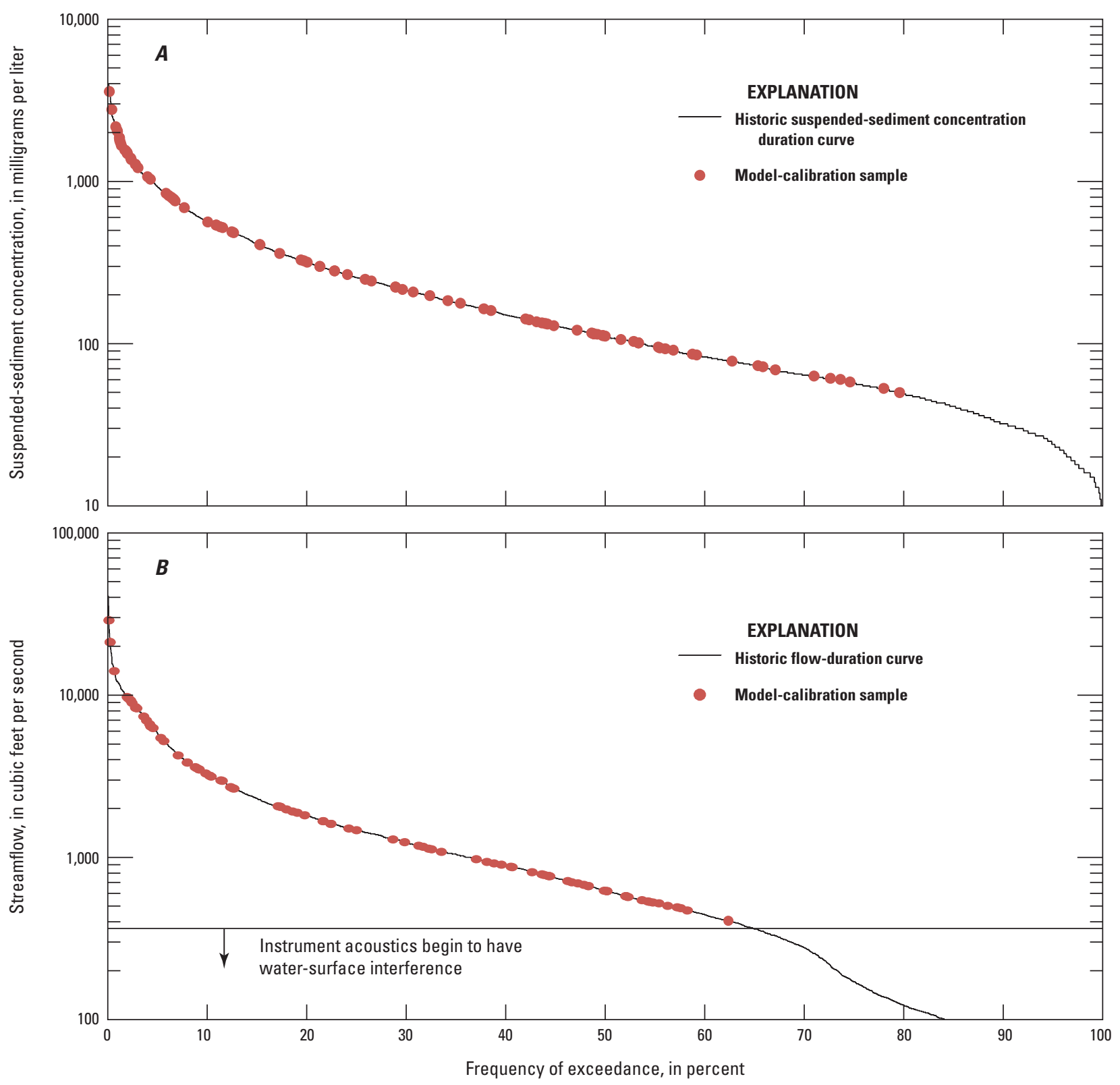

Figure 16. Model-calibration samples plotted on flow-duration curves for $A$, daily data from water year 2003-2013 for suspended-sediment concentration and for B, streamflow for the Spoon River at Seville, Illinois (USGS 05570000).

\section{Regression Analysis}

The sediment acoustic index rating is developed using linear regression between SSC and acoustic surrogates. Development of the acoustic index rating requires the following recommended procedures that are described in detail in Helsel and Hirsch (2002) and Eng and others (2009):

- Summarize and graph single and multivariate data.

- Develop candidate simple and multiple linear regressions on untransformed and transformed data.
- Analyze residuals.

- Select best regression model and evaluate model uncertainty.

A step-by-step summary for these procedures is provided in table 7; however, in practice, an iterative approach may be required. In addition to these procedures, it is essential to document the steps, logic, and results of the regression model development in the sediment station analysis (app. 1).

The response or dependent variable for the acoustic index rating will typically be the total SSC for studies in which records of total sediment concentration and load are needed to 
address the sediment issues. The relevant issues in some studies may benefit from the computed concentration of suspended sand (sizes equal to and greater than 62.5 microns and less than 2,000 microns; $\mathrm{SSC}_{\text {sand }}$ ) and of silt and clay (sizes less than 62.5 microns; $\mathrm{SSC}_{\text {fines }}$ ). If all calibration samples are analyzed for the percent finer than 62.5 microns, then evaluation of separate ratings for $\mathrm{SSC}_{\text {sand }}$ and $\mathrm{SSC}_{\text {fnes }}$ can be developed (Wood and Teasdale, 2013). However, using single-frequency acoustic methods described herein will result in some bias in $\mathrm{SSC}_{\text {sand }}$ if there is substantial variation in the particle size within the sand range over the measured conditions (Topping and others, 2015). This bias is caused by particle-size driven changes in $\overline{S C B}$ that are not accounted for in the singlefrequency method. A simple test for this potential bias is to look for the presence of hysteresis in bivariate plots of SSC and $\overline{S C B}$ measured over runoff events (Medalie and others, 2014; and Landers and Sturm, 2013). The user who wishes to estimate $\mathrm{SSC}_{\text {sand }}$ and (or) $\mathrm{SSC}_{\text {fines }}$ is encouraged to evaluate the potential for bias and consider using a multifrequency approach (Topping and others, 2015; and Moore and others, 2013) to address the bias caused by single-frequency size-concentration ambiguity. Also, under conditions where backscatter produced by silt-and-clay-sized sediment may approach that of sand, a correction is needed to remove the silt-and-clayproduced backscatter in order to develop relations between $\overline{S C B}$ and $\mathrm{SSC}_{\text {sand }}$ (Topping and others, 2015).

The principal explanatory variables for acoustic index ratings are $\overline{S C B}$ and (or) $S A C$. Although $S A C$ is used in the computation of $\overline{S C B}$, the two are not highly correlated in many cases because they relate to different characteristics of the total suspended sediment. Thus, both may be used as explanatory variables in the same equation if they satisfy regression requirements discussed below. The $\overline{S C B}$ generally correlates more strongly with suspended sand concentrations, while the $S A C$ has been shown to correlate more strongly with silt-clay concentrations, as discussed in appendix 2. Also, the $S A C$ may be less sensitive than $\overline{S C B}$ to changing sediment particle size, as discussed by Moore and others (2013).

Any statistically significant explanatory variable can be used that improves the regression model uncertainty for SSC, is not overcorrelated with other explanatory variables, and has some theoretical basis. For example, significant model improvement may result from the inclusion of streamflow, season (as a periodic date function), turbidity, grain-size distribution, or the percent of flow contributed by selected tributaries. Many statistical software applications are adequate for the data exploration and regression analysis. The SAID program (Domanski and others, 2015; http://water.usgs.gov/ osw/SALT/) is specifically designed for the regression analysis and rating model development, and also calculates the acoustic surrogates and generates a statistical summary needed for the sediment station analysis.

\section{Data Exploration, Graphical Analysis, and Transformation}

Best practices for evaluation of sediment acoustic index ratings begin with graphical and statistical exploration of the calibration dataset. Evaluation of the range of the observed data and the adequacy of the sampled conditions using duration curves were previously discussed. Single-parameter box plots are valuable to identify outliers and evaluate the distribution of the data. Scatter plots should be used together with coefficients of determination $\left(R^{2}\right)$ or Pearson correlation coefficients $(R)$ to evaluate the strength and linearity of relations between SSC and potential explanatory variables. Scatter plots also should be used to identify outliers and to evaluate data transformations that may improve linearity. The relation between SSC and potential explanatory variables will be the focus of the data exploration, but relations between other variables can yield insight to the sediment transport processes and (or) the surrogate response to changing environmental conditions (for example, between $\overline{S C B}, S A C$, and discharge, velocity, or season). Correlation between explanatory variables also provides information on whether they provide unique information as predictors of SSC, which can be further evaluated using regression diagnostics.

Outlier evaluation should be done throughout the analysis. Observations that are outliers to the general trend or specific model rating curve should be reviewed to evaluate potential causes, such as measurement or recording errors, or unusual conditions at the time of the measurement. Documentation of this review, particularly for any outliers removed from the model calibration dataset, is an important part of the sediment station analysis.

Transformation of explanatory or response variables often is needed to improve linear regression results where a nonlinear trend exists in the untransformed data. Transformation also may correct for unequal variability in SSC over the range of selected explanatory variables (heteroscedasticity) and may improve normality in the residuals, as described in the Model Residual Analysis section. Evaluation and examples of transformations are described in Helsel and Hirsch (2002, p. 229). At most sites, the best and most theoretically sound sediment acoustic index ratings are produced using log-transformed SSC and $\overline{S C B}$ or SSC (without transformation) and $S A C$. In general, $\overline{S C B}$ should not be log transformed because it is already measured in the logarithmic decibel scale. By theory, the $S A C$ is linearly related to SSC, so any log transformation of that relation would not be appropriate. If inadequate results are obtained from using these two regression options, then consideration should be given to using multiple frequencies or moving the instrument to a better location. Although the most common transformation is logarithmic, other transformations can be used to improve linearity. Guidelines in Helsel and Hirsch (2002) should be followed when selecting an appropriate transformation. An example of a logarithmic transformation of the SSC and $\overline{S C B}$ relation is shown in appendix 1. The data exploration, graphical analysis, and transformations can 
be done iteratively with the initial linear regression analysis to develop the best sediment acoustic index rating.

\section{Linear Regression}

The sediment acoustic index rating is developed using ordinary least squares (OLS) linear regression. The user of these methods should have a good understanding of linear regression and the underlying assumptions and limitations (for example, as provided in Helsel and Hirsch, 2002). If the linear model contains only one explanatory variable (sometimes referred to as predictor variable), then the regression is called a simple linear regression (SLR); otherwise (two or more explanatory variables), the regression is known as a multiple linear regression (MLR).

$\overline{S C B}$ often is the best correlated and most statistically significant explanatory variable for SSC. The SLR model equation using $\overline{S C B}$ takes the form of:

$$
\log _{10} S S C=b_{0}+b_{1} \overline{S C B}
$$

where the coefficients $b_{0}$ (y intercept) and $b_{1}$ (slope) are evaluated using regression for paired $\log _{10} \mathrm{SSC}$ and $\overline{S C B}$ observations. The sign of the $b_{1}$ should be positive, and the theoretical value of $b_{1}$ should be approximately 0.1 (Wright and others, 2010 ) if the SSC in the insonified volume is directly proportional to the SSC in the river cross section. In several recent studies, the value of $b_{1}$ has been found to be between 0.03 and 0.10 (Thevenot and Kraus, 1993; Wall and others, 2006; Landers, 2012; Wood and Teasdale, 2013; Medalie and others, 2014). The value of $b_{0}$ can be negative or positive. The value of $b_{0}$ must not be forced to equal zero because the resulting regression statistics, such as $R^{2}$ and significance of $b_{1}$, may no longer represent the best fit of the data. The log-transformed linear model can then be retransformed to predict SSC as

$$
S S C=10^{\left(b_{0}+b_{1} \overline{S C B}\right)} \times B C F,
$$

where $B C F$ is the bias-correction factor used to account for retransformation bias and is determined from the model residuals as described later in the next section of this report.

The sediment attenuation coefficient ( $S A C$, also referred to as $\alpha_{s}$ ) may be a better explanatory variable than $\overline{S C B}$ in rivers with very low sand concentrations and moderate-to-high fines concentrations. For an SLR regression of $\log _{10}(\mathrm{SSC})$ on $\log _{10}(S A C)$, the slope $\left(b_{1}\right)$ tends to increase with acoustic frequency; for example, $b_{1}$ values of $0.11,0.15$, and 0.17 were computed for datasets from frequencies of 1.2, 1.5, and 3.0 MHz, respectively (results from data in Landers, 2012). The relation of SSC to $S A C$ is linear in theory, but SSC may be transformed if it does not violate statistical assumptions, and the $\log$ transformation is convenient if $S A C$ and $S C B$ are both used as explanatory variables. Written for simple linear regression, the equation is:

$$
\log _{10} S S C=b_{0}+b_{1} S A C
$$

As noted previously, $S A C$ could be used as part of a MLR having $\overline{S C B}$ and (or) other statistically independent explanatory variables. The following equation shows how $S A C$ and $\overline{S C B}$ could be added as part of an MLR:

$$
\log _{10} S S C=b_{0}+b_{1} \overline{S C B}+b_{2} S A C+b_{k} x_{k}
$$

where $b_{2}$ is the coefficient for $S A C$ and $b_{k}$ is the coefficient for the kth explanatory variable $x_{k}$. In some models, the $S A C$ or other explanatory variables may need to be transformed.

Several steps are discussed in the following sections that are important to building a good linear regression model. A checklist that includes these steps is presented in table 7. The sediment station analysis (app. 1) shows the discussion, plots, and regression model summary that are needed for documentation and review of the model. Regression diagnostics are valuable tools to evaluate and improve the model.

\section{Residual Analysis of Model Assumptions and Bias Correction Factor}

Model residual analysis is important to help determine if assumptions of an OLS regression are met. For the ith observation, the residual $e_{\mathrm{i}}$ is defined as the difference between the observed $\left(y_{i}\right)$ and predicted response, or fitted value $\left(\hat{y}_{i}\right)$, as denoted below:

$$
e_{i}=y_{i}-\hat{y}_{i}
$$

To meet the assumptions of the OLS, the residuals need to be evaluated for homoscedasticity, normality, and independence. Homoscedasticity is the condition of the residuals having a variance that is constant with the explanatory variable.

A plot of residuals versus fitted values (as shown in app. 1) can be used to determine if the residuals are homoscedastic. If the variance in the residuals is not uniform over the observed values (in other words, are heteroscedastic), then transformation of the data should be considered. A normal probability plot can indicate how well residuals follow a normal distribution. The more linear the residuals normality plot is, the more closely the residuals follow a normal distribution (app. 1). A related quantitative measure is the probability plot correlation coefficient (PPCC), which is the value of the Pearson's linear correlation coefficient between the data and their normal quantiles. A PPCC with a value close to 1.0 is an indication that the residuals follow a normal distribution. As the residuals deviate from a normal distribution, the PPCC becomes less than one. A hypothesis test can be conducted with the PPCC, as described in Helsel and Hirsch (2002, p. 113, section 4.4).

Temporal trends can be evaluated by plotting residuals versus time. If the residuals exhibit a dependence or correlation in time, then the assumption of independence is violated 
Table 7. Checklist for sediment acoustic index rating development and time-series prediction (modified from Rasmussen and others, 2009).

[SSC, suspended-sediment concentration; SSL, suspended-sediment load; $R^{2}$, coefficient of determination; $R^{2}{ }_{\text {a }}$, adjusted coefficient of determination; RMSE, root-mean-squared error; VIF, variance inflation factor; BCF, bias correction factor; ANCOVA, analysis of covariance]

\section{Worked Reviewed Approved}

\section{Compile calibration datasets}

a. Retrieve approved time-series data: surrogate and streamflow

b. Retrieve discrete sample data: SSC, and sand-silt percentage

c. Match surrogate, sample, and streamflow values to be used in regression

d. Tabulate summary statistics of calibration dataset and time-series variables

e. Plot samples on streamflow, surrogate, and (or) SSC duration curves

f. Describe calibration dataset and evaluate adequacy in sediment station analysis

\section{Graph and explore data}

a. Create scatter plots between SSC, sand, and fines concentrations and explanatory variables

b. Use scatter and (or) box plots to detect observations that may be outliers

c. Use scatter plots to determine if data transformations may be needed to improve linearity

\section{Develop regression model}

a. Simple linear regressions and diagnostics of all data $\left(R^{2}, \mathrm{RMSE}\right)$

b. Model residual plots (residual against both SSC and time and season)

c. Determine proper transformation of data, if needed

d. Identify and review potential outliers (leverage, Cook's D, DFFITS, time-series plots)

e. Reevaluate simple linear regressions, residual plots, and diagnostics $\left(R^{2}, \mathrm{RMSE}\right)$

f. Evaluate multiple linear regressions, residual plots, and diagnostics $\left(R^{2}{ }_{\mathrm{a}}, \mathrm{RMSE}, \mathrm{VIF}\right)$

g. Determine bias correction factor (BCF) if the response variable is transformed

h. Determine a covariance matrix for the 90-percent prediction interval

i. Summarize regression model in sediment station analysis

j. Compile statistical summary of final model calibration dataset

$\mathrm{k}$. Write final model-calibration dataset summary in sediment station analysis

\section{Compute and store time-series SSC and load record}

a. Select period of suspended-sediment record for application of model

b. Compute SSC time series using calibrated regression model rating

c. Compute SSL time series

d. Estimate missing SSC or SSL data

e. Evaluate period of record time-series graphs

f. Finalize sediment station analysis

\section{Verify model annually}

a. Plot calibration dataset and recent annual data

b. Compare original model to model with additional data using ANCOVA analysis

c. Update model in database, if needed

d. Determine start date and time of new model

e. Update sediment station analysis 
due to one of the following conditions or some combination (Helsel and Hirsch, 2002, p. 251, section 9.5.4): seasonality, a long-term trend, or dependence on some other serially correlated variable not used in the model. Long-term trends should be evaluated using a plot of residuals against dates and the statistical significance of the date as an explanatory variable. Seasonality can be evaluated by plotting residuals against the month of the samples. Seasonality can be included in the model using a periodic date function as an explanatory variable, as described by Helsel and Hirsch (2002, Section 12.4.3).

Serial correlation (also called autocorrelation) occurs when individual measurements of a parameter in the calibration dataset are not independent, but are correlated with other measurements made immediately earlier and (or) afterward in the time series. Serial correlation can be significant, for example, when samples are collected in time series (as from an autosampler). Because SSC samples are normally taken at intermittent time intervals, the most common method to test for serial correlation, the Durbin-Watson statistic, cannot be used. Instead, a plot of standardized serial correlation values of the residuals should be plotted against time with a trend line, such as LOcally WEighted Scatter-plot SmootherLOWESS, where the standardized serial correlation values are given by

$$
\frac{\left(X\left(t_{i}\right)-\bar{X}\right)\left(X\left(t_{j}\right)-\bar{X}\right)}{s_{x}^{2}},
$$

for all $X$, where $t_{i}-t_{j}>0$. Here, $\bar{X}$ is the mean of the residuals, $X\left(t_{i}\right)$ is the residual at time $t_{i}, X\left(t_{j}\right)$ is the residual at time $t_{j}$, and $s_{x}^{2}$ is the variance of the residuals. If serial correlation is present, there will be a nonzero trend indicated by the trend line. Note that the presence of serial correlation should not affect the coefficients of the regression model, such as $b_{0}$ and $b_{1}$; however, serial correlation can affect other regression statistics, including model standard error and p-values. If serial correlation is significant, it may be appropriate to build a model using maximum likelihood estimation, which does not require serial independence.

Similar to residual scatter plots for SLR, partial residual plots for an MLR show the relationship between the response variable and a single explanatory variable by removing the effects of the other variables in the regression. These can be used to determine if a transformation of the explanatory variable is necessary. For more information on the construction of partial residual plots, see Helsel and Hirsch (2002, p. 301, section 11.5.1).

Model residuals also can be used to compute a retransformation bias correction factor $(B C F)$. If logarithmic transformation of the observed response variable is used to improve linearity, homoscedasticity, or normality in OLS linear regression, then retransformation (back into linear space) of the equation will cause underestimation bias in the mean, but not the median, of the retransformed, predicted values (Cohn and others, 1989). For prediction of sediment concentration that often will be used to compute sediment loads, the mean predicted value is particularly important. However, there is not an exact correction that can be generally applied to handle this bias. One nonparametric method of estimating an unbiased retransformed variable is the bias correction factor $(B C F)$ (Duan, 1983; Helsel and Hirsch, 2002).

The $B C F$ (for base 10 logarithmic transformation) is defined as

$$
B C F=\frac{\sum_{i=1}^{n} 10^{e_{i}}}{n} .
$$

For any rating model in which the SSC data are log transformed, the residuals from the final regression equation should be saved and used to compute the $B C F$, using the above equation. Typical $B C F$ values for regression of log-transformed SSC on $S C B$ have been observed on the order of 1.01 to 1.1. For $B C F$ values larger than about 1.1, additional evaluation of residual variance and distribution (relative to normal) should be performed (as in app. 1). Bias correction methods may produce overestimates for regression models with large variance and with nonnormally distributed residuals (Cohn and others, 1989; Koch and Smillie, 1986; Ferguson, 1986a,b). In general, the $B C F$ should be applied to the final rating curve equation for SSC to $S C B$ regressions (which typically have low variance) for which the residuals are not substantially skewed to the normal quantiles.

\section{Residual Analysis of Outlier and High Influence Observations}

Residual analysis is valuable to identify large outliers and high-influence observations in the calibration dataset. For SLR, graphical analysis can easily identify outlier observations that impact model error or high-leverage observations (at the upper or lower end of the curve) that impact model slope to a relatively large extent. In MLR, however, these are more difficult to identify and most statistical programs provide regression diagnostics for this purpose. Observations can be quantitatively identified as outliers with the computation of standardized residuals (raw residuals divided by their estimated standard deviation). Observations with a standardized residual greater than 2 should be evaluated; an extreme outlier has a standardized residual greater than 3 .

High-influence observations are outliers in the calibration data set that exert a relatively strong leverage on the rating curve. Widely used measures of statistical influence are the "Cook's D" and "DFFITS" regression diagnostics. The values of Cook's D and DFFITS, and the threshold indicating high influence, depend on the number of observations and of explanatory variables in the model. A simple bar chart of these can be used to identify the observations with relatively high 
influence in the model (Helsel and Hirsch, 2002, p. 247-250;

Eng and others, 2009, p. 6).

Residuals should be carefully evaluated and observations should not be rejected on the sole basis that they are identified as outliers or as having high leverage and (or) influence. The following additional qualitative criteria should also be used when evaluating observations:

1. Field note comments regarding the methods used, instruments, and sampling conditions.

2. Review of other sample results besides SSC. Determine if other parameters such as sand-fine split were run on the sample, and if those results are reasonable for the field and flow conditions.

3. Check that the data entered from the laboratory were correct, and verify that any database entry problems that occurred between when the laboratory entered the data and the hydrographer used the data in model development were resolved.

4. Check acoustic instrument reliability and functionality in the time leading up to and after the sample time.

5. Determine how the sample in question compares with the line that connects the samples taken before and after. Also, how well does the sample in question and the before and after samples agree with the trend of predicted time-series SSC. If the before and after samples agree with the trend in the predicted times series and the sample in question does not, then this gives additional evidence that there could be a problem with the sample in question (for an example, see excluded points in March, April, and May in the predicted time-series plot in app. 1).

\section{Regression Model Summary}

The methods described in this section should be used to evaluate the calibration dataset, test and compare alternate regression models and explanatory variables, and test adherence to general OLS assumptions. Selection of the best model for the sediment acoustic index rating is based on model accuracy, statistical significance of the individual explanatory variables and overall model, independence of the explanatory variables, and model complexity. An initial measure of OLS model quality is the coefficient of determination $\left(R^{2}\right)$ for SLR or the adjusted $R^{2}$ value $\left(R_{a d j}^{2}\right)$ for MLR, which measures the percent of the variance in the response variable (SSC) explained by the explanatory variables. The root mean square error (RMSE) gives an estimate of the departure of the model results from the observed values, combining both bias and lack of precision (Helsel and Hirsch, 2002, p. 358). The RMSE is usually the best measure of overall model accuracy for OLS models. It is useful to report the RMSE (if the regression was done on log-transformed data) in both log units and in percent (Eng and others, 2009, p. 5).
Explanatory variables should only be retained in the regression model if they (1) improve the model accuracy; (2) are statistically significant; (3) are adequately independent; and (4) are theoretically sound. Generally, a significance level of 0.01 (highly significant), 0.05 (significant), or 0.1 (moderately significant) is chosen. If the probability value (p-value) for the explanatory variable is less than or equal to the chosen significance level, then the explanatory variable is likely linearly related to SSC and may be used in the regression model. In the case of a MLR, the explanatory variables should be checked for multicollinearity, as discussed in the following section.

Multicollinearity is the condition where two or more prediction variables in an MLR are nearly linearly dependent and highly correlated. When creating an MLR, multicollinearity can lead to undesirable results (Helsel and Hirsch, 2002, p. 305, section 11.5.3), including coefficients that may be unrealistic in sign (in other words, possibly counter balancing each other). Multicollinearity can be detected by computing the variance inflation factor (VIF) for each explanatory variable. The VIF for the explanatory variable $j$ is:

$$
V I F=\frac{1}{1-R_{j}^{2}},
$$

where $R_{j}^{2}$ is the $\mathrm{R}^{2}$ from the regression of the jth explanatory variable on all the other explanatory variables. All explanatory variables in MLR should be checked for multicollinearity. Any variables with $\mathrm{VIF}>3\left(R_{j}^{2}>0.8\right)$ should be investigated further and the rationale for including the variable in the model should be discussed in the sediment station analysis. VIF values above 10 (indicating an $R_{j}^{2}>0.9$ ) indicate serious problems could occur by including the explanatory variable (Helsel and Hirsch, 2002).

The sediment acoustic index rating model developed using these methods should be summarized in the sediment station analysis following the general template shown in appendix 1 . The final regression equation, retransformed if necessary, must be listed along with its summary performance measurements (at minimum the $R^{2}$ or $R^{2}{ }_{a d j}$, RMSE, and VIF for MLR models). The documented rating model should be checked, reviewed, and approved before being used to compute published SSC time-series records.

\section{Computation of Suspended-Sediment Concentration and Load Time-Series Records}

After a sediment acoustic index rating is developed and determined to be adequate, it can be used to compute continuous time-series SSC from the time-series data for the acoustic surrogates and any other explanatory variables. It is important 
to provide not only the computed estimate of SSC, but also prediction interval time series to quantify and illustrate the uncertainty associated with the estimates. The prediction interval is a confidence interval for each prediction in the time series and is often confused with the confidence interval for the mean response. The prediction interval differs from the confidence interval for the mean response in that "[t]he prediction interval incorporates the unexplained variability of [the response variable] in addition to the uncertainties in the [coefficient] parameter estimates..." (Helsel and Hirsch, 2002, p. 240-241, section 9.4.3). In other words, confidence intervals express uncertainty in placement of the regression line. Prediction intervals include both that uncertainty and the uncertainty due to unexplained variance that results in scatter of observations about the regression line. Prediction intervals are always larger than confidence intervals.

The following equation is used to calculate the prediction interval given an observation:

$$
\hat{y}-t_{\left(\frac{\alpha}{2}, n-p\right)} \sqrt{s^{2}\left\langle 1+x\left(X^{\prime} X\right)^{-1} x\right\rangle} \leq y \leq \hat{y}+t_{\left(\frac{\alpha}{2}, n-p\right)} \sqrt{s^{2}\left\langle 1+x\left(X^{\prime} X\right)^{-1} x\right\rangle},
$$

where

$$
\begin{aligned}
y & \text { is the value of the response variable, } \\
\hat{y} & \text { is the estimated mean value from the linear regression model, } \\
x & \text { is the observation vector, } \\
\left(X^{\prime} X\right)^{-1} & \text { is the "X prime } \mathrm{X} \text { inverse" matrix, } \\
S^{2} & \text { is the mean squared error, } \\
t_{(\alpha / 2, \mathrm{n}-\mathrm{p})} & \text { is the value of the Student's t-distribution at probability } \alpha / 2 \text { and degrees of } \\
& \text { freedom n-p. }
\end{aligned}
$$

Software tools have been developed to facilitate computation and real-time presentation of sediment acoustic index ratings and prediction intervals. In practice, the user must simply provide the $\left(X^{\prime} X\right)^{-1}$ matrix as input to these software tools. The $\left(X^{\prime} X\right)^{-1}$ matrix is output in most regression analysis packages, including the SAID program (Domanski and others, 2015).

At many sites, the seasonal or annual load of suspended sediment is of interest. The suspended-sediment load (SSL) can be calculated by multiplying the SSC, flow (Q), time step $\Delta t$, and conversion factor $\left(c_{f}\right)$ :

$$
S S L=Q \times S S C \times \Delta t \times c_{f}
$$

The SSL for each time step can then be added for the time period of interest. Below is an example calculation of a conversion factor to calculate load in tons per day (short tons where 1 ton $=2000$ pounds), when SSC is in $\mathrm{mg} / \mathrm{L}$ and $\mathrm{Q}$ is in $\mathrm{ft}^{3} / \mathrm{s}$,

$$
c_{f}=\frac{86400 s}{d a y} \times \frac{28.32 L}{f t^{3}} \times \frac{l b}{453,592 \mathrm{mg}} \times \frac{\text { ton }}{2000 \mathrm{lb}}=0.0027 \frac{\mathrm{s} L \text { ton }}{\text { day } f t^{3} \mathrm{mg}},
$$

and when $\mathrm{SSC}$ is in $\mathrm{mg} / \mathrm{L}$ and $\mathrm{Q}$ is in $\mathrm{m}^{3} / \mathrm{s}$,

$$
c_{f}=\frac{86400 s}{\text { day }} \times \frac{1000 L}{m^{3}} \times \frac{\mathrm{lb}}{453,592 \mathrm{mg}} \times \frac{\text { ton }}{2000 \mathrm{lb}}=0.0952 \frac{\mathrm{s} L \mathrm{ton}}{\text { day } \mathrm{m}^{3} \mathrm{mg}} .
$$

Common conversion factors for various units and time steps are presented in table 8 . 
Table 8. Conversion factors for the computation of load.

$\left[\mathrm{kg}\right.$, kilogram; lb, pound; $\mathrm{ft}^{3} / \mathrm{s}$, cubic foot per second; $\mathrm{m}^{3} / \mathrm{s}$, cubic meter per second; "E" signifies scientific numerical notation]

\begin{tabular}{rcccc}
\hline \multirow{2}{*}{$\begin{array}{c}\text { Time } \\
\text { interval } \\
\text { (minutes) }\end{array}$} & $\mathbf{k g}$ & lb & short ton & metric ton \\
\cline { 2 - 5 } & \multicolumn{5}{c}{ If streamflow (0) is in units of ft ${ }^{3} / \mathrm{s}$} \\
\hline 5 & $8.496 \mathrm{E}-02$ & $1.873 \mathrm{E}-02$ & $9.365 \mathrm{E}-06$ & $8.496 \mathrm{E}-06$ \\
15 & $2.549 \mathrm{E}-01$ & $5.619 \mathrm{E}-02$ & $2.810 \mathrm{E}-05$ & $2.549 \mathrm{E}-05$ \\
30 & $5.098 \mathrm{E}-01$ & $1.124 \mathrm{E}-01$ & $5.619 \mathrm{E}-05$ & $5.098 \mathrm{E}-05$ \\
60 & $1.020 \mathrm{E}+00$ & $2.248 \mathrm{E}-01$ & $1.124 \mathrm{E}-04$ & $1.020 \mathrm{E}-04$ \\
1,440 & $2.447 \mathrm{E}+01$ & $5.394 \mathrm{E}+00$ & $2.697 \mathrm{E}-03$ & $2.447 \mathrm{E}-03$ \\
\hline \multicolumn{5}{c}{ If streamflow (0) is in units of m³/s } \\
\hline 5 & $3.000 \mathrm{E}+00$ & $6.614 \mathrm{E}-01$ & $3.307 \mathrm{E}-04$ & $3.000 \mathrm{E}-04$ \\
15 & $9.000 \mathrm{E}+00$ & $1.984 \mathrm{E}+00$ & $9.921 \mathrm{E}-04$ & $9.000 \mathrm{E}-04$ \\
30 & $1.800 \mathrm{E}+01$ & $3.968 \mathrm{E}+00$ & $1.984 \mathrm{E}-03$ & $1.800 \mathrm{E}-03$ \\
60 & $3.600 \mathrm{E}+01$ & $7.937 \mathrm{E}+00$ & $3.968 \mathrm{E}-03$ & $3.600 \mathrm{E}-03$ \\
1,440 & $8.640 \mathrm{E}+02$ & $1.905 \mathrm{E}+02$ & $9.524 \mathrm{E}-02$ & $8.640 \mathrm{E}-02$ \\
\hline
\end{tabular}

\section{Estimates for Periods of Missing Data}

Periods of missing data may occur due to loss of power, instrument damage, interference in the acoustic beam path, or other causes. If one beam of an acoustic meter is not functioning or has interference, then, unlike velocity calculations, the sediment acoustic parameters can still be calculated because data from only one beam are required. In these cases, it is best to calculate the sediment acoustic data from the working beam if backscatter readings are generally similar when both beams are working. If backscatter readings consistently vary by more than three counts between beams during normal operation, it may be best to develop a regression between backscatter readings in the individual beams during periods when both are working. The regression can then be used to estimate data for the nonworking beam during the period of missing data and then calculate the average backscatter from both beams. If both beams are not working or blocked, ideally, a redundant data source, such as another acoustic instrument, turbidity probe, or other surrogate technology, is located at the site and can be used to estimate SSC. If a pump sampler is being used to collect periodic or intermittent samples, a combination of interpolation between samples and use of a streamflow-toSSC rating curve can be used to estimate SSC. A streamflowto-SSC rating curve can also be used to estimate SSC, but careful consideration should be given to the hysteresis that may occur during a flow event (Porterfield, 1972; Koltun and others, 2006). If periods of missing data cannot be reasonably estimated, then no values should be computed for that missing period.

\section{Validation and Long-Term Maintenance of the Rating}

After a rating is developed, ongoing validation is required by collecting concurrent ADVM data and physical SSC samples at various sediment conditions beyond the period of record used in rating development. Validation sampling plans should endeavor to cover the range of SSC and flow conditions for the year (or period of study) to minimize rating extrapolation for the year (or period of study). Best practices for validation sampling will focus on medium to high flows and conditions that are undersampled in the calibration dataset (as may be indicated in flow-duration curves). The ideal number and seasonal distribution of validation samples will depend on the variability and temporal stationarity of the sediment acoustic index rating, and will typically consist of at least four samples representing the range of flow and seasonal conditions. The results of these samples should be plotted with the existing rating to determine if the rating is still valid. Also, the analysis of covariance (Helsel and Hirsch, 2002, p. 316, and Rasmussen and others, 2009) can determine if the slope and the $y$ intercept are statistically different with the new data included in the rating development. The increasing dataset should provide improved model error and a significant error improvement may justify creating a new rating with the entire dataset. The rating may need to be revised in response to changes in sediment source areas or sediment transport conditions. If these changes are occurring gradually, then trend analysis should indicate if some portion of the dataset should be considered nonrepresentative and removed from the rating calibration.

The validation and long-term maintenance of the rating must be documented, checked, and reviewed at least annually in the sediment station analysis package, which should then be updated, reviewed, and approved. If data are being telemetered in real time, data quality checks should occur on at least a daily basis at the same time that checks are being made to see if the overall site is functioning. If data are not telemetered in real time, then the checks should be made as soon as possible after returning from the field with the downloaded data. A first check can be to make sure that the computed SSC and SSL values are reasonable for the field conditions. Comparing either or both parameters with plots of streamflow, rainfall, and (or) turbidity will give a useful first indication as to whether the instrument is operating correctly. This preliminary check should also include checks of velocity, ADVM water temperature, and range-averaged cell end (a parameter recorded by SonTek/Xylem Argonaut ADVMs) as described in Levesque and Oberg (2012). "Changes to the cell end data can indicate that site conditions have changed (change in scatterers or obstruction in acoustic beams) or that the ADVM configuration has changed (changes to [range-averaged] measurement volume, instrument malfunction, and so forth)" (Levesque and Oberg, 2012, p. 28). For reasons noted in Levesque and Oberg (2012), changes to the range-averaged cell end for a 
side-looker are generally not desirable and may indicate poorquality multicell data.

Possible problems in SSC may not be apparent or replicated in the velocity or other data mentioned above. The acoustic surrogates used to estimate SSC can be more sensitive to environmental and instrument issues. The best indication of possible problems is to look at the measured backscatter and, in particular, the profile of measured backscatter along the acoustic axis of the beam. Disruptions in the backscatter profile can indicate the presence of obstructions, such as debris in the channel or near the instrument, low scattering material, or low water depth. Backscatter profiles can be viewed in manufacturer software or using the SAID tool (Domanski and others, 2015).

\section{Changes to Acoustic Sensor Setup, Model, or Type}

Changes to the ADVM configuration, location, model, or transducer characteristics can affect the measured backscatter along the acoustic axis of the beam and may render the prior rating unusable. These potential changes or shifts can be evaluated, as discussed in appendix 2. However, one cannot take the raw data from past deployments and determine the backscatter that would have been reported for different cell sizes or other configuration changes. Errors or deviations in the rating can occur (but are not well documented or quantified) if an instrument malfunctions and is swapped with another instrument, even if the instrument is of the same instrument model, type, and configuration. If replacement of an instrument is necessary, care should be taken to replicate the configuration of the original instrument and to closely monitor for sudden shifts in backscatter readings or departures in the sediment acoustic rating.

\section{Summary and Conclusions}

Sediment monitoring in rivers is essential to developing informed solutions to a wide range of concerns related to sediment and sediment-associated constituents. However, fluvial sediment is monitored primarily by collecting discrete samples without the substantial information benefit of continuous monitoring using surrogates. Also, sediment concentrations can vary greatly over time, which is not typically well quantified by samples alone because of long gaps between measured conditions. Continuous estimates of sediment characteristics can provide more accurate and informative data. Continuous sediment characteristics from surrogates also can be provided in real time, which can inform operational or response decisions. Continuous suspended-sediment concentration (SSC) and suspended-sediment load (SSL) can be obtained by developing relations between sampled sediment concentrations and continuously measured surrogate parameters. Traditionally, streamflow at a nearby streamgage has been used as a sediment surrogate; however, streamflow often does not accurately estimate sediment concentrations. New techniques that make use of acoustic backscatter have been successfully used to provide accurate and cost-effective estimates of SSC and SSL. These techniques are applied in the operation of sediment acoustic index gages, which involves deploying an acoustic Doppler current meter (ADVM) in a fixed location, collecting an adequate rating calibration dataset of concurrent ADVM backscatter surrogates and physical samples analyzed for SSC. Ultimately, use of sediment acoustic index gages can decrease long-term sediment monitoring costs. This report describes techniques and procedures for installing and operating sediment acoustic index gages and developing ratings to estimate SSC and SSL on a continuous basis.

The sediment acoustic index monitoring site should have relatively consistent, well-mixed flow and sediment distribution over a range of hydrologic conditions. Site and instrument selection should consider whether an ADVM will be able to measure acoustic data in a sediment zone that is well mixed and homogeneous and that varies consistently and proportionally with the overall average cross-section SSC. When establishing a sediment acoustic index gage, it is essential to evaluate the optimal location and configuration of the ADVM beam length, cell size, blanking distance, averaging period, and measurement interval, among other settings. These factors can affect the final sediment acoustic index rating and, if possible, should remain unchanged.

Collecting SSC samples representative of the range of sediment and acoustic conditions for a site is essential to the successful development of a sediment acoustic index rating. Accurate, comparable, representative SSC sampling must use appropriate instrumentation and methods described in key guidance reports and associated training. SSC samples should be analyzed for, at a minimum, concentration and sand/ silt break. If possible, selected samples also should be analyzed for full particle-size distribution and concentration of organic matter, which may help in interpreting patterns in the developed rating. The raw acoustic backscatter data must be corrected for losses due to beam spreading, absorption of the acoustic signal by water, and attenuation of the acoustic signal by sediment. Two sediment acoustic surrogates result from the data correction process: the sediment-corrected backscatter $(\overline{S C B})$ and the sediment attenuation coefficient $(S A C)$. The calibration dataset consists of the sampled SSC (and potentially $\mathrm{SSC}_{\text {fines }}$ and $\mathrm{SSC}_{\text {sands }}$ ) and concurrently measured $\overline{S C B}$ and (or) $S A C$, and any other explanatory variables used to develop the sediment acoustic index rating. The adequacy of the calibration dataset depends primarily on how well it represents the range of hydrologic and sedimentologic conditions and any temporal trends over which the sediment acoustic rating is used to estimate SSC. In particular, the dataset should envelope a substantial portion of the range of observed flow and sediment conditions for the period of continuous SSC time-series computation, so that there is limited rating extrapolation. Discrete sediment sample data and computed SSC time-series data should be stored in the NWIS database, and 
all data used to develop the rating should be stored in the station records and summarized in the sediment station analysis.

The sediment acoustic index rating is developed using OLS linear regression analysis. Components of the regression analysis include analysis of outliers, transformations, potential explanatory variables, and model statistics using selected regression diagnostic tools. If the regression model is deemed adequate, it may be used to calculate continuous estimates of SSC and, if continuous streamflow data are available, SSL. Prediction intervals also should be calculated and displayed to convey uncertainty in the rating estimates. The sediment acoustic index analysis must be documented in the sediment station analysis. The sediment station analysis will include site and instrument characteristics, analytical discussion, calibration dataset, regression model summary, regression diagnostics, and assumptions made during development of the sediment acoustic index rating. After a sediment acoustic index rating is developed, ongoing validation is required by collecting concurrent ADVM data and physical SSC samples at various sediment conditions beyond the period of record used in the rating development. The validation and long-term maintenance of the rating must be documented in an updated sediment station analysis, which is checked and reviewed at least annually.

Reliable sediment acoustic index ratings are founded on best practices in site selection and installation, instrument configuration and operation, physical SSC sampling, acoustic data processing, good calibration datasets, quality regression analysis, and thorough documentation. If these practices are followed, then the development and application sediment acoustic index rating will be straightforward and the model uncertainty can be reliably evaluated.

\section{References Cited}

Boldt, J.A., 2015, From mobile ADCP to high-resolution SSC; a cross-section calibration tool-Proceedings of the 3d Joint Federal Interagency Conference on Sedimentation and Hydrologic Modeling, April 19-23, 2015: Reno, Nev., p. 1258-1260, accessed March 1, 2016, at http://acwi.gov/ sos/pubs/3rdJFIC/Proceedings.pdf.

Bragg, H.M., Sobieszczyk, Steven, Uhrich, M.A., and Piatt, D.R., 2007, Suspended-sediment loads and yields in the North Santiam River Basin, Oregon, water years 19992004: U.S. Geological Survey Scientific Investigations Report 2007-5187, 26 p., accessed March 1, 2016, at http:// pubs.usgs.gov/sir/2007/5187/.

Clark, G.M., Fosness, R.L., and Wood, M.S., 2013, Sediment transport in the lower Snake and Clearwater River Basins, Idaho and Washington, 2008-11: U.S. Geological Survey Scientific Investigations Report 2013-5083, 56 p., accessed March 1, 2016, at http://pubs.usgs.gov/sir/2013/5083/.
Cohn, T.A., Delong, L.L., Gilroy, E.J., Hirsch, R.M., and Wells, D.K., 1989, Estimating constituent loads: Water Resources Research, v. 25, no. 5, p. 937-942, accessed March 1, 2016, at http:/www.timcohn.com/Publications/ CohnDelong1989.pdf.

Davis, B.E., 2005, A guide to the proper selection and use of Federally approved sediment and water-quality samplers: U.S. Geological Survey Open-File Report 2005-1087, 20 p., accessed March 1, 2016, at http://pubs.usgs.gov/ of/2005/1087/.

Deines, K.L., 1999, Backscatter estimation using broadband acoustic Doppler current profilers: Proceedings of the IEEE Sixth Working Conference on Current Measurement, March 11-13, 1999: Current Measurement Technology Committee of the Oceanic Engineering Society, Institute of Electrical and Electronics Engineers: San Diego, Calif., p. 249-253, accessed March 11, 2016, at http://www.commtec.com/Library/Technical_Papers/RDI/echopaper.pdf.

Domanski, M.M., Straub, T.D., Wood, M.S., Landers, M.N., Wall, G.R., and Brady, S.J., 2015, Surrogate analysis and index developer (SAID) tool and real-time dissemination utilities: Proceedings of the 10th Federal Interagency Sedimentation Conference, April 19-23, 2015: Reno, Nev., p. 847-858, accessed March 12016 , at http://acwi.gov/sos/ pubs/3rdJFIC/Proceedings.pdf.

Domanski, M.M., Straub, T.D., and Landers, M.N., 2015, Surrogate Analysis and Index Developer (SAID) tool (version 1.0, September 2015): U.S. Geological Survey OpenFile Report 2015-1177, 38 p., accessed March 1, 2016, at http://dx.doi.org/10.3133/ofr20151177.

Downing, A., Thorne, P.D., and Vincent, C.E., 1995, Backscattering from a suspension in the near field of a piston transducer: Journal of the Acoustical Society of America, p. 1614-1620, accessed March 4, 2016, at http://scitation. aip.org/content/asa/journal/jasa/97/3/10.1121/1.412100.

Duan, Naihua, 1983, Smearing estimate; A nonparametric retransformation method: Journal of the American Statistical Association, v. 78, no. 383, p. 605-610, accessed March 11, 2016, at http://www.tandfonline.com/doi/abs/10.1080/01 621459.1983 .10478017$.

Edwards, T.K., and Glysson, G.D., 1999, Field methods for measurement of fluvial sediment: U.S. Geological Survey Techniques of Water-Resources Investigations, book 3, chap. C2, 89 p., accessed March 7, 2016, at https://pubs. er.usgs.gov/publication/twri03C2.

Eng, Ken, Chen, Yin-Yu, and Kiang, J.E., 2009, User's guide to the weighted-multiple-linear-regression program (WREG version 1.0): U.S. Geological Survey Techniques and Methods, book 4, chap. A8, 21 p., accessed March 11, 2016, at http://pubs.usgs.gov/tm/tm4a8. 
Ferguson, R.I., 1986a, River loads underestimated by rating curves: Water Resources Research, v. 22, no. 1, p. 74-76, accessed March 11, 2016, at doi:10.1029/ WR022i001p00074.

Ferguson, R.I., 1986b, Reply to "Comment on "River loads underestimated by rating curves," by R. I. Ferguson": American Geophysical Union, Water Resources Research, v. 22, no. 13, p. 2123-2124, accessed March 11, 2016, at doi:10.1029/WR022i013p02123.

Flagg, C.N., and Smith, S.L., 1989, On the use of the acoustic Doppler current profiler to measure zooplankton abundance: Deep-Sea Research: v. 36, p. 455-474, accessed March 11, 2016, at http://www.sciencedirect.com/science/article/ pii/0198014989900472.

Flammer, G.H.,1962, Ultrasonic measurement of suspended sediment: U.S. Geological Survey Bulletin 1141-A, 48 p., accessed March 7, 2016, at https://pubs.er.usgs.gov/publication/b1141A.

Gartner, J.W., 2004, Estimating suspended solids concentrations from backscatter intensity measured by acoustic Doppler current profiler in San Francisco Bay, California: Elsevier, Marine Geology, v. 211, p. 169-187, accessed March 7, 2016, at http://www.sciencedirect.com/science/ article/pii/S0025322704001872.

Gray, J.R., and Gartner, J.W., 2009, Technological advances in suspended-sediment surrogate monitoring: Water Resources Research, v. 45, W00D29, accessed March 7, 2016, at http:// water.usgs.gov/osw/techniques/2008WR007063.pdf.

Gray, J.R., Glysson, G.D., and Edwards, T.E., 2008, Suspended-sediment samplers and sampling methods, in Garcia, Marcelo, ed., Sedimentation engineering-Processes, measurements, modeling, and practice: American Society of Civil Engineers Manual 110, chap. 5.3, p. 320-339, accessed March 11, 2016, at http://water.usgs.gov/osw/techniques/Diplas_Kuhnle_others.pdf.

Gray, J.R., and Landers, M.N., 2014, Measuring suspended sediment, in Ahuja, Satinder, ed., Comprehensive water quality and purification: United States of America, Elsevier, v. 1, p. 157-204, accessed March 11, 2016, at http://water. usgs.gov/osw/techniques/sediment/gray_landers_elsevier_ chapter_12_10_17_2013.pdf.

Guerrero, Massimo, Szupiany, R.N., and Amsler, M.L., 2011, Comparison of acoustic backscattering techniques for suspended sediments investigation: Elsevier, Flow Measurement and Instrumentation, v. 22, no. 5, p. 392-401, accessed March 11, 2016, at http:/www.sciencedirect.com/ science/article/pii/S0955598611000689.
Hay, A.E., 1983, On the remote acoustic detection of suspended sediment at long wavelengths: American Geophysical Union, Journal of Geophysical Research, v. 88, no. C12, p. 7525-7542, accessed March 7, 2016, at http://onlinelibrary.wiley.com/doi/10.1029/JC088iC12p07525/epdf.

Hay, A.E., and Sheng, J., 1992, Vertical profiles of suspended sand concentration and size from multi-frequency acoustic backscatter: American Geophysical Union, Journal of Geophysical Research, v. 97, p. 15661-15677, accessed March 7, 2016, at http://onlinelibrary.wiley.com/ doi/10.1029/92JC01240/pdf.

Helsel, D.R., and Hirsch, R.M., 2002, Statistical methods in water resources-hydrologic analysis and interpretation: U.S. Geological Survey Techniques of Water-Resources Investigations, book 4, chap. A3, 510 p., accessed March 7, 2016, at http://pubs.usgs.gov/twri/twri4a3/.

Holdaway, G.P., Thorne, P.D., Flatt, D., Jones, S.E., and Prandle, David, 1999, Comparison between ADCP and transmissometer measurements of suspended sediment concentration: Elsevier, Continental Shelf Research, v. 19, p. 421-441, accessed March 7, 2016, at http://www.ldeo. columbia.edu/ bhuber/LADCP/wh1200/references/adcp_ transmissometer.pdf.

Horowitz, A.J., Clarke, R.T., and Merten, G.H., 2014, The effects of sample scheduling and sample numbers on estimates of the annual fluxes of suspended sediment in fluvial systems: Hydrological Processes, accessed March 11, 2016, at http://dx.doi.org/10.1002/hyp.10172.

Koch, R.W., and Smillie, G.M., 1986, Comment on "River loads underestimated by rating curves" by R.I. Ferguson: Water Resources Research, v. 22, no. 13, p. 2121-2122, accessed March 11, 2016, at doi:10.1029/ WR022i013p02121.

Koltun, G.F., Eberle, Michael, Gray, J.R., and Glysson, G.D., 2006, User's manual for the Graphical Constituent Loading Analysis System (GCLAS): U.S. Geological Survey Techniques and Methods, book 4, chap. C1, 51 p., accessed March 7, 2016, at https://pubs.er.usgs.gov/publication/ tm4C1.

Landers, M.N., 2011, Fluvial suspended sediment characteristics by high-resolution, surrogate metrics of turbidity, laser-diffraction, acoustic backscatter, and acoustic attenuation: Dissertation, Georgia Institute of Technology, 236 p., accessed March 11, 2016, at http://hdl.handle. net/1853/43747.

Landers, M.N., Arrigo, J., and Gray, J.R., 2012, Advancing hydoacoustic technologies for sedimentology research and monitoring: American Geophysical Union, Eos Transactions, v. 93, no. 26, p. 244, doi: 10.1029/2012EO260007, accessed March 11, 2016, at http://onlinelibrary.wiley.com/ doi/10.1029/2012EO260007/pdf. 
Landers, M.N., and Sturm, T.W., 2013, Hysteresis in suspended sediment to turbidity relations due to changing particle size distributions: Water Resources Research, v. 49, no. 9, accessed March 11, 2016, at doi:10.1002/wrcr.20394.

Lee, C.J., Rasmussen, P.P., Ziegler, A.C., and Fuller, C.C., 2009, Transport and sources of suspended sediment in the Mill Creek watershed, Johnson County, northeast Kansas, 2006-07: U.S. Geological Survey Scientific Investigations Report 2009-5001, 52 p., accessed March 7, 2016, at https://pubs.er.usgs.gov/publication/sir20095001.

Levesque, V.A., and Oberg, K.A., 2012, Computing discharge using the index velocity method: U.S. Geological Survey Techniques and Methods, book 3, chapter A23, 148 p., accessed March 11, 2016, at http://pubs.usgs.gov/tm/3a23/.

Lynch, J.F., Irish, J.D., Sherwood, C.R., and Agrawal, Y.C., 1994, Determining suspended sediment particlesize information from acoustical and optical backscatter measurements: Elsevier, Continental Shelf Research, v. 14, nos. 10-11, p. 1139-1165, accessed March 7, 2016, at http://www.sciencedirect.com/science/article/ pii/0278434394900329.

Marczak, Wojciech, 1997, Water as a standard in the measurements of speed of sound in liquids: Journal of the Acoustical Society of America, v. 102, no. 5, p. 2776-2779, accessed March 11, 2016, at http://scitation.aip.org/content/asa/journal/jasa/102/5/10.1121/1.420332.

Medalie, Laura, Chalmers, A.T., Kiah, R.G., and Copans, Benjamin, 2014, Use of acoustic backscatter to estimate continuous suspended sediment and phosphorus concentrations in the Barton River, northern Vermont, 2010-2013: U.S. Geological Survey Open-File Report 2014-1184, 29 p., 4 appendixes, accessed March 11, 2016, at http:// dx.doi.org/10.3133/ofr20141184.

Moore, S.A., Le Coz, J., Hurther, D., and Paquier, A., 2013, Using multi-frequency acoustic attenuation to monitor grain size and concentration of suspended sediment in rivers: Journal of the Acoustical Society of America, v. 133, no. 4, p. 1959-1970, accessed March 11, 2016, http://dx.doi. org/10.1121/1.4792645.

Mueller, D.S., Wagner, C.R., Rehmel, M.S., Oberg, K.A, and Rainville, Francois, 2013, Measuring discharge with acoustic Doppler current profilers from a moving boat (ver. 2.0, December 2013): U.S. Geological Survey Techniques and Methods, book 3, chap. A22, accessed March 11, 2016, at http://dx.doi.org/10.3133/tm3A22.

Nolan, K.M., Gray, J.R., and Glysson, G.D., 2005, Introduction to suspended-sediment sampling: U.S. Geological Survey Scientific Investigations Report 2005-5077, 1 CD-ROM, accessed March 11, 2016, at http://pubs.usgs. gov/sir/2005/5077/.
Porterfield, George, 1972, Computation of fluvial-sediment discharge: U.S. Geological Survey Techniques of WaterResources Investigations, book 3, chap. C3, 66 p., accessed March 7, 2016, at https://pubs.er.usgs.gov/publication/ twri03C3.

Rantz, S.E., and others, 1982, Measurement and computation of streamflow, volumes 1 and 2: U.S. Geological Survey Water-Supply Paper 2175, 631 p., accessed March 7, 2016, at https://pubs.er.usgs.gov/publication/wsp2175_vol1 and https://pubs.er.usgs.gov/publication/wsp2175.

Rasmussen, P.P., Gray, J.R., Glysson, G.D., and Ziegler, A.C., 2009, Guidelines and procedures for computing time-series suspended-sediment concentrations and loads from instream turbidity-sensor and streamflow data: U.S. Geological Survey Techniques and Methods book 3, chap. C4, 53 p., accessed March 7, 2016, at https://pubs.er.usgs.gov/ publication/tm3C4.

Sauer, V.B., 2002, Standards for the analysis and processing of surface-water data and information using electronic methods: U.S. Geological Survey Water-Resources Investigations Report 01-4044, 91 p., accessed March 7, 2016, at http://pubs.usgs.gov/wri/2001/4044/report.pdf.

Schulkin, M., and Marsh, H.W., 1962, Sound absorption in sea water: Journal of the Acoustical Society of America, v. 34, no. 6, p. 864-865, accessed March 7, 2016, at http://dx.doi. org/10.1121/1.1918213.

Sheng, J., and Hay, A.E., 1988, An examination of the spherical scatter approximation in aqueous suspensions of sand: Journal of the Acoustical Society of America, v. 83, no. 2, p. 598-610, accessed March 7, 2016, at http://dx.doi. org/10.1121/1.396153.

Simmons, S.M., Parsons, D.R., Best, J.L., Orfeo, O., Lane, S.N., Kostaschuk, R., Hardy, R.J., West, G., Malzone, C., Marcus, J., and Pocwiardowski, P., 2010, Monitoring suspended sediment dynamics using MBES: Journal of Hydrologic Engineering, v. 136, no. 1, p. 45-49, accessed March 7, 2016, at http://ascelibrary.org/doi/10.1061/\%28AS CE\%29HY.1943-7900.0000110.

Simpson, M.R., 2001, Discharge measurements using a broadband acoustic doppler current profiler: U.S. Geological Survey Open-File Report 01-1, 123 p., accessed March 8, 2016, at http://pubs.usgs.gov/of/2001/ofr0101/.

Thevenot, M.M., Prickett, T.L., and Kraus, N.C., eds., 1993, Tylers Beach, Virginia, dredged material plume monitoring project 27 September to 4 October 1991: Washington D.C., U.S. Army Corps of Engineers, Dredging Research Program Technical Report DRP-92-7, 204 p., accessed March 8, 2016, at http://www.dtic.mil/dtic/tr/fulltext/u2/a261036.pdf. 
Thorne, P.D., and Hardcastle, P.J., 1997, Acoustic measurements of suspended sediments in turbulent currents and comparison with in-situ samples: Journal of the Acoustical Society of America, v. 101, no. 5, p. 2603-2614, accessed March 8, 2016, at http://scitation.aip.org/content/asa/jour$\mathrm{nal} / \mathrm{jasa} / 101 / 5 / 10.1121 / 1.418501$.

Thorne, P.D., Hurther, David, and Moate, B.D., 2011, Acoustic inversions for measuring boundary layer suspended sediment processes: Journal of the Acoustical Society of America, v. 130, no. 3, p. 1188-1200, accessed March 8, 2016, at http://scitation.aip.org/content/asa/journal/ jasa/130/3/10.1121/1.3618728.

Thorne, P.D., Vincent, C.E., Hardcastle, P.J., Rehman, S., and Pearson, N., 1991, Measuring suspended sediment concentrations using acoustic backscatter devices: Elsevier, Marine Geology, v. 98, no. 1, p. 7-16, accessed March 8, 2016, at http://www.sciencedirect.com/science/article/ pii/002532279190031X.

Topping, D.J., Melis, T.S., Rubin, D.M., and Wright, S.A., 2004, High-resolution monitoring of suspended-sediment concentration and grain size in the Colorado River in Grand Canyon using a laser acoustic system-Proceedings of the Ninth International Symposium on River Sedimentation, October 18-21, 2004:Yichang, China, Tsinghua University Press, v. 4, p. 2507-2514, accessed March 8, 2016, at http:// www.irtces.org/old/irtces/report/9isrs/E_isrs06.htm\#4.

Topping, D.J., Rubin, D.M., Wright, S.A., and Melis, T.S., 2011, Field evaluation of the error arising from inadequate time averaging in the standard use of depth-integrating suspended-sediment samplers: U.S. Geological Survey Professional Paper 1774, 95 p., accessed March 8, 2016, at http://pubs.usgs.gov/pp/1774/.

Topping, D.J., Wright, S.A., Griffiths, R.E., and Dean, D.J., 2015, Physically based method for measuring suspendedsediment concentration and grain size using multi-frequency arrays of single-frequency acoustic-doppler profilers-Proceedings of the Third Joint Federal Interagency Sedimentation Conference on Sedimentation and Hydrologic Modeling, April 19-23, 2015: Reno, Nev., p. 833-846, accessed March 8, 2016, at http://acwi.gov/sos/pubs/3rdJFIC/Proceedings.pdf.

Topping, D.J., Wright, S.A., Melis, T.S., and Rubin, D.M., 2006, High-resolution monitoring of suspended-sediment concentration and grain size in the Colorado River using laser-diffraction instruments and a three-frequency acoustic system-Proceedings of the Eighth Federal Interagency Sedimentation Conference, April 2-6, 2006: Reno, Nev., U.S. Geological Survey, p. 539-546, accessed March 8, 2016, at http://pubs.usgs.gov/misc/FISC_1947-2006/ pdf/1st-7thFISCs-CD/8thFISC/Session\%206C-3_Topping. pdf.
Topping, D.J., Wright, S.A., Melis, T.S., and Rubin, D.M., 2007, High-resolution measurements of suspended-sediment concentration and grain size in the Colorado River in Grand Canyon using a multi-frequency acoustic system-Proceedings, 10th International Symposium on River Sedimentation, August 1-4, 2007: Moscow, Russia, v. 3, p. 330-339, ISBN 978-5-89575-124-4, 978-5-89575-127-5, accessed March 8, 2016, at https://www.researchgate.net/ publication/258999420_High-resolution_measurements of_suspended-sediment_concentration_and_grain_size_in the_Colorado_River_in_Grand_Canyon_using_a_multifrequency_acoustic_system.

Turnipseed, D.P., and Sauer, V.B., 2010, Discharge measurements at gaging stations: U.S. Geological Survey Techniques and Methods book 3, chap. A8, 87 p., accessed March 8, 2016, at https://pubs.er.usgs.gov/publication/ tm3A8.

Urick, R.J., 1948, The absorption of sound in suspensions of irregular particles: Journal of the Acoustical Society of America, v. 20, p. 283-289, accessed March 9, 2016, at http://scitation.aip.org/content/asa/journal/ jasa/20/3/10.1121/1.1906373.

Urick, R.J., 1975, Principles of underwater sound, 2d ed.: New York, McGraw Hill, 384 p.

Urick, R.J., 1983, Principles of underwater sound: New York, McGraw-Hill Co.

U.S. Environmental Protection Agency (EPA), 2008, Handbook for Developing Watershed Plans to Restore and Protect Our Waters: Office of Water, Nonpoint Source Control Branch, EPA 841-B-08-002, 400 p.

U.S. Environmental Protection Agency (EPA), 2014, National summary of impaired waters and TMDL information: EPA Web page, accessed January 5, 2015, at http://iaspub.epa. gov/tmdl_waters10/attains_nation_cy.control?p_report type $=\mathrm{T}$.

U.S. Geological Survey, 2006, Collection of water samples (ver. 2.0): U.S. Geological Survey Techniques of WaterResources Investigations, book 9, chap. A4, September 2006, accessed December 1, 2015, at http://pubs.water.usgs. gov/twri9A4.

U.S. Geological Survey, 2010, Independent water temperature measurement for hydroacoustic measurements: U.S. Geological Survey, Office of Surface Water Technical Memorandum 2010.07, accessed January 5, 2015, at http://water. usgs.gov/admin/memo/SW/sw10.07.html. 
Voichick, N., and Topping, D.J, 2014, Extending the turbidity record - making additional use of continuous data from turbidity, acoustic-Doppler, and laser diffraction instruments and suspended-sediment samples in the Colorado River in Grand Canyon: U.S. Geological Survey Scientific Investigations Report 2014-5097, 31 p., accessed March 11, 2016, at http://dx.doi.org/10.3133/sir20145097.

Wagner, R.J., Boulger, R.W., Jr., Oblinger, C.J., and Smith, B.A., 2006, Guidelines and standard procedures for continuous water-quality monitors - station operation, record computation, and data reporting: U.S. Geological Survey Techniques and Methods, book 1, chap. D3, 51 p., 8 attachments, accessed March 11, 2016, at http://pubs.water.usgs. gov/tm1d3.

Wall, G.R., Nystrom, E.A., and Litten, S., 2006, Use of an ADCP to compute suspended-sediment discharge in the Tidal Hudson River, New York: U.S. Geological Survey Scientific Investigations Report 2006-5055, accessed March 9, 2016, at http://pubs.usgs.gov/sir/2006/5055/.

Wilson, W.D., 1960, Equation for the speed of sound in sea water: Journal of the Acoustical Society of America, v. 32, no. 10 , p. 1357.

Wood, M.S., 2014, Estimating suspended sediment in rivers using acoustic Doppler meters: U.S. Geological Survey Fact Sheet 2014-3038, 4 p., accessed March 11, 2016, at http:// dx.doi.org/10.3133/fs20143038.

Wood, M.S., Fosness, R.L., and Etheridge, A.B., 2015, Sediment transport and evaluation of sediment surrogate ratings in the Kootenai River near Bonners Ferry, Idaho, Water Years 2011-14: U.S. Geological Survey Scientific Investigations Report 2015-5169, 45 p., accessed March 14, 2016, at http://dx.doi.org/10.3133/sir20155169.

Wood, M.S., and Teasdale, G.N., 2013, Use of surrogate technologies to estimate suspended sediment in the Clearwater River, Idaho, and Snake River, Washington, 2008-10: U.S. Geological Survey Scientific Investigations Report 2013-5052, 30 p., accessed March 9, 2016, at http://pubs. usgs.gov/sir/2013/5052/.

Wright, S.A., Topping, D.J., and Williams, C.A., 2010, Discriminating silt-and-clay from suspended-sand in rivers using side-looking acoustic profilers-Proceedings of the Second Joint Federal Interagency Conference: Las Vegas, Nev., 12 p., U.S. Geological Survey [Abstract], accessed March 11, 2016, at http://acwi.gov/sos/pubs/2ndJFIC/ Contents/2C_Wright_03_01_10_paper.pdf.
Ziegler, A.C., 2003a, Issues related to use of turbidity measurements as a surrogate for suspended sediment, in Gray, J.R., and Glysson, G.D., eds., Proceedings of the Federal Interagency Workshop on Turbidity and Other Sediment Surrogates, April 30-May 2, 2002: Reno, Nev., U.S. Geological Survey, accessed March 11, 2016, at http://water. usgs.gov/osw/techniques/TSS/ZieglerT.pdf.

Ziegler, A.C., 2003b, Breakout session 1; definition of optical methods for turbidity and data reporting, in Gray, J.R., and Glysson, G.D., eds., Proceedings of the Federal Interagency Workshop on Turbidity and Other Sediment Surrogates, April 30-May 2, 2002: Reno, Nevada, U.S. Geological Survey Circular 1250, p. 9-13, accessed March 11, 2016, at http://pubs.usgs.gov/circ/2003/circ1250/pdf/circ1250. book_web.pdf.

\section{Acknowledgments}

The authors wish to thank John Gray, National Sediment Specialist (retired) with the USGS, for his early leadership and guidance in promoting standard methods for sediment acoustic index research. The authors also wish to thank the following fellow members of the Sediment Acoustics Leadership Team (SALT) for their contributions to this report and their support in advancing sediment acoustic index monitoring: Tim Calappi (U.S. Army Corps of Engineers), Patrick Dickhudt (USGS), Daniel Dombroski (Bureau of Reclamation), Ryan Jackson (USGS), Michael Lee (USGS), David Mueller (USGS), Cory Williams (USGS), and Scott Wright (USGS). 



\section{Glossary}

Acoustic beam A beam of acoustic energy with a specific beam width and typically having a fixed acoustic frequency.

ADVM Acoustic Doppler velocity meteran electronic/acoustic instrument that measures water velocity using the principle of the Doppler shift and measures backscatter as a byproduct of the water velocity measurement.

Amp Backscatter amplitude, in countsthe strength of sound energy returned to the ADVM, set to range from 0 to 255 .

BCF Bias correction factor applied in regression equations to correct logarithmic retransformation bias.

Blanking distance The distance from the transducer face within which no velocity or backscatter measurements are made and that corresponds to electronic and transducer recovery time after a ping is transmitted.

$\mathrm{Hz}$ Hertz; used to measure frequency where one hertz is one cycle per second.

LOWESS LOcally WEighted Scatter-plot Smoother is a statistical smoothing technique used to create smooth trend curves based on subsets of data points local to each point on the curve.

MB Measured backscatter, amplitude or signal strength, in decibels.

$\mathbf{M B}_{S N R}$ Measured backscatter, signal-to-noise ratio.

Measurement interval The time between two successive backscatter measurements, usually measured from the beginning of each measurement.

Measurement volume A region of flow along the main beam in which backscatter is measured and recorded by an ADVM.

Multicell Multiple, discrete volumes of water measured with an ADVM for the measurement of backscatter. Usually a subset of the measurement volume.
MLR Multiple linear regression is a statistical method to define a linear regression equation between multiple explanatory variables and a response variable.

NL Noise level is the acoustic amplitude of background noise from electronic and environmental sources above which the acoustic signal cannot be detected.

OLS Ordinary least squares is a statistical method to define a linear regression equation between explanatory and response variables based on minimizing the least squared error of estimate.

p-value Represents the probability that the relation between two variables is invalid, or not truly linearly related.

$\boldsymbol{R}^{2}$ Coefficient of determination-A statistic that gives information about the goodness of fit of a model; it represents the percent of variability in the response variable explained by explanatory variables.

$\boldsymbol{R}^{2}$. Coefficient of determination, adjustedA statistic that gives information about the goodness of fit of a multiple linear regression model; computed by adjusting $R^{2}$ based on the number of explanatory variables.

Residuals The difference between a measured value and the predicted value obtained from a regression model.

RMSE Root mean square error.

SAC Sediment attenuation coefficient; also referred to as $\alpha_{s}$, in decibels per meter.

SCB Sediment-corrected backscatter.

SLR Simple linear regression.

SSC Suspended-sediment concentration.

SSL Suspended-sediment load.

SNR Signal-to-noise ratio.

WCB Water-corrected backscatter. 


\section{Appendix 1. Example Station Analysis Format for Sediment Acoustic Index Rating}

This model archive summary documents the suspended-sediment concentration (SSC) model developed to compute 15-minute SSC from October 1, 2012. This is the first model developed for the site. The methods used follow U.S. Geological Survey (USGS) guidance as referenced in relevant Office of Surface Water/Office of Water Quality Technical Memoranda and USGS Techniques and Methods, book 3, chap. C5 (Landers and others, 2016).

\section{SITE AND MODEL INFORMATION:}

Site number: 05570000

Site name: Spoon River at Seville, Illinois (IL)

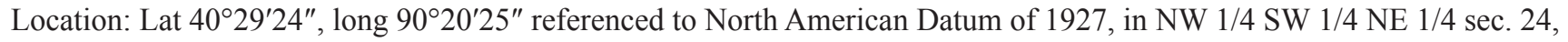
T.6 N., R.1 E., Fulton County, IL, Hydrologic Unit 07130005

Drainage area: $1,636 \mathrm{mi}^{2}$

Date rating model was created: $01 / 21 / 2015$

Model calibration data period: 10/01/2012-09/30/2014

Model application date: From 10/01/2012

Computed by: Amanda Manaster, USGS, Urbana, IL

(admanaster@usgs.gov)

Reviewed by: Timothy Straub, USGS, Urbana, IL

(tdstraub@usgs.gov)

Approved by: USGS, Center Director, Illinois Water Science Center

PHYSICAL SAMPLING EQUIPMENT AND SAMPLING DETAILS: Samples are routinely collected at least twice a week at a single station (observer) with a depth-integrating DH-59 suspended-sediment sampler housed in a shelter attached to the downstream side of the 0600E road. During periods of storm runoff, samples are taken more frequently to define the event. Cross-section samples are collected from the downstream side of the 0600E Bridge. The equal-width-interval (EWI) method is used, and samples typically are composited for analysis. Cross-section samples are obtained approximately every 6-8 weeks during ice-off periods, plus during selected runoff events. A FISP US DH-76 or DH-2 depth integrating sampler is used from the bridge, and a DH-48 hand sampler is used for wading samples. Samples are analyzed for SSC in the USGS Sediment Laboratory in Louisville, Kentucky.

\section{SURROGATE EQUIPMENT AND SETUP DETAILS:}

At the bridge on 0600E, a Sontek Argonaut SL acoustic Doppler velocity meter (ADVM; for sediment backscatter study) and physical sediment sampler are installed. The ADVM is mounted on the streamward face of the right pier, near the downstream end. The beams are horizontal and perpendicular to the flow. The ADVM is mounted at water-level stage $472.1 \mathrm{ft} \mathrm{NGVD} \mathrm{(gage}$ datum) at the location of the vertical beam transducer. The battery, power regulator, and solar panel for the ADVM are located in an enclosure at the downstream side of the bridge. The ADVM manufactured characteristics and configuration are below:

\begin{tabular}{|c|c|c|c|c|c|c|}
\hline \multicolumn{7}{|c|}{ ADVM Manufactured characteristics } \\
\hline Make & lodel & $\begin{array}{l}\text { Frequency } \\
\text { in kilohertz) }\end{array}$ & Serial number & $\begin{array}{c}\text { Effective transducer } \\
\text { diameter (in meters, m) }\end{array}$ & $\begin{array}{l}\text { Slant beam angle } \\
\text { (in degrees) }\end{array}$ & $\begin{array}{l}\text { Echo intensity } \\
\text { factor }\end{array}$ \\
\hline \multicolumn{7}{|c|}{ ADVM Configuration } \\
\hline 1.0 & 10 & 1.75 & & 90 & 900 & $09 / 30 / 12$ \\
\hline
\end{tabular}


BOX COEFFICIENTS: The relation between SSC from EWI cross-section samples and from single-station depth-integrated samples is evaluated using concurrent samples. This evaluation used 54 concurrent samples (from water year [WY] 2003 to WY2014) of which 7 were collected in the last 2 water years. The statistics of the ratio of cross-section XS_SSC to singlestation SS_SSC are: mean 1.06, median 1.00, maximum 1.95, and minimum 0.42. One sample out of the 54 samples was removed from the mean and max computation. This sample occurred on May 17, 2013, and the ratio was 6.65, indicating a probable digging of the sampler during the cross-section sampling. Sixty-seven percent of the ratios are within 0.9 and 1.1, and 80 percent are within 0.8 and 1.2. A plot of box coefficients versus streamflow indicates scatter about the 1.0 axis (fig. 1-1). A constant ratio of cross-section to single-station SSC appears reasonable for this site for WY2013-2014. All single-station samples were multiplied by a coefficient (box coefficient) of 1.00 to adjust to cross-section concentration.

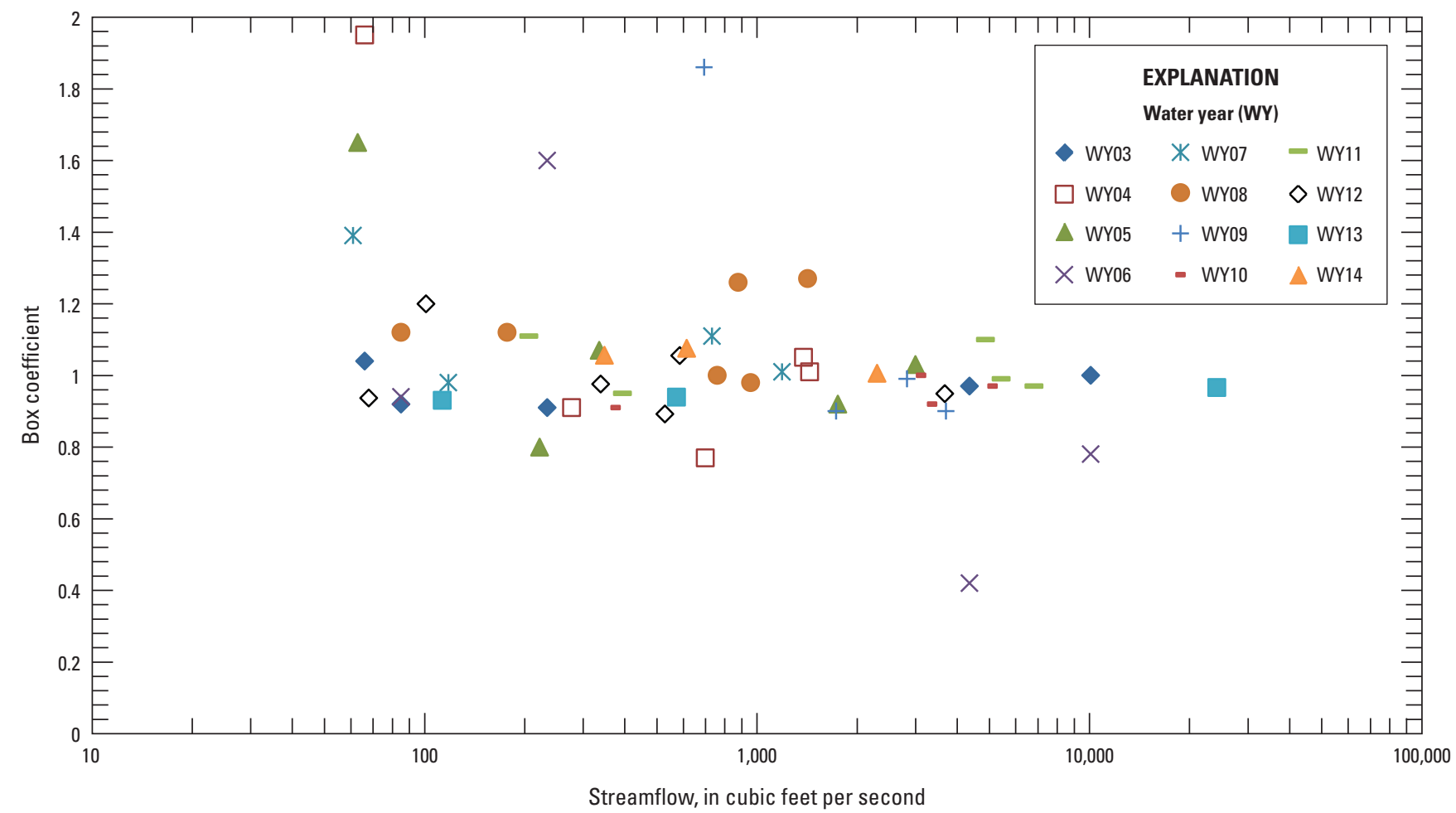

Figure 1-1. Evaluation of the relation between suspended-sediment concentration from equal-width-interval cross-section samples and from single-station depth-integrated samples using 54 concurrent samples.

MODEL DEVELOPMENT DATA PERIOD: 10/01/12-09/30/2014

MODEL-CALIBRATION DATASET: All data were collected using USGS protocols and are stored in the National Water Information System (NWIS) database. The regression model dataset considered 261 concurrent measurements of SSC (seven cross-section and 254 single-vertical samples) and ADVM data collected from October 1, 2012, through September 30, 2014. Ninety-six samples collected at a gage height below $6.36 \mathrm{ft}$ (elevation of $473.4 \mathrm{ft}$ ) were excluded because they are below the functional depth of the ADVM. Of the remaining samples, an additional 11 samples were excluded due to ADVM temperatures below zero degrees Celsius and concerns about ice interference with the acoustic signal. An additional 52 samples were excluded because of ADVM malfunction or missing data. Six samples were removed as outliers based on time-series analysis, and the outlier diagnostic indicators as shown later in the time-series plot and outlier table. From the 261 samples available, a total of 96 samples were used in the model-calibration dataset. 
These 96 samples were collected over the range of continuously observed suspended-sediment and streamflow conditions as indicated in the table below and duration curves (fig. 1-2). The samples are plotted on duration curves plots for daily SSC, and for streamflow from WY2003-WY2013 and SCB for the period of record. The table and plots show that the concurrent samples were taken for a range of sediment and flow conditions with concurrent ADVM data.

Brief summary statistics for computed sediment characteristics are noted in the following table and a complete model calibration dataset and summary statistics are provided in the following sections. Data points that were statistical outliers were evaluated graphically and based on residual diagnostic indicators. Those confirmed to be anomalous because of site conditions or problems with the ADVM data or laboratory analytical results were removed from the calibration data set; and are listed separately below.

\begin{tabular}{|c|c|c|c|}
\hline Parameter & Count & Minimum & Maximum \\
\hline SSC [milligrams per liter $(\mathrm{mg} / \mathrm{L})]$; all samples in calibration dataset & 96 & $\begin{array}{l}50 \text { on } 3 / 08 / 2013 \\
\text { at } 16: 00\end{array}$ & $\begin{array}{l}3,570 \text { on } 9 / 10 / 14 \\
\text { at } 08: 30\end{array}$ \\
\hline $\mathrm{SSC}(\mathrm{mg} / \mathrm{L})$; samples collected during the time of the computed record & 261 & $\begin{array}{l}9 \text { on } 12 / 02 / 2012 \\
\text { at } 10: 00\end{array}$ & $\begin{array}{l}3,570 \text { on } 9 / 10 / 14 \\
\text { at } 08: 30\end{array}$ \\
\hline Computed SSC $(\mathrm{mg} / \mathrm{L})$ during the time of the computed record & -- & 7 on multiple days & $\begin{array}{l}7,181 \text { on } 4 / 11 / 13 \\
\text { at } 02: 30\end{array}$ \\
\hline
\end{tabular}

MODEL DEVELOPMENT: Sediment characteristics at this site are computed from a calibrated regression model between suspended characteristics and continuously measured surrogates. The model was developed by examining average sedimentcorrected backscatter $(\overline{S C B})$, sediment attenuation coefficient (SAC), streamflow, and other continuously measured data as explanatory variables for SSC. The $\overline{S C B}$ and SAC were determined from the measured backscatter following methods outlined in this report. The table below shows the ADVM processing settings used in the Surrogate Analysis and Index Developer (SAID) tool (Domanski and others, 2015).

\begin{tabular}{ccccccc}
\hline \multicolumn{1}{c}{ ADVM Processing } \\
\hline $\begin{array}{c}\text { Beam used } \\
(\mathbf{1}, \mathbf{2} \text {, or average) }\end{array}$ & $\begin{array}{c}\text { Moving average } \\
\text { span }^{1}\end{array}$ & $\begin{array}{c}\text { Backscatter values } \\
\text { (SNR, amp, RSSI) }\end{array}$ & $\begin{array}{c}\text { Intensity scale factor (if } \\
\text { using amp or RSSI) }\end{array}$ & $\begin{array}{c}\text { Cells used } \\
\text { (SN) }\end{array}$ & $\begin{array}{c}\text { Near field } \\
\text { correction }\end{array}$ & $\begin{array}{c}\text { WCB profile } \\
\text { adjustment }\end{array}$ \\
\hline 2 & 1 & Amp & 0.43 & $2-10$ & Yes \\
\hline
\end{tabular}

${ }^{1}$ The span, in number of observations, used in a centered, moving, averaging of the backscatter time series. The span must be an odd positive integer.

An ordinary least squares linear regression analysis was prepared using the SAID tool, which examined streamflow, $\overline{S C B}$, and SAC as explanatory variables for estimating SSC. Different combinations of untransformed and log 10-transformed data were evaluated and summarized as alternative models in the last section of the package. (See "Alternative Models" table.) $\overline{S C B}$ was selected as the best explanatory variable of SSC based on residual plots, model standard error, $R^{2}$ or adjusted $R^{2}$, significance tests (p-values), and correlation of explanatory variables (variance inflation factor). Values for all of the aforementioned statistics and metrics were computed for various models and are included below, along with all relevant sample data and more in-depth statistical information. (See "Detailed Regression Model Results" table.)

MODEL SUMMARY: Summary of final regression analysis of SSC at site number 05570000.

\begin{tabular}{cc}
\hline Linear regression model & Coefficient of determination $\left(\boldsymbol{R}^{2}\right)$ \\
\hline $\log _{10} S S C=-4.28+0.0752 \overline{S C B}$ & 0.86 \\
\hline
\end{tabular}

where

SSC $=$ suspended-sediment concentration, in milligrams per liter; and

$\overline{S C B}=$ mean sediment-corrected backscatter, in decibels.

Because SSC was transformed for the regression model building, the predicted mean of the variable may be biased and needs to be multiplied by a nonparametric-smearing bias correction factor (BCF), which was determined to be 1.10 .

\begin{tabular}{ccccc}
\hline Model & Start date & End date & Linear regression model & BCF \\
\hline 1 & $10 / 01 / 2012$ & --- & $S S C=0.0000525 \times 10^{0.0752 \overline{S C B}} \times B C F$ & 1.10 \\
\hline
\end{tabular}



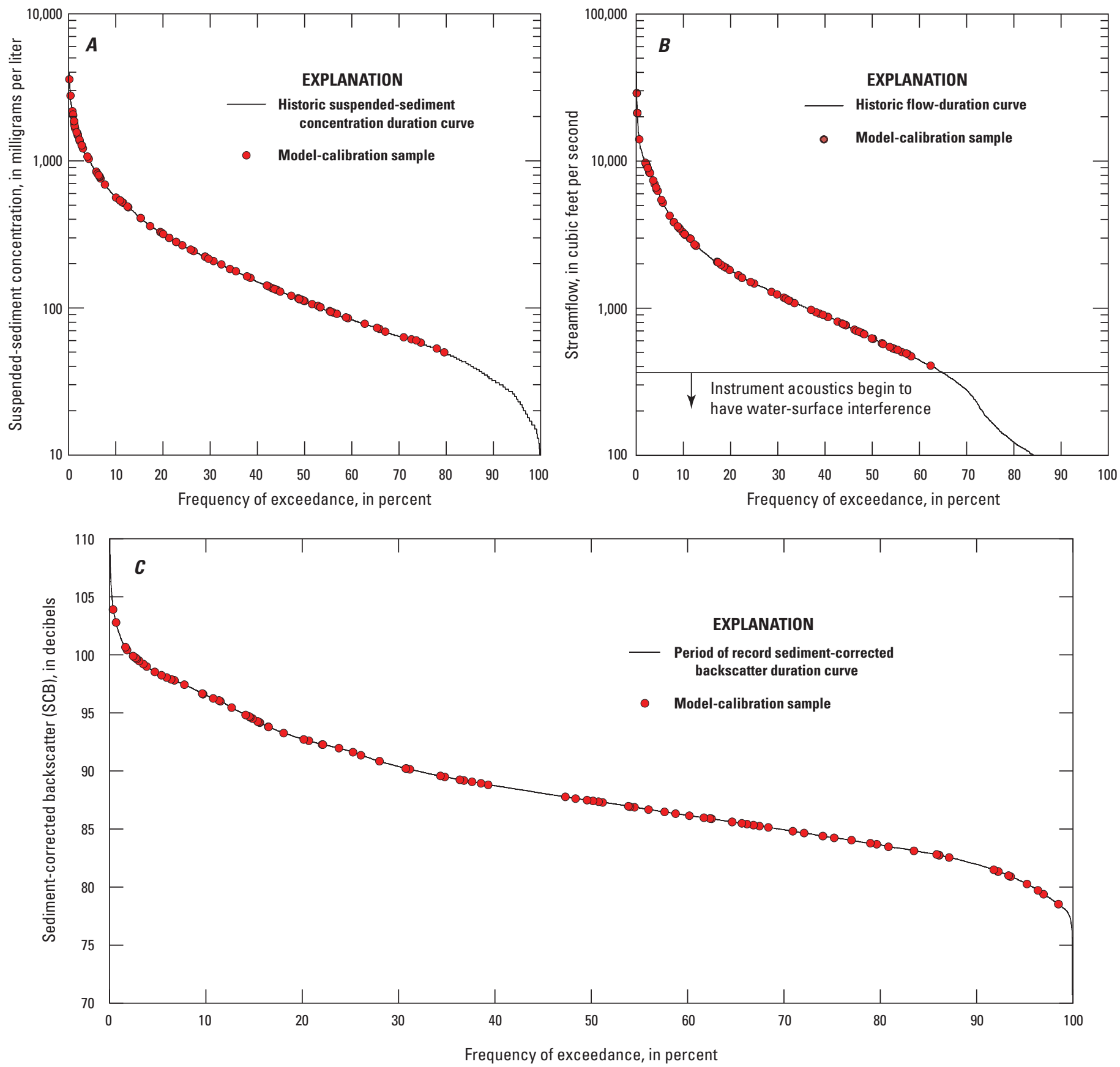

Figure 1-2. Suspended-sediment concentration (SSC) measurements plotted on duration curves for $A$, daily computed SSC, $B$, streamflow, and $C$, sediment-corrected backscatter. 
The use of acoustic surrogates $\overline{S C B}$ and (or) SAC as explanatory variables is theoretically and statistically sound. The positive coefficient confirms increasingly adjusted acoustic backscatter with increasing SSC. The value of 0.0752 is reasonable, as past studies have found values in the range of 0.03 to 0.1 . The scatter plots of observed and computed SSC for this model are shown in figures $1-3$ and $1-4$.

\section{Detailed Regression Model Results.}

\section{Rating Equation Form \\ $\log _{10} \mathrm{SSC}=-4.28+0.0752 \mathrm{MeanSCB}$}

Explanatory and Response Variable Summary Statistics

$\begin{array}{lccr} & \text { MeanSCB (dB) } & \text { SSC (mg/L) } & \log _{\mathbf{1 0}}(\mathbf{S S C}) \\ \text { Minimum } & 79 & 50 & 1.699 \\ \text { 1st quartile } & 85 & 112 & 2.049 \\ \text { Median } & 89 & 258 & 2.411 \\ \text { Mean } & 90 & 605 & 2.493 \\ \text { 3rd quartile } & 95 & 830 & 2.919 \\ \text { Maximum } & 104 & 3,570 & 3.553\end{array}$

\section{Rating Calibration}

Number of Observations 96

Error degrees of freedom $\quad 94$

Root Mean Square Error (Standard Error) $\quad 0.18979$

R-squared 0.863

Adjusted R Squared $\quad 0.862$

F-statistic vs. constant model 592

p-value

$2.32 \mathrm{E}-42$

Estimated Coefficients

Estimate

SE

(Intercept)

$-4.2848$

MeanSCB

0.0752

0.2792

0.0031

tStat

p-value

Lower $\mathbf{9 0 \%}$ Upper $\mathbf{9 0 \%}$

$-15.3480$

0.0000

$-4.7486$

$-3.8210$

24.3370

0.0000

0.0701

0.0803

Nonparametric smearing bias correction

factor

1.099

Probability plot correlation coefficient

0.9965

Variance-covariance matrix

(Intercept)

MeanSCB

(Intercept)

0.077939

$-0.00086065$

MeanSCB

$-0.00086065$

9.5498E-06

\section{Test Criteria}

High leverage

0.0625

Extreme outlier (Standardized residual)

3 (absolute value)

High influence (Cook's D)

2.141

High influence (DFFITS)

0.28868 

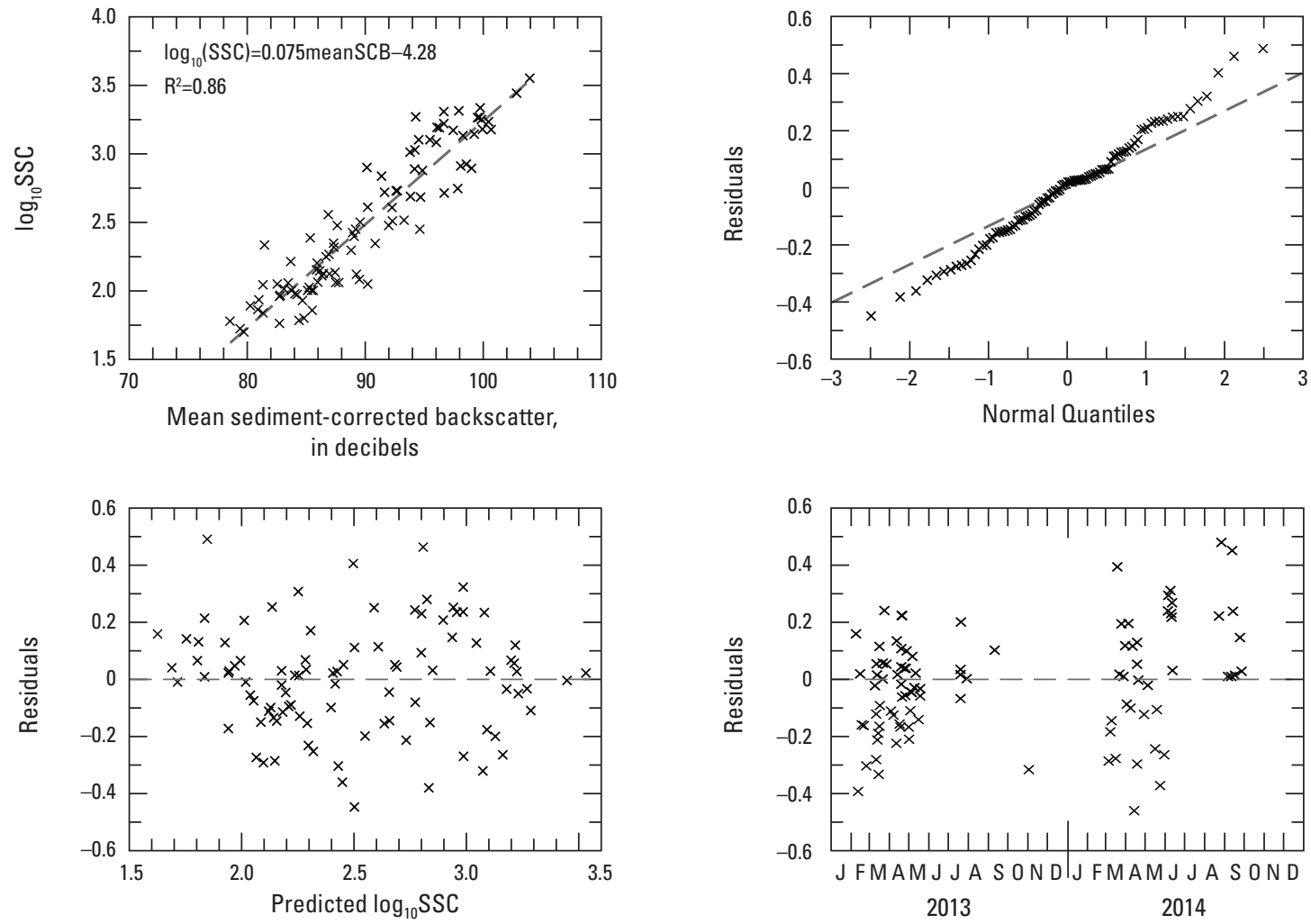

Figure 1-3. Plots of $\log _{10}$ SSC and explanatory variables and residual diagnostic plots.

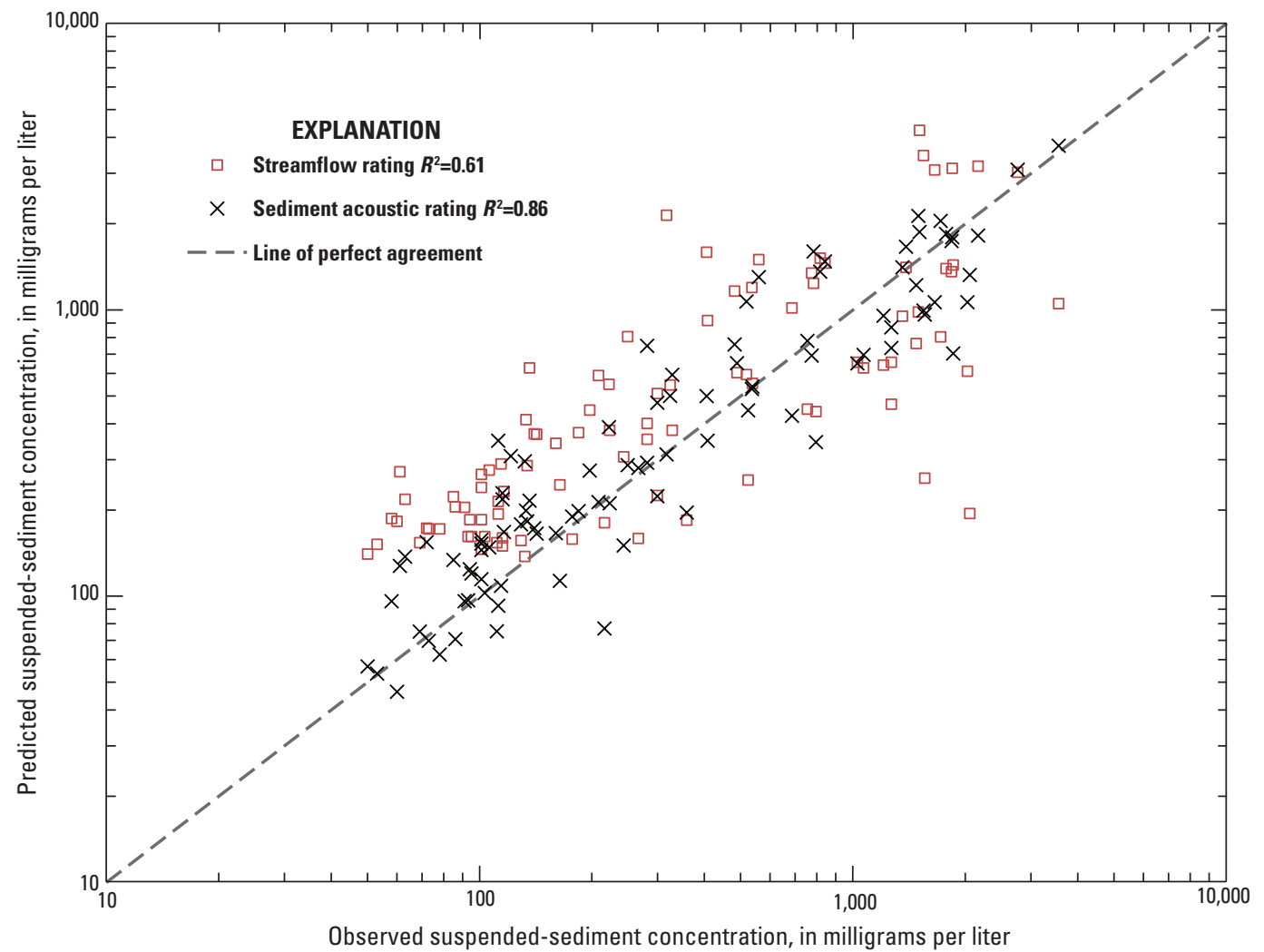

Figure 1-4. Predicted and observed suspended-sediment concentration. 


\section{Calibration Dataset}

[CST, Central Standard Time; mg/L, milligram per liter; SSC, suspended-sediment concentration]

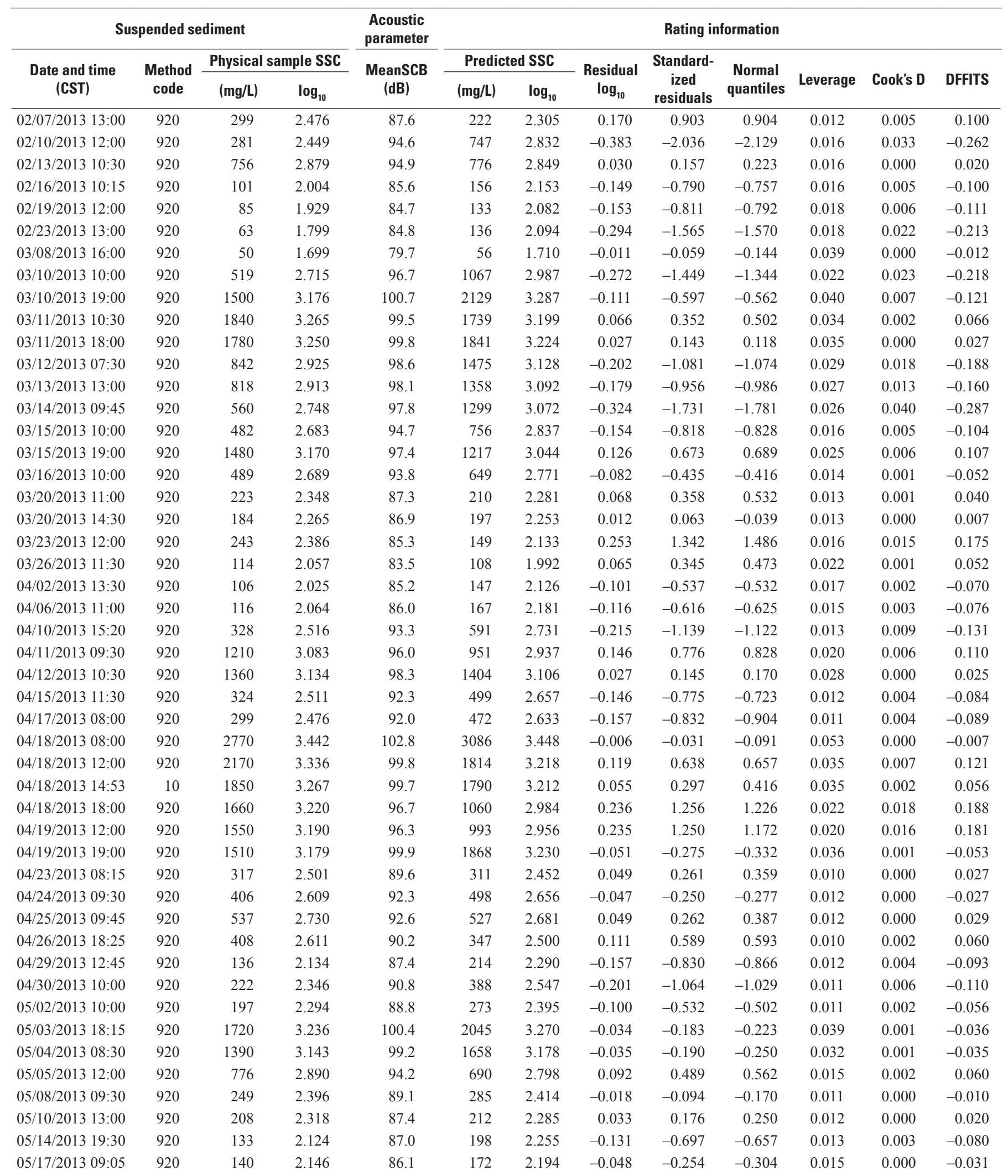




\section{Calibration Dataset-Continued}

[CST, Central Standard Time; mg/L, milligram per liter; SSC, suspended-sediment concentration]

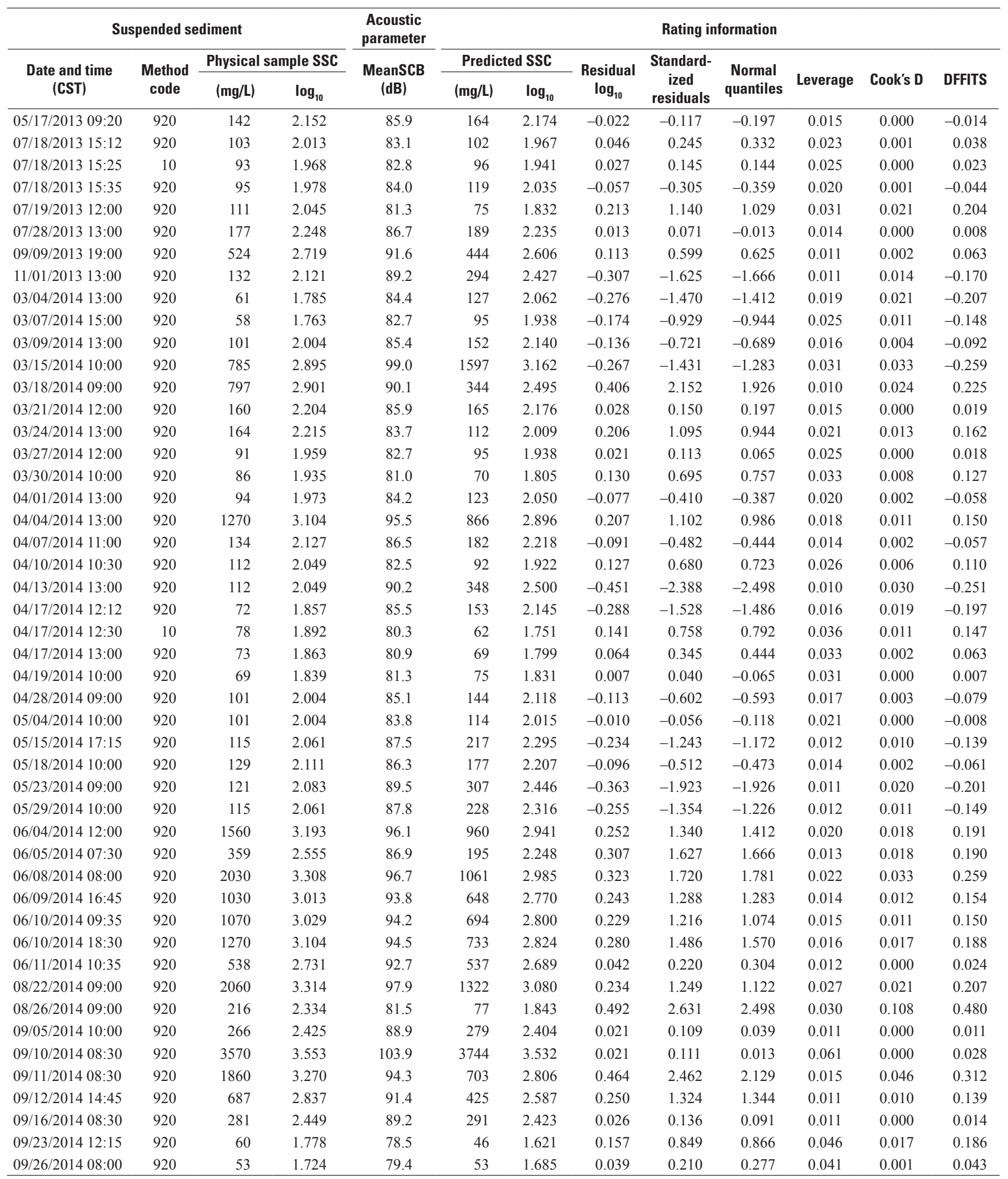


Outliers Removed from Calibration Dataset.

\begin{tabular}{|c|c|c|c|c|c|c|c|c|c|c|c|c|}
\hline \multicolumn{4}{|c|}{ Suspended sediment } & \multirow{3}{*}{$\begin{array}{c}\text { Acoustic } \\
\text { parameter } \\
\begin{array}{c}\text { MeanSCB } \\
\text { (dB) }\end{array}\end{array}$} & \multicolumn{8}{|c|}{ Rating Information } \\
\hline \multirow{2}{*}{$\begin{array}{l}\text { Date and time } \\
\text { (CST) }\end{array}$} & \multirow{2}{*}{$\begin{array}{l}\text { Method } \\
\text { code }\end{array}$} & \multicolumn{2}{|c|}{ Physical sample SSC } & & \multicolumn{2}{|c|}{ Predicted SSC } & \multirow[b]{2}{*}{$\begin{array}{c}\text { Residual } \\
\log _{10}\end{array}$} & \multirow{2}{*}{$\begin{array}{l}\text { Standard- } \\
\text { ized } \\
\text { residuals }\end{array}$} & \multirow{2}{*}{$\begin{array}{c}\text { Normal } \\
\text { quantiles }\end{array}$} & \multirow[b]{2}{*}{ Leverage } & \multirow[b]{2}{*}{ Cook's D } & \multirow[b]{2}{*}{ DFFITS } \\
\hline & & (mg/L) & $\log _{10}$ & & $(\mathrm{mg} / \mathrm{L})$ & $\log _{10}$ & & & & & & \\
\hline 03/18/2013 19:00 & 920 & 622 & 2.794 & 88.2 & 288 & 2.360 & 0.434 & 1.583 & 1.695 & 0.011 & 0.014 & 0.167 \\
\hline 04/22/2013 10:15 & 920 & 2810 & 3.449 & 87.6 & 262 & 2.318 & 1.131 & 4.125 & 2.520 & 0.012 & 0.100 & 0.487 \\
\hline 05/17/2013 09:13 & 10 & 938 & 2.972 & 85.9 & 199 & 2.198 & 0.774 & 2.829 & 2.153 & 0.015 & 0.059 & 0.357 \\
\hline 06/07/2014 18:30 & 920 & 1890 & 3.276 & 102.9 & 3120 & 3.394 & -0.118 & -0.437 & -0.498 & 0.050 & 0.005 & -0.100 \\
\hline
\end{tabular}

SUSPENDED-SEDIMENT CONCENTRATION (SSC) RECORD: The continuous time-series SSC record is computed using the regression model from WY2012 through WY2014. Data are computed at 15-minute intervals. The complete water-quality record can be found in the NWIS database. The record is complete; however, ice can affect the acoustic data during freeze and thaw conditions. Also, water levels can drop below the functional depth of the ADVM at this site and there were periods where the ADVM was malfunctioning. For the time periods where one or more of these conditions were an issue, the SSC was computed using the Graphical Constituent Loading Analysis System and physical samples. An example of predicted time series from concurrent ADVM and SSC sample observations for February 7 through May 17, 2013, is shown in figure 1-5.

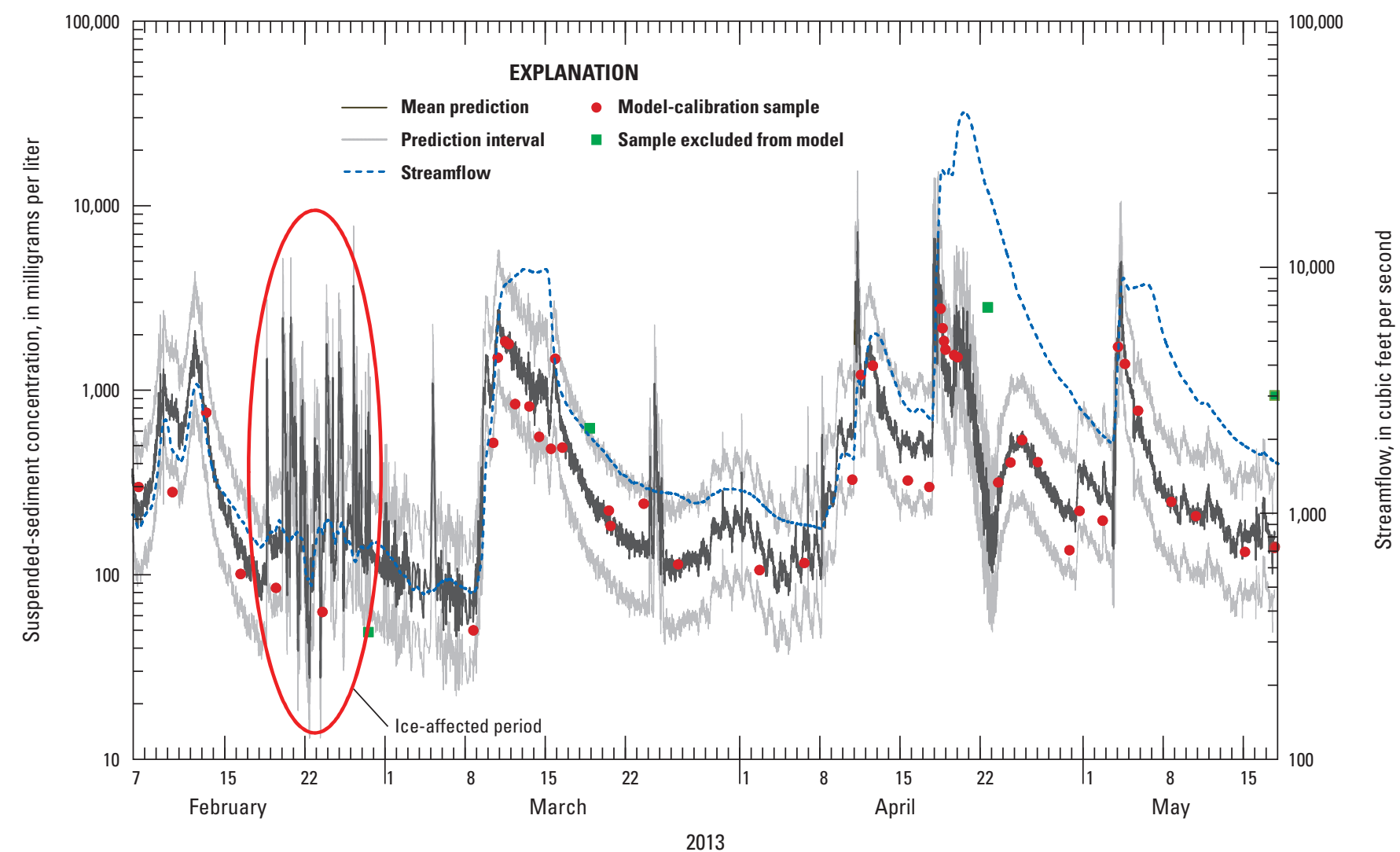

Figure 1-5. An example of predicted time series from concurrent acoustic Doppler velocity meter and suspended-sediment sample observations for February 7 through May 17, 2013. 
Alternative Models.

\begin{tabular}{|c|c|c|c|c|c|}
\hline Response variable & Explanatory variable(s) & $\begin{array}{c}\text { RMSE } \\
\text { (root-mean-squared } \\
\text { error) }\end{array}$ & $\begin{array}{c}R^{2} \\
\text { (coefficient of } \\
\text { determination) }\end{array}$ & $\begin{array}{c}\operatorname{adj} R^{2} \\
\text { (adjusted } R^{2} \text { value) }\end{array}$ & $\begin{array}{c}\text { VIF } \\
\text { (variance inflation } \\
\text { factor) }\end{array}$ \\
\hline $\mathrm{SSC}^{1}$ & meanSCB & 397 & 0.69 & 0.69 & --- \\
\hline $\log _{10} \mathrm{SSC}$ & meanSCB & 0.190 & 0.86 & 0.86 & --- \\
\hline $\log _{10} \mathrm{SSC}$ & $\log _{10} \mathrm{Q} \_\mathrm{cfs}$ & 0.322 & 0.61 & 0.61 & --- \\
\hline $\mathrm{SSC}^{1}$ & SAC & 234 & 0.89 & 0.89 & --- \\
\hline $\log _{10} \mathrm{SSC}$ & meanSCB, $\log _{10} \mathrm{Q} \_$cfs & 0.185 & 0.87 & 0.87 & 3 \\
\hline $\log _{10} \mathrm{SSC}^{2}$ & meanSCB, SAC & 0.180 & 0.88 & 0.88 & 3,3 \\
\hline $\log _{10} \mathrm{SSC}$ & $\begin{array}{c}\text { meanSCB, SAC, } \\
\log _{10} \mathrm{Q} \_ \text {cfs }\end{array}$ & 0.176 & 0.89 & 0.88 & $5,3,3$ \\
\hline
\end{tabular}

${ }^{1}$ Residuals were not homoscedastic.

${ }^{2}$ Slightly better diagnostic results than using meanSCB alone, but does not predict concentrations over 2,500 milligrams per liter as accurate.
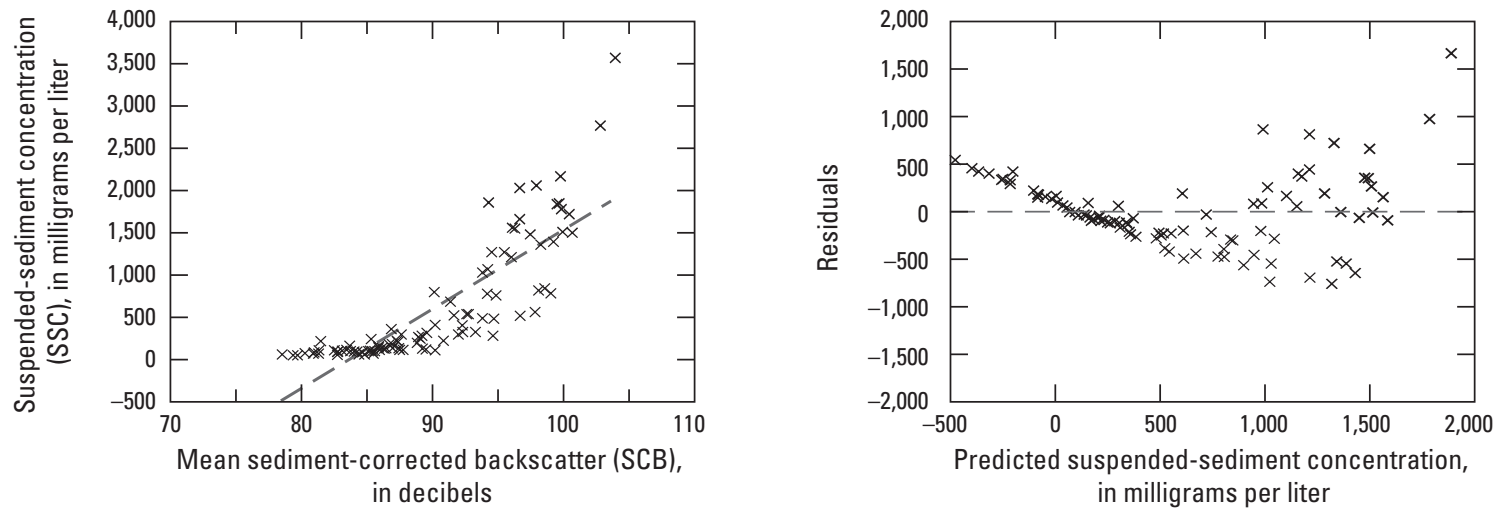

Figure 1-6. An example of an evaluated regression model where residuals were not homoscedastic. 


\section{Appendix 2. Sediment Acoustic Theory}

This appendix contains a detailed review of sediment acoustic theory. It summarizes many of the references noted in the Previous Studies and Applications section of the main report. It also gives additional information, details, and derivations for some of the equations shown in the Basic Acoustic Principles and Analytical Methods sections.

\section{Model Development}

The development of an expression relating acoustic surrogates to sediment concentration for use in a simple linear regression begins with Urick's (1983) echo level sonar equation. This form of the sonar equation is written in logarithmic units of decibels as:

$$
R L=S L-2 T L+T S,
$$

where $R L$ is the volume reverberation level, $S L$ is the source level, $2 T L$ is the two-way transmission loss, and $T S$ is the target strength and is described as the intensity of the signal echoed by the particles in the insonified volume. $R L$ is equivalent to the measured backscatter intensity, $M B$, as designated elsewhere in the text. Each of the terms in the sonar equation is in units of decibels and is expressed as 10 times the 10-based logarithm of a ratio of acoustic intensity or, in the case of $M B$, intensity multiplied by transducer surface area, which equals power. The terms can be defined generally by the following equations (Urick, 1983):

$$
\begin{gathered}
M B=10 \log _{10} \frac{\text { Measured backscatter signal power at transducer }}{\text { Standard reference signal power }}, \\
S L=10 \log _{10} \frac{\text { Transmitted signal intensity of the source }}{\text { Standard reference signal intensity }}, \\
T L=10 \log _{10} \frac{\text { Signal intensity at } 1 \mathrm{~m}}{\text { Signal intensity at target or receiver }}, \text { and } \\
T S=10 \log _{10} \frac{\text { Echo intensity at } 1 \mathrm{~m} \text { from target }}{\text { Incident intensity }} .
\end{gathered}
$$

The one-way transmission loss accounting for spherical spreading and attenuation due to water absorption and the presence of suspended particles is

$$
T L=20 \log _{10} r+\alpha_{w} r+\alpha_{s} r,
$$

where $r$ is the range from the transducer to the target cell $\alpha_{w}$ and $\alpha_{s}$ and are the water and sediment attenuation coefficients, respectively.

From volume-reverberation theory (Urick, 1983), the target strength of a reverberating volume containing suspended spherical particles is defined as

$$
T S=S_{v}+10 \log _{10} V,
$$


where $V$ is the reverberating volume and the scattering strength parameter, $S_{v}$, is defined as

$$
S_{v}=10 \log _{10}\left(\frac{n f^{2} a_{p}^{2}}{4}\right),
$$

where $n$ is the total number of particles per unit volume, $f$ is the average particle form function, which describes the scattering properties of the particle as a function of the particle size and instrument frequency (Thorne and Hanes, 2002), and $a_{p}$ is the average particle radius.

Inserting the terms for transmission loss and target strength into the reverberation level equation gives the volume reverberation level equation that accounts for two-way transmission losses due to beam spreading and attenuation caused by water absorption and the presence of suspended particles:

$$
M B=S L-40 \log _{10} r-2 \alpha_{w} r-2 \alpha_{s} r+S_{v}+10 \log _{10} V .
$$

Suspended-sediment concentration is defined by

$$
S S C=\frac{M_{s}}{V}=n \bar{M}_{p},
$$

where $M_{s}$ is the total mass of sediment in the volume of water $V$, and $\bar{M}_{p}$ is the mean mass of sediment particles. Making the assumption that the suspended particles are spherical, the mean mass of sediment particles can be further defined as

$$
\bar{M}_{p}=\frac{4}{3} \pi a_{p}^{3} \rho_{s}
$$

where $\rho_{s}$ is the density of the sediment, which is assumed to be constant among all sediment particles. Solving the SSC equation for $n$ and substituting for $\bar{M}_{p}$ gives

$$
n=\frac{3 S S C}{4 \pi a_{p}^{3} \rho_{s}}
$$

Substituting $n$ into $S_{v}$ and simplifying gives

$$
S_{v}=10 \log _{10}\left(f^{2} \frac{3 S S C}{16 \pi a_{p} \rho_{s}}\right) .
$$

A general reverberating volume is defined by Urick (1983) as

$$
V=\frac{c \tau}{2} r^{2} \int b b^{\prime} d \Omega
$$

where $c$ is the speed of sound in water, $\tau$ is the pulse duration, $b$ and $b^{\prime}$ are the sending and receiving beam patterns of the hydrophone, and $d \Omega$ is the differential element of the solid angle of the beam. The integral has been approximated by Thorne and others (1991) as

$$
\int b b^{\prime} d \Omega \approx 2 \pi\left[\frac{0.96}{k a_{T}}\right]^{2},
$$


where $k$ is the wave number equal to $2 \pi / \lambda$, where $\lambda$ is the acoustic wavelength, and $a_{T}$ is the radius of the transducer. Substituting the approximation and simplifying gives the reverberating volume term of the sonar equation as

$$
10 \log _{10} V=10 \log _{10}\left(c \tau \pi\left[\frac{0.96}{k a_{T}}\right]^{2} r^{2}\right)
$$

Substituting the expressions for $S_{v}$ and $V$ into the volume reverberation equation yields

$$
M B=S L-40 \log _{10} r-2 \alpha_{w} r-2 \alpha_{s} r+10 \log _{10}\left(f^{2} \frac{3 S S C}{16 \pi a_{p} \rho_{s}}\right)+10 \log _{10}\left(c \tau \pi\left[\frac{0.96}{k a_{T}}\right]^{2} r^{2}\right) .
$$

Sediment-corrected backscatter $(S C B)$ has been defined as

$$
S C B=M B+20 \log _{10} r+2 \alpha_{w} r+2 \alpha_{s} r
$$

In the current method for calculating $S C B, \alpha_{s}$ is estimated with the assumption that it can be measured from the slope of the water-corrected backscatter signal along the range of the major axis of the acoustic beam under consideration. Once $\alpha_{s}$ is measured, $S C B$ is calculated for each cell in the range, and an average value of $S C B$ is used as an explanatory variable in the linear regression model for $\mathrm{SSC}$.

Using the definition for $S C B$, simplifying and solving for $\log _{10} \mathrm{SSC}$ gives

$$
\log _{10} S S C=0.1\left\{S C B-S L-10 \log _{10}\left(f^{2} \frac{3 c \tau}{16 a_{p} \rho_{s}}\left[\frac{0.96}{k a_{T}}\right]^{2}\right)\right\}
$$

Topping and others (2015) introduced the Unit Target Strength (UTS) term, defined as

$$
U T S=10 \log _{10}\left(f^{2} \frac{3 c \tau}{16 a_{p} \rho_{s}}\left[\frac{0.96}{k a_{T}}\right]^{2}\right)
$$

Making the assumption that source level and unit target strength remain constant throughout sampling, a constant can be defined as

$$
K=S L+U T S
$$

The value of $\mathrm{K}$ will be constant if factors other than sediment concentration remain constant. These factors include the SL; insonified volume; frequency and instrument characteristics; and sediment size, density, and scattering characteristics. The equation for $\log _{10} \mathrm{SSC}$ can be rewritten as

$$
\log _{10} S S C=-0.1 K+0.1 S C B
$$

In the method described within this manual, the linear regression model for the above equation is

$$
Y=\beta_{0}+\beta_{1} X+\varepsilon
$$

The response variable, $Y$, is $\log _{10} \mathrm{SSC}$. The intercept term, $\beta_{0}$, is then $-0.1 K$. Theoretically, the slope $\beta_{1}$ is equal to 0.1 , but is typically solved for empirically as $b_{1}$. The value of $b_{1}$ is typically less than 0.1 , which is expected where the SSC in the insonified volume is larger than that in cross section. The explanatory variable, $X$, corresponds to the sediment-corrected backscatter, $S C B$. 
Using the estimated coefficients $b_{0}$ and $b_{1}$ to find the estimate of the mean SSC, solving for SSC and estimating the bias due to the logarithmic transform of SSC in the linear regression gives

$$
S S C=B C F \times 10^{b_{0}+b_{1} S C B} .
$$

Beginning with the echo-level sonar equation from Urick (1983), using definitions from Urick (1983) and Topping and others (2015) and an approximation from Thorne and others (1991), an equation for use in simple linear regression was developed (Urick, 1983).

\section{Attenuation}

Rayleigh (1896, section 334) developed the theory and expressions for the pressure disturbance (scattering) due to planar acoustic waves impinging on fluid spheres in an inviscid medium. Sewell (1910) derived expressions for the energy loss (absorption) for rigid, fixed spheres in a viscous fluid. Lamb (1916, sections 296-298) extended Sewell's method to rigid spherical objects that are free to move in the sound field. Urick (1948) extended Lamb's theoretical absorption equation to include scattering and viscous loss components for a given concentration of spherical particles. Urick (1948) wrote his equation as a coefficient for the attenuation of acoustic energy by sediment, $\alpha_{s}$, expressed in $\mathrm{dB} / \mathrm{cm}$, so that larger values quantify larger acoustic attenuation per unit length. This equation may be expressed in $\mathrm{dB} / \mathrm{cm}$ as:

$$
\alpha_{s}=\operatorname{SSC}_{V}\left[k(\gamma-1)^{2}\left\{\frac{s}{s^{2}+(\gamma+\tau)^{2}}\right\}+\frac{1}{6}\left(k^{4} a_{s}^{3}\right)\right] 4.34,
$$

where $\mathrm{SSC}_{V}$ is the volumetric sediment concentration (SSC divided by sediment density); $k$ is the wave number, $2 \pi / \lambda$, in which

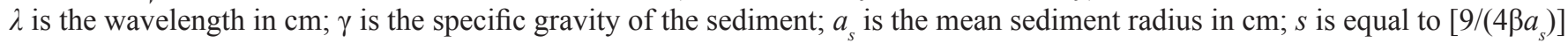
$\left[1+1 /\left(\beta a_{s}\right)\right]$; $\tau$ is equal to $\left[0.5+9 /\left(4 \beta a_{s}\right)\right]$, in which $\beta$ is equal to $[\omega / 2 v]^{0.5} ; \omega$ is $2 \pi f, f$ is frequency in $\mathrm{Hz} ; v$ is the kinematic viscosity of water in stokes; and 4.34 is for the conversion from nepers to decibels for the attenuation. The first term of the sum within the brackets is the acoustic attenuation due to viscous losses and the second is the acoustic attenuation due to scattering losses. This form is dimensionally consistent and has been used by several subsequent researchers (Flammer, 1962; Hay, 1983; Gartner, 2004; Wall, 2006).

Urick (1948) tested equation 16 with laboratory data using quartz and kaolinite particles with median diameters of 2.2 and 0.9 microns, respectively, in frequencies of 1 to $15 \mathrm{MHz}$. Urick found good agreement between equation 16 and laboratory results and noted that viscous losses accounted for nearly all of the absorption for the small particle sizes investigated in the frequency range of 1 to $15 \mathrm{MHz}$. Flammer (1962) tested Urick's theoretical expression for scattering attenuation, but did not investigate viscous losses because of equipment limitations for smaller particle sizes. Flammer conducted experiments over a range of frequencies from 2.5 to $25 \mathrm{MHz}$ and sediment size distributions with mean diameters from 44 to 1,000 microns. Sheng and Hay (1988) investigated methods of estimating attenuation due to scattering loss using data from four prior investigations, with most of the data coming from Flammer (1962). They observed a maximum scattering loss that is not represented in Urick's (1948) equation. Their expression was further developed in Crawford and Hay (1993) and expressed as:

$$
\alpha_{s}=S S C_{V}\left[\frac{k^{4} a_{s}^{3}}{5\left(1+1.3 k^{2} a_{s}^{2}+0.24 k^{4} a_{s}^{4}\right)}\right] 4.34
$$

This expression has been used by many authors investigating sediment surrogates in near-bed marine environments where particle sizes larger than 62.5 microns are dominant (Thorne and others, 1991; Hay and Sheng, 1992; Thorne and Hardcastle, 1997; Holdaway and others, 1999; Thorne and Hanes, 2002).

In many fluvial environments, the size distribution of suspended sediments may include significant fractions of both silt and clay (less than 62.5 microns) and sand (equal to or greater than 62.5 microns and less than 2,000 microns) sizes. Some investigators (Wright and others, 2010; Landers, 2012) have proposed replacing the scattering loss function in Urick's equation with that of Sheng and Hay to produce the following estimator of acoustic attenuation by SSC shown in figure 2-1 and equation 18:

$$
\alpha_{s}=\operatorname{SSC}_{V}\left[k(\gamma-1)^{2}\left\{\frac{s}{s^{2}+(\gamma+\tau)^{2}}\right\}+\frac{k^{4} a^{3}}{5\left(1+1.3 k^{2} a^{2}+0.24 k^{4} a^{4}\right)}\right] 4.34 \text {. }
$$


Viscous losses are primarily due to the concentration of finer particles while scattering losses are primarily due to coarser particles. The acoustic attenuation due to viscous loss is caused by shear stress at the fluid-particle boundaries because of a lag between the sound-wave-induced vibration of the particle and that of the fluid. The magnitude of the viscous loss is a function of the particle surface area, sound frequency, fluid viscosity, and the ratio of particle to fluid density. As particle size (and inertia) becomes very small (left edge of plot in fig. 2-1), viscous loss approaches a maximum because the increased surface area is offset by a decreased lag for these very small particles. As the total particle surface area decreases with increasing particle size for given SSC, there is decreasing shear and viscous loss.

Scattering of acoustic energy is related primarily to sediment diameter rather than surface area (as for viscous losses). The scattering loss is due to reradiation of the acoustic energy incident on a particle. Scattering loss is a function of the ratio of acoustic wavelength, $\lambda$, to particle circumference $2 \pi \mathrm{a}_{s}$. For $\lambda \gg 2 \pi \mathrm{a}_{s}$, scattering is concentrated in the backward direction and scattering losses rise rapidly with increasing sediment size. As $\lambda$ approaches $2 \pi \mathrm{a}_{s}$, scattering becomes complex and changes rapidly with sediment size and frequency (Urick, 1948; Flammer, 1962).

The minimum acoustic attenuation occurs at the transition between viscous and scattering losses. The particle size, associated with this minimum attenuation, increases with wavelength (decreasing frequency). The minimum acoustic attenuation occurs, according to equation 18, at particle

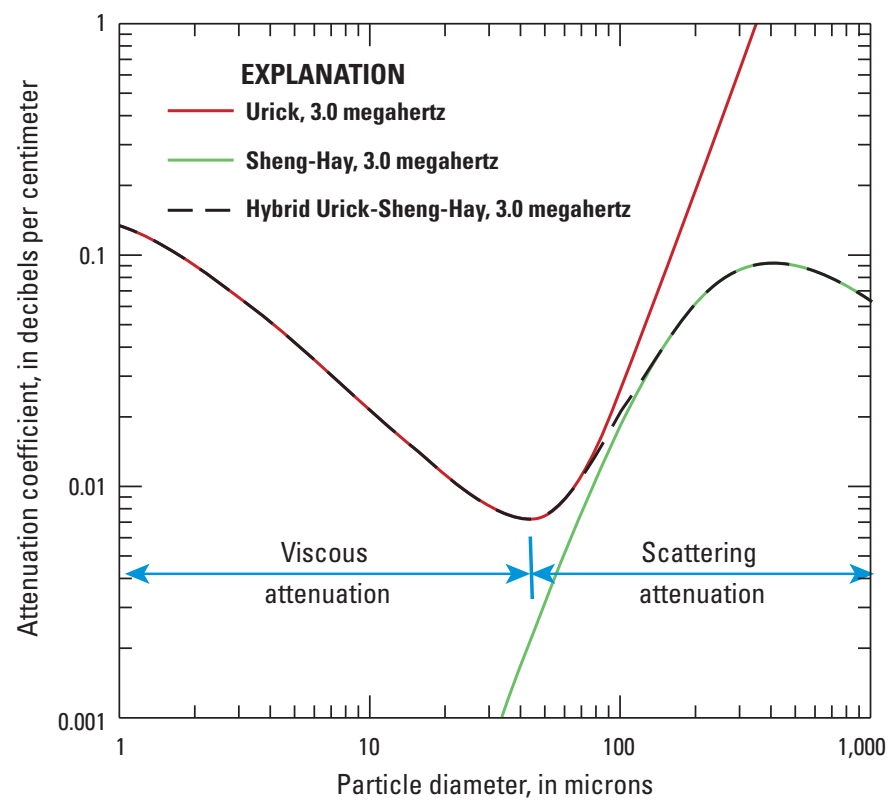

Figure 2-1. Coefficients of acoustic attenuation due to suspended sediment and particle size, for 3.0- megahertz (MHz) frequency at concentration of 1,000 parts per million from hybrid Urick-Shen-Hay equation (in decibels per centimeter). diameters of 90, 74, and 42 microns for frequencies of 1.2 , 1.5 , and 3.0 MHz, respectively, using 1,484 meters per second as the speed of sound in water. These particle diameters are in the coarse silt to very fine sand range.

Research on acoustic attenuation with sediment has focused on sediments of only one or two sizes in suspension. Recent studies by Topping and others (2015) and Moore and others (2013) have evaluated acoustic attenuation for a range of sediment gradations. Topping and others (2015) found that as the geometric standard deviation of the size distribution increases, the magnitudes of the $\alpha_{\mathrm{s}}$ viscous- and scattering-loss maxima both decrease while the magnitude of both increase. For geometric standard deviations of about 4 (very poorly sorted sediments), the relation of $\alpha_{s}$ to median sediment size becomes approximately linear.

Theoretical acoustic absorption varies linearly with $\mathrm{SSC}_{\mathrm{V}}$ for a given frequency and sediment size. Linear variation of absorption with concentration implies that the absorption effects from individual particles are independent because the particles are "far enough apart" so that the scattering from one does not affect that of its neighbors. This assumption has been proven valid for a range of sediment sizes for concentrations up to $10,000 \mathrm{mg} / \mathrm{L}$ (Urick, 1948; Flammer, 1962; Sheng and Hay, 1988).

\section{Backscatter}

Early investigations of acoustic surrogates relied on instruments with a separate sound source and receiver, rather than a combined source and receiver, such as modern transceivers (referred to here and typically as transducers). The transducer emits an acoustic pulse and then, after an interval just long enough to stop "ringing," it receives the echoes backscattered from particles suspended in the acoustic path, as illustrated in the simplified cartoon of figure 2. Acoustic Doppler velocity meters measure the Doppler shift in the frequency of the backscattered signal to determine the velocity of the particles scattering the signal (the assumed water velocity) relative to the transducer. Two or three transducers at fixed angles may be used to resolve a two- or three-dimensional flow-velocity vector. As acoustic transducers became available, researchers began to investigate the amplitude of backscattered sound at the transducer as a surrogate for sediment concentration. In an investigation of fluvial sediment, Braithwaite (1974) measured SSC and backscatter amplitude from a $1-\mathrm{MHz}$ transducer in seven rivers in England. Limitations in the methods make the results qualitative, but good correlation was proven for backscatter amplitude and sediment concentration in fluvial environments. Investigations in marine environments using single-frequency acoustic backscatter include those of Young and others (1982), Hay (1983), and Hess and Bedford (1985). Flagg and Smith (1989) showed good correlations between acoustic backscatter amplitude and zooplankton abundance with high temporal and high spatial resolution. 


\section{Limitations and Assumptions}

Sediment acoustic index ratings from single-frequency systems may change due to changes in sediment-size distributions, creating a size-concentration ambiguity. This limitation may be overcome using multi-frequency acoustic systems, although these systems increase complexity and cost. The sensitivity of acoustic surrogates of suspended sediment is limited for low concentrations and generally may not be applicable for concentrations less than about $10 \mathrm{mg} / \mathrm{L}$ for frequencies in the 0.5 -to-5-MHz frequency range (Gray and Gartner, 2009). All methods that use measurements of a subsection or single point of the channel cross section require concurrent point and cross-section SSC measurements for calibration to the entire cross section and assumed stability of those calibrations. This limitation is more restrictive for surrogates based on small point-volume measurements than for acoustic surrogates, which typically are based on a much larger volume than point measurements.

\section{References Cited}

Ainslie, M.A., and McColm, J.G., 1998, A simplified formula for viscous and chemical absorption in sea water: Journal of the Acoustical Society of America, v. 103, no. 3, p. 1671-1672, accessed March 14, 2016, at http://scitation. aip.org/content/asa/journal/jasa/103/3/10.1121/1.421258.

Braithwaite, H., 1974, Some measurements of acoustic conditions in rivers: Journal of Sound and Vibration, v. 37, p. $557-560$.

Brown, E.H., and Clifford, S.F., 1976, On the attenuation of sound by turbulence: Journal of the Acoustical Society of America, v. 60, p. 788-794, accessed March 14, 2016, at http://scitation.aip.org/content/asa/journal/ jasa/60/4/10.1121/1.381159.

Crawford, A.M., and Hay, A.E., 1993, Determining suspended sand size and concentration from multifrequency acoustic backscatter: Journal of the Acoustical Society of America, v. 94, p. 3312-3324, accessed March 14, 2016, at http://scitation.aip.org/content/asa/journal/ jasa/94/6/10.1121/1.407237.

Downing, A., Thorne, P.D. and Vincent, C.E., 1995, Backscattering from a suspension in the near field of a piston transducer: Journal of the Acoustical Society of America, v. 97, p. 1614-1620, accessed March 4, 2016, at http://scitation. aip.org/content/asa/journal/jasa/97/3/10.1121/1.412100.

Fisher, F.H., and Simmons, V.P., 1977, Sound absorption in sea water: Journal of the Acoustical Society of America, v. 62, no. 3, p. 558-564, accessed March 11, 2016, at http://scitation.aip.org/content/asa/journal/jasa/62/3/10.1121/1.381574.
Flagg, C.N., and Smith, S.L., 1989, On the use of the acoustic Doppler current profiler to measure zooplankton abundance: Deep-Sea Research, v. 36, p. 455-474, accessed March 7, 2016, at http://www.sciencedirect.com/science/article/ pii/0198014989900472.

Flammer, G.H., 1962, Ultrasonic measurement of suspended sediment: U.S. Geological Survey Bulletin, p. 1141-A, 48 p., accessed March 10, 2016, at http://pubs.usgs.gov/ bul/1141a/report.pdf.

Gartner, J.W., 2004, Estimating suspended solids concentrations from backscatter intensity measured by acoustic Doppler current profiler in San Francisco Bay, California: Elsevier, Marine Geology, v. 211, p. 169-187, accessed March 7, 2016, at http://www.sciencedirect.com/science/ article/pii/S0025322704001872.

Gartner, J.W., and Cheng, R.T., 2001, Promises and pitfalls of estimating TSS from backscatter: Proceedings of the Seventh Federal Interagency Sedimentation Conference, v. III, March 25-29, 2001: Reno, Nev.

Gray, J.R., and Gartner, J.W., 2009, Technological advances in suspended-sediment surrogate monitoring: Water Resources Research, v. 45, W00D29, accessed March 7, 2016, at http:// water.usgs.gov/osw/techniques/2008WR007063.pdf.

Hamilton, L.J., Shi, Z., and Zhang, S.Y., 1998, Acoustic backscatter measurements of estuarine suspended cohesive sediment concentration profiles: Journal of Coastal Research, v. 14, p. 1213-1224, accessed March 14, 2016, at http:// www.jstor.org/stable/4298881?seq=1\#page_scan_tab_contents.

Hay, A.E., 1983, On the remote acoustic detection of suspended sediment at long wavelengths: Journal of Geophysical Research: v. 88, no. C12, p. 7525-7542, accessed March 7, 2016, at http://onlinelibrary.wiley.com/ doi/10.1029/JC088iC12p07525/epdf.

Hay, A.E., and Sheng, J., 1992, Vertical profiles of suspended sand concentration and size from multi-frequency acoustic backscatter: Journal of Geophysical Research: v. 97, p. 15661-15677, accessed March 7, 2016, at http://onlinelibrary.wiley.com/doi/10.1029/92JC01240/pdf.

Hess, F.R., and Bedford K.W., 1985, Acoustic Backscatter System (ABSS): The instrument and some preliminary results: Elsevier, Marine Geology, v. 66, p. 357-379, accessed March 14, 2016, at http://www.sciencedirect.com/ science/article/pii/0025322785900398.

Holdaway, G.P., Thorne, P.D., Flatt, D., Jones, S.E., and Prandle, D., 1999, Comparison between ADCP and transmissometer measurements of suspended sediment concentration: Continental Shelf Research, v. 19, p. 421-441, accessed March 7, 2016, at http://www.ldeo.columbia. edu/ bhuber/LADCP/wh1200/references/adcp_transmissometer.pdf. 
Lamb, Horace, 1916, Hydrodynamics (4th ed.): Cambridge University Press, 708 p.

Landers, M.N., 2012, Fluvial suspended sediment characteristics by high-resolution, surrogate metrics of turbidity, laser-diffraction, acoustic backscatter, and acoustic attenuation: Dissertation, Georgia Institute of Technology, 236 p., accessed March 11, 2016, at http://hdl.handle. net/1853/43747.

Levesque, V.A., and Oberg, K.A., 2012, Computing discharge using the index velocity method: U.S. Geological Survey Techniques and Methods, book 3, chapter A23, 148 p., accessed March 11, 2016, at http://pubs.usgs.gov/tm/3a23/.

Medalie, Laura, Chalmers, A.T., Kiah, R.G., and Copans, Benjamin, 2014, Use of acoustic backscatter to estimate continuous suspended sediment and phosphorus concentrations in the Barton River, northern Vermont, 2010-2013: U.S. Geological Survey Open-File Report 2014-1184, 29 p., 4 appendixes, accessed March 11, 2016, at http:// dx.doi.org/10.3133/ofr20141184.

Moore, S.A., Le Coz, J., Hurther, D., and Paquier, A., 2013, Using multi-frequency acoustic: Journal of the Acoustical Society of America, v. 133, no. 4, p. 1959-1970, accessed March 11, 2016, http://dx.doi.org/10.1121/1.4792645.

Noir, D.T., and George, A.R., 1978, Absorption of sound by homogeneous turbulence: Journal of Fluid Mechanics, v. 86, no. 3, p. 593-608, accessed March 14, 2016, at http://journals.cambridge. org/action/displayAbstract? fromPage $=$ onlin e\&aid=379925\&fileId=S0022112078001299.

Rayleigh, Lord, 1937, The surface layer of polished silica and glass with further studies on optical contact-Proceedings of the Royal Society of London: Series A, Mathematical and Physical Sciences, v. 160, no. 903, p. 507-526.

Reichel, G., and Nachtnebel, H.P., 1994, Suspended sediment monitoring in a fluvial environment: Advantages and limitations applying an acoustic Doppler current profiler: Water Research, v. 28, p. 751-761, accessed March 14, 2016, at http://www.sciencedirect.com/science/article/ pii/0043135494900833.

Ross, T., and Lueck, R., 2005, Estimating turbulent dissipation rates from acoustic backscatter: Deep-Sea Research, v. 52, p. 2353-2365, accessed March 14, 2016, at http://www. sciencedirect.com/science/article/pii/S0967063705002074.

Sauer, V.B., 2002, Standards for the analysis and processing of surface-water data and information using electronic methods: U.S. Geological Survey Water-Resources Investigations Report 01-4044, 91 p., accessed March 10, 2016, at http://pubs.usgs.gov/wri/2001/4044/report.pdf.
Sewell, C.J.T., 1910, The extinction of sound in a viscous atmosphere by small obstacles of cylindrical and spherical form: Philosophical Transactions of the Royal Soc. of London, Series A, v. 210, p. 239-270.

Sheng, J., and Hay, A.E., 1988, An examination of the spherical scatter approximation in aqueous suspensions of sand: Journal of the Acoustical Society of America, v. 83, no. 2, p. 598-610, accessed March 7, 2016, at http://dx.doi. org/10.1121/1.396153.

Simpson, M.R., 2001, Discharge measurements using a broadband acoustic Doppler current profiler: U.S. Geological Survey Open-File Report 01-1, 123 p., accessed March 10, 2016, at http://pubs.usgs.gov/of/2001/ofr0101/.

Smith, C.K., Wren, D., and Chambers, J., 2006, Estimation of particle sizes for a range of narrow size distributions of natural sands suspended in water using multi-frequency acoustic backscatter-Proceedings of the Eighth Federal Interagency Sedimentation Conference, April 2-6, 2006: Reno, Nev., p. 531-538.

Thevenot, M.M., and Kraus, N.C., 1993, Comparison of acoustical and optical measurements of suspended material in the Chesapeake Estuary: Journal of Marine Environmental Engineering, v. 1, p. 65-79.

Thorne, P.D., and Hanes, D.M., 2002, A review of acoustic measurement of small-scale sediment processes: Continental Shelf Research, v. 22, p. 603-632, accessed March 14, 2016, at http://www.sciencedirect.com/science/article/pii/ S0278434301001017.

Thorne, P.D., and Hardcastle, P.J., 1997, Acoustic measurements of suspended sediments in turbulent currents and comparison with in-situ samples: Journal of the Acoustical Society of America, v. 101, p. 2603-2614, accessed March 8, 2016, at http://scitation.aip.org/content/asa/journal/jasa/101/5/10.1121/1.418501.

Thorne, P.D., Hurther, David, and Moate, B.D., 2011, Acoustic inversions for measuring boundary layer suspended sediment processes: Journal of the Acoustical Society of America, v. 130, no. 3, p. 1188-1200, accessed March 8, 2016, at http://scitation.aip.org/content/asa/journal/ jasa/130/3/10.1121/1.3618728.

Thorne, P.D., Vincent, C.E., Hardcastle, P.J., Rehman, S., and Pearson, N., 1991, Measuring suspended sediment concentrations using acoustic backscatter devices: Elsevier, Marine Geology, v. 98, p. 7-16, accessed March 8, 2016, at http://www.sciencedirect.com/science/article/ pii/002532279190031X. 
Topping, D.J., Melis, T.S., Rubin, D.M., and Wright, S.A., 2004, High-resolution monitoring of suspended-sediment concentration and grain size in the Colorado River in Grand Canyon using a laser acoustic system-Proceedings of the Ninth International Symposium on River Sedimentation, October 18-21, 2004: Yichang, China, Tsinghua University Press, p. 2507-2514, accessed March 8, 2016, at http:// www.irtces.org/old/irtces/report/9isrs/E_isrs06.htm\#4.

Topping, D.J., Wright, S.A., Griffiths, R.E., and Dean, D.J., 2015, Physically based method for measuring suspendedsediment concentration and grain size using multifrequency arrays of single-frequency acoustic-doppler profilers - Proceedings of the 10th Federal Interagency Sedimentation Conference, April 19-23, 2015: Reno, Nev., p. 833-846, accessed March 11, 2016, at http://acwi.gov/ sos/pubs/3rdJFIC/Proceedings.pdf.

Topping, D.J., Wright, S.A., Melis, T.S., and Rubin, D.M., 2006, High-resolution monitoring of suspended-sediment concentration and grain size in the Colorado River using laser-diffraction instruments and a three-frequency acoustic system - Proceedings of the Eighth Federal Interagency Sedimentation Conference, April 2-6, 2006: Reno, Nev., p. 555-559, accessed March 8, 2016, at http://pubs.usgs. gov/misc/FISC_1947-2006/pdf/1st-7thFISCs-CD/8thFISC/ Session\%206C-3_Topping.pdf.

Topping, D.J., Wright, S.A., Melis, T.S., and Rubin, D.M., 2007, High-resolution measurement of suspended-sediment concentrations and grain size in the Colorado River in Grand Canyon using a multi-frequency acoustic system-Proceedings of the 10th International Symposium on River Sedimentation, August 1-4, 2007: Moscow, Russia, p. 330-339, accessed March 8, 2016, at https://www. researchgate.net/publication/258999420_High-resolution measurements_of_suspended-sediment_concentration and_grain_size_in the_Colorado_River_in_Grand_Canyon_using_a_multi-frequency_acoustic_system.
Urick, R.J., 1948, The absorption of sound in suspensions of irregular particles: Journal of the Acoustical Society of America, v. 20, p. 283-289.

Urick, R.J., 1983, Principles of underwater sound: New York, McGraw Hill.

Wall, G.R., Nystrom, E.A., and Litten, S., 2006, Use of an ADCP to compute suspended-sediment discharge in the tidal Hudson River, New York: U.S. Geological Survey Scientific Investigations Report 2006-5055, accessed March 9, 2016, at http://pubs.usgs.gov/sir/2006/5055/.

Williams, G.P., 1989, Sediment concentration versus water discharge during single hydrologic events in rivers: Journal of Hydrology, v. 111, p. 89-106, accessed March 14, 2016, at http://www.sciencedirect.com/science/article/ pii/0022169489902540.

Wood, M.S., and Teasdale, G.N., 2013, Use of surrogate technologies to estimate suspended sediment in the Clearwater River, Idaho, and Snake River, Washington, 2008-10: U.S. Geological Survey Scientific Investigations Report 2013-5052, 30 p., accessed January 14, 2016, accessed March 10, 2016, at http://pubs.usgs.gov/sir/2013/5052/.

Wright, S.A., Topping, D.J., and Williams, C.A., 2010, Discriminating silt-and-clay from suspended-sand in rivers using side-looking acoustic profilers-Proceedings of the Second Joint Federal Interagency Conference: Las Vegas, Nev., accessed March 11, 2016, at http://acwi.gov/sos/ pubs/2ndJFIC/Contents/2C_Wright_03_01_10_paper.pdf.

Young, R.A., Merrill, J.T., Clarke, T.L., and Proni, J.R., 1982, Acoustic profiling of suspended sediments in the marine bottom boundary layer: Geophysical Research Letters, v. 9, no. 3, p. 175-178, accessed March 11, 2016, at http:// onlinelibrary.wiley.com/doi/10.1029/GL009i003p00175/ full. 


\section{Appendix 3. Sensitivity of Suspended-Sediment Concentration Computed from a Sediment Acoustic Index Rating to Changes in Acoustic Attenuation}

In this appendix, the effect that a change in acoustic attenuation has on the estimation of suspended-sediment concentration (SSC) is explored through the theoretical equation that relates SSC to sediment-corrected backscatter ( $S C B$ ). The sediment acoustic index method requires correcting the measured backscatter $(M B)$ for transmission losses due to beam spreading and attenuation, as described in the body of this publication. The acoustic attenuation is caused by water properties (primarily temperature in fluvial systems) and sediment properties. For the purpose of this sensitivity analysis, the attenuation coefficient is generalized as the sum of the water absorption and sediment attenuation coefficients and designated as $\alpha$.

Beginning with the $S C B$ equation that considers the two-way transmission losses (repeated from equation 2, setting the near-field coefficient $[\psi]$ to equal 1 , and combining the water and sediment attenuation into one term $\left.\left[\alpha=\alpha_{w}+\alpha_{s}\right]\right)$ :

$$
S C B=M B+20 \log _{10}(r)+2 r \alpha .
$$

The mean $S C B$ over a range is defined as

$$
\overline{S C B}=\frac{1}{R_{1}-R_{0}} \int_{R_{0}}^{R_{1}} S C B d r
$$

where $R_{0}$ is the beginning and $R_{1}$ is the ending distance from the acoustic transducer of the range $(r)$ over which the $S C B$ is being integrated.

Replacing the $S C B$ equation with the definition of the mean $S C B$ gives

$$
\overline{S C B}=\frac{1}{R_{1}-R_{0}} \int_{R_{0}}^{R_{1}}\left[M B+20 \log _{10}(r)+2 r \alpha\right] d r .
$$

Separating the attenuation term gives

$$
\int_{R_{0}}^{R_{1}}\left[M B(r)+20 \log _{10} r+2 \alpha r\right] d r=\int_{R_{0}}^{R_{1}}\left[M B(r)+20 \log _{10} r\right] d r+2 \int_{R_{0}}^{R_{1}} \alpha r d r .
$$

Assuming the combined water and sediment attenuation is independent of range between $R_{0}$ and $R_{1}$ and integrating, the attenuation term gives

$$
2 \alpha \int_{R_{0}}^{R_{1}} r d r=\left(R_{1}^{2}-R_{0}^{2}\right) \alpha=\left(R_{1}-R_{0}\right)\left(R_{1}+R_{0}\right) \alpha
$$

Substituting the solved integral into the definition yields

$$
\overline{S C B}=\frac{1}{R_{1}-R_{0}}\left\{\int_{R_{0}}^{R_{1}}\left[M B(r)+20 \log _{10} r\right] d r+\left(R_{1}^{2}-R_{0}^{2}\right) \alpha\right\} .
$$

The mean $S C B$ as a function of attenuation coefficient is

$$
\overline{S C B}(\alpha)=\frac{1}{R_{1}-R_{0}} \int_{R_{0}}^{R_{1}}\left[M B(r)+20 \log _{10} r\right] d r+\left(R_{1}+R_{0}\right) \alpha .
$$

Adding a perturbation to the attenuation coefficient: 


$$
\overline{S C B}(\alpha+\Delta \alpha)=\frac{1}{R_{1}-R_{0}} \int_{R_{0}}^{R_{1}}\left[M B(r)+20 \log _{10} r\right] d r+\left(R_{1}+R_{0}\right)(\alpha+\Delta \alpha) .
$$

To find the resulting perturbation in $S C B$, subtract the nonperturbed backscatter from the perturbed:

$$
\Delta \overline{S C B}=\overline{S C B}(\alpha+\Delta \alpha)-\overline{S C B}(\alpha)=\left(R_{1}+R_{0}\right) \Delta \alpha .
$$

The change in mean $S C B$ due to a change in attenuation coefficient is then

$$
\Delta \overline{S C B}=\left(R_{1}+R_{0}\right) \Delta \alpha .
$$

The linear regression model for SSC and mean $S C B$ is

$$
\log _{10} S S C=\beta_{0}+\beta_{1} \overline{S C B}+\varepsilon .
$$

Solving for SSC as a function of mean $S C B$ gives

$$
\operatorname{SSC}(\overline{S C B})=10^{\beta_{0}+\beta_{1} \overline{S C B}+\varepsilon}
$$

Adding a perturbation to mean $S C B$ :

$$
S S C(\overline{S C B}+\Delta \overline{S C B})=10^{\beta_{0}+\beta_{1}(\overline{S C B}+\Delta \overline{S C B})+\varepsilon} .
$$

Defining the change in SSC:

$$
\Delta S S C=S S C(\overline{S C B}+\Delta \overline{S C B})-\operatorname{SSC}(\overline{S C B}) .
$$

Substituting and simplifying:

$$
\begin{gathered}
\Delta S S C=10^{\beta_{0}+\beta_{1}(\overline{S C B}+\Delta \overline{S C B})+\varepsilon}-10^{\beta_{0}+\beta_{1} \overline{S C B}+\varepsilon} \\
\Delta S S C=10^{\varepsilon} 10^{\beta_{0}+\beta_{1} \overline{S C B}} 10^{\beta_{1} \Delta \overline{S C B}}-10^{\varepsilon} 10^{\beta_{0}+\beta_{1} \overline{C C B}} \\
\Delta S S C=10^{\varepsilon} 10^{\beta_{0}+\beta_{1} \overline{S C B}}\left(10^{\beta_{1} \Delta \overline{S C B}}-1\right) .
\end{gathered}
$$

From the estimates of the linear regression, where the estimate of the error factor $10^{\varepsilon}$ is the nonparametric bias correction factor, and the estimate of the coefficients $\beta_{0}$ and $\beta_{1}$ are $b_{0}$ and $b_{1}$, respectively:

$$
\Delta S S C=B C F \times 10^{b_{0}+b_{1} \overline{S C B}}\left(10^{b_{1} \Delta \overline{S C B}}-1\right) .
$$

The estimate of SSC from the regression is defined as

$$
\widehat{S S C}=B C F \times 10^{b_{0}+b_{1} \overline{S C B}} .
$$


Including the definition of the estimated SSC in the change of SSC:

$$
\triangle S S C=\widehat{S S C}\left(10^{b_{1} \triangle \overline{S C B}}-1\right)
$$

Substituting the relationship between change in mean $S C B$ with the relation to change in attenuation coefficient found above:

$$
\Delta S S C=\widehat{S S C}\left(10^{b_{1}\left(R_{1}+R_{0}\right) \Delta \alpha}-1\right)
$$

Normalizing the change by the estimated SSC, we may express this change as a percentage:

$$
\Delta S S C \%=100\left(10^{b_{1}\left(R_{1}+R_{0}\right) \Delta \alpha}-1\right) .
$$

This equation is illustrated in figure $3-1$ and tabulated in table $3-1$. The sensitivity of computed SSC increases with the coefficient $b_{1}$ and with the range of the insonified beam. In several recent studies, the value of $b_{1}$ has been found to be between 0.03 and 0.10 , as noted in this publication. Range varies with acoustic frequency and sediment conditions, but could be over 100 meters for frequencies of 0.5 megahertz and lower, so that values of $b_{1}\left(R_{1}+R_{0}\right)$ could exceed those shown here. Attenuation is sensitive to water temperature as shown in table 4 of the publication; however, this is unlikely to produce errors if the ADVM temperature sensor is operating normally. The sediment attenuation coefficient is highly variable with instrument and sedimentconcentration characteristics, and was shown to vary from about 2 to $15 \mathrm{~dB} / \mathrm{m}$ for one storm at a site with high concentrations of fine material in figure 1. This sensitivity analysis illustrates the importance of accurate measurements of acoustic attenuation using the methods described in this publication, particularly for longer insonified ranges.

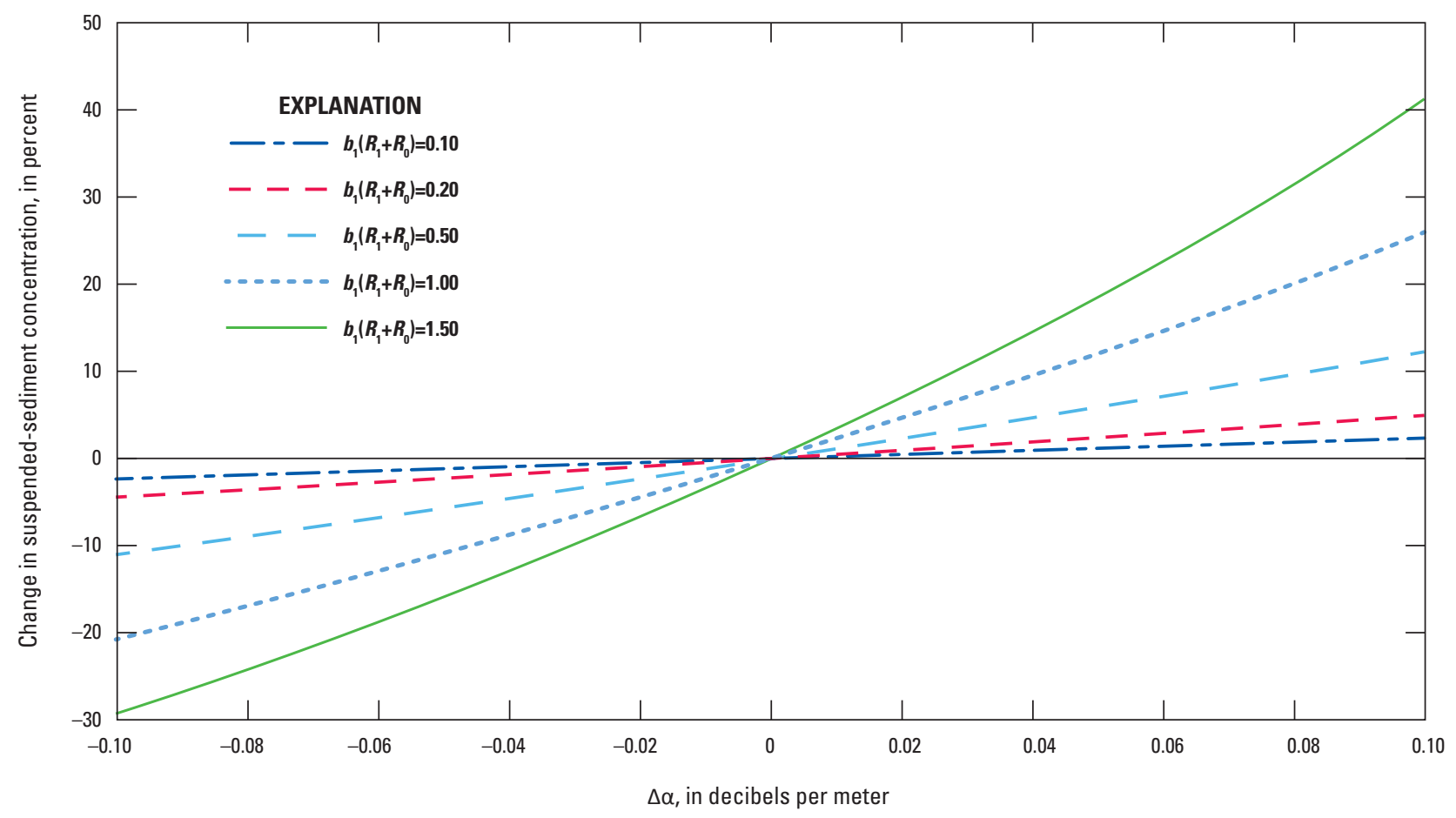

Figure 3-1. Sensitivity of suspended-sediment concentration to changes in acoustic attenuation $(\Delta \alpha)$ for values of sedimentcorrected backscatter (slope coefficient, $\left[b_{1}\right]$; range $\left.\left[R_{1}+R_{0}\right]\right)$. 
Table 3-1. Sensitivity of suspended-sediment concentration (SSC) to changes in acoustic attenuation $(\Delta \alpha)$ for values of sediment-corrected backscatter.

[slope coefficient $\left(b_{1}\right)$; range $\left(R_{1}+R_{0}\right) ; \mathrm{dB} / \mathrm{m}$, decibel per meter; \%, percent]

\begin{tabular}{|c|c|c|c|c|c|}
\hline \multirow{3}{*}{$\Delta \alpha(\mathrm{dB} / \mathrm{m})$} & \multicolumn{5}{|c|}{$b_{1}\left(R_{1}+R_{0}\right)(R$ in meters $)$} \\
\hline & 0.10 & 0.20 & 0.50 & 1.00 & 1.50 \\
\hline & \multicolumn{5}{|c|}{$\Delta \operatorname{SSC}(\%)$} \\
\hline-0.10 & -2.28 & -4.50 & -10.87 & -20.57 & -29.21 \\
\hline-0.09 & -2.05 & -4.06 & -9.84 & -18.72 & -26.72 \\
\hline-0.08 & -1.83 & -3.62 & -8.80 & -16.82 & -24.14 \\
\hline-0.07 & -1.60 & -3.17 & -7.74 & -14.89 & -21.48 \\
\hline-0.06 & -1.37 & -2.73 & -6.67 & -12.90 & -18.72 \\
\hline-0.05 & -1.14 & -2.28 & -5.59 & -10.87 & -15.86 \\
\hline-0.04 & -0.92 & -1.83 & -4.50 & -8.80 & -12.90 \\
\hline-0.03 & -0.69 & -1.37 & -3.39 & -6.67 & -9.84 \\
\hline-0.02 & -0.46 & -0.92 & -2.28 & -4.50 & -6.67 \\
\hline-0.01 & -0.23 & -0.46 & -1.14 & -2.28 & -3.39 \\
\hline 0.00 & 0.00 & 0.00 & 0.00 & 0.00 & 0.00 \\
\hline 0.01 & 0.23 & 0.46 & 1.16 & 2.33 & 3.51 \\
\hline 0.02 & 0.46 & 0.93 & 2.33 & 4.71 & 7.15 \\
\hline 0.03 & 0.69 & 1.39 & 3.51 & 7.15 & 10.92 \\
\hline 0.04 & 0.93 & 1.86 & 4.71 & 9.65 & 14.82 \\
\hline 0.05 & 1.16 & 2.33 & 5.93 & 12.20 & 18.85 \\
\hline 0.06 & 1.39 & 2.80 & 7.15 & 14.82 & 23.03 \\
\hline 0.07 & 1.62 & 3.28 & 8.39 & 17.49 & 27.35 \\
\hline 0.08 & 1.86 & 3.75 & 9.65 & 20.23 & 31.83 \\
\hline 0.09 & 2.09 & 4.23 & 10.92 & 23.03 & 36.46 \\
\hline 0.10 & 2.33 & 4.71 & 12.20 & 25.89 & 41.25 \\
\hline
\end{tabular}


Publishing support provided by the:

Reston and Rolla Publishing Service Centers

For more information concerning this publication, contact: Chief, USGS Office of Surface Water

415 National Center

12201 Sunrise Valley Drive

Reston, VA 20192

(703) 648-5301

Or visit the Office of Surface Water Web site at: http://water.usgs.gov/osw/ 

